\author{
Universidade de Brasília \\ Instituto de Psicologia
}

Programa de Pós-Graduação em Psicologia Social, do Trabalho e das Organizações

\title{
ELABORAÇÃO E VALIDAÇÃO DE ESCALA DE DIFERENCIAL SEMÂNTICO PARA AVALIAÇÃO DE PERSONALIDADE.
}

Maria Fabiana Damásio Passos

Brasília - DF

2014 
Maria Fabiana Damásio Passos

Elaboração e validação de escala de diferencial semântico para avaliação de personalidade.

Tese elaborada sob orientação do Prof. PhD. Jacob Arie Laros, apresentada ao Programa de PósGraduação em Psicologia Social, do Trabalho e das Organizações da Universidade de Brasília, como requisito parcial à obtenção do título de Doutora em Psicologia.

Brasília 
Universidade de Brasília

Instituto de Psicologia

Programa de Pós-Graduação em Psicologia Social, do Trabalho e das Organizações

Prof. PhD. Jacob Arie Laros (Orientador)

Universidade de Brasília - UnB

Prof. Dr. Josemberg Moura Andrade (Membro)

Universidade Federal da Paraíba - UFPB

Prof $^{\mathrm{a}}$. Dra ${ }^{\mathrm{a}}$. Cláudia Cristina Fukuda (Membro)

Universidade Católica de Brasília - UCB

Prof. PhD. Hartmut Günther (Membro)

Universidade de Brasília - UnB

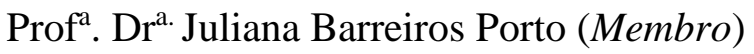

Universidade de Brasília - UnB

Prof $^{\mathrm{a}}$. PhD. Isolda Araújo Günther (Membro Suplente)

Universidade de Brasília - UnB

Brasília, 14 de novembro de 2014 
O que me tranquiliza é que tudo o que existe, existe com uma precisão absoluta. O que for do tamanho de uma cabeça de alfinete não transborda nem uma fração de milímetro além do tamanho de uma cabeça de alfinete. Tudo o que existe é de uma grande exatidão. Pena é que a maior parte do que existe com essa exatidão nos é tecnicamente invisivel. Apesar da verdade ser exata e clara em si própria, quando chega até nós se torna vaga pois é tecnicamente invisível. O bom é que a verdade chega a nós como um sentido secreto das coisas. Nós terminamos adivinhando, confusos, a perfeição. 


\section{Agradecimentos}

“Navegar é preciso, viver não é preciso” (Fernando Pessoa)

Finda a travessia. Ainda não sei quais são as cores, sons e formas que irei encontrar ao pisar nas margens de chegada, mas sei dos sabores e dissabores que provei ao navegar por um mar salgado, marcado mais por tempestades do que por calmarias. Hoje, se estou prestes a chegar nesta margem, foi porque encontrei nesse trajeto, pessoas que puderam me ensinar que a navegação é uma ciência exata e que a bússola é uma companheira de todas as horas na construção das rotas.

A minha gratidão vai em primeiro lugar para Marina, minha cria, que, ao pegá-la no meu colo pela primeira vez, me conduziu a fazer uma pergunta diária: afinal o que quero deixar de herança para você, minha pequena? Em meio ao afeto e ao amor, senti que precisava deixar um modelo de mulher que procura estar inteira, ser honesta e ter coragem para abraçar as navegações para as quais tenho sido convidada (ou convocada) a fazer ao longo da vida.

À minha mãe, Zélia, pelo companheirismo constante, mesmo estando longe e por fazer o exercício constante de aceitar as minhas escolhas. Ao meu pai, Adilson, que, com todas as nossas diferenças de rotas, aprendeu, junto comigo, a importância de fazer prevalecer o afeto. Aos meus irmãos, Joana, Maju e Adil, pelo amor e pelo respeito à diversidade. Essa é a nossa maior marca.

Aos meus amigos de Salvador, pela possibilidade de fortalecimento de vínculo, mesmo estando fora. Em especial, agradeço a Gabriela e a Patrícia, pelo incentivo, pela presença e por acreditarem em mim, até mesmo quando, por inúmeras vezes, questionei meus rumos e as minhas escolhas. Um agradecimento especial ainda às minhas amigas Sônia Bahia, Sônia Regina e Telma Mascarenhas, pelo apoio incondicional e a Wilson Sampaio, pelas reflexões constantes sobre a trajetória de um doutorado.

Aos meus amigos de Brasília, ainda bem que eu não acredito no que me contam! Obrigada por terem contribuído para que eu encontrasse aridez apenas no clima e nas palavras ditas por pessoas que nunca vieram aqui. Tive a sorte, por meio da convivência com vocês, de acolher essa cidade embelezada pelos seus ipês e de transformar aqui no meu canto. A vocês, Lharissa Novo, Meiri Lima, Vanessa Costa, Bruno Andrade e Raphael Alexandre, a minha gratidão. 
Aos companheiros de PSTO, com quem eu pude trocar ideias e enfrentar cada um dos desafios apresentados pelo programa: Renata Manuelly, Camila Karino, Luiz Vinha, Sandra Brant e Jussara Prado. À Gina Pancorbo, por estar sempre disponível para realizar as traduções para o espanhol. Agradeço a Felipe Valentini e Ingrid Neto, não só pela amizade, como também pelas contribuições criteriosas, atenciosas e bem-vindas à etapa empírica da pesquisa. Um agradecimento especial, faço aos amigos do PSTO, Clara Cantal, Patrícia Emanuele, Daniel Kinpara e Isabelle Chariglionne. Desejo à nossa amizade vida longa.

E no meio da minha rota, surge a Fiocruz, que balançou o meu mar e me apresentou o desafio de concluir o doutorado e trabalhar ao mesmo tempo. À Francini Guizardi, Dulce Ferraz e Angela Almeida, o meu agradecimento por terem feito com que este percurso fosse menos árduo. Agradeço também à Marina Dessen, não só pelo apoio no contexto de trabalho como também pela disponibilidade em participar da minha qualificação e pelas importantes contribuições dadas nesse momento.

Agradeço também à Zane Stneimertz, Gisele Silva, Lanna Afonso e Ernesto Steinmertz pelo amplo apoio na realização da minha coleta de dados e a Marcelo Jesus, pelo apoio na análise de dados. A todos os juízes que deram contribuições na fase de elaboração da escala. E à CAPES, pelo apoio por meio de pagamento de bolsa nos dois primeiros anos, para que eu pudesse ingressar no programa e sustentar meus estudos durante esse período.

Quero, por fim, agradecer ao Programa de Pós-Graduação em Psicologia Social, do Trabalho e das Organizações, PSTO, pela possibilidade de ampliar os meus conhecimentos sobre a Psicologia e os seus modos de fazer ciência. Com sua seriedade e disciplina, contribuiu para o meu aprendizado ao me mostrar a complexidade da precisão, a importância dos caminhos estatísticos que percorri e que ainda necessito percorrer. Sei que foi apenas o começo, mas recebo a régua e o compasso com responsabilidade para continuar a construindo outras rotas. Agradeço, em especial, a cada um dos professores das disciplinas que cursei e que deram importantes contribuições para a reflexão sobre o meu projeto: Bartholomeu Trocolli, Elaine Neiva, Fabio Iglesias, Gardênia Abaad, Jairo Borges-Andrade, Luiz Pasquali e Ronaldo Pilati. Agradeço ainda ao PSTO pela oportunidade de ter participado do Programa Erasmus Mundus, tendo despertado em mim o desejo de ir mais longe.

Agradeço também aos professores Claudia Fukuda, Juliana Porto e Josemberg Andrade pela disponibilidade em participarem da minha banca e pelas importantes contribuições dadas à tese. 
Quero declarar, de forma particular, minha gratidão a quatro professores. Professora Kátia Puente-Palácios, agradeço pela acolhida afetuosa e pelas orientações para a minha vida pessoal e acadêmica. À professora Isolda Günther que, com sua doçura, simplicidade e sabedoria, demonstrou disponibilidade constante para colaborar com o meu projeto de forma precisa e cuidadosa, sem perder o afeto. Ao professor Hartmut Günther, que desde o primeiro momento, despertou em mim o desejo de conhecer mais sobre métodos. Mas foi muito mais. Ao longo desses anos, evidenciou, por meio da sua capacidade de síntese, a habilidade de, ora me instigar, ora me acolher, usando apenas uma palavra ou uma curta pergunta curta. A vida foi muito generosa comigo ao colocá-lo na minha trilha acadêmica, profissional e pessoal.

Por fim, ao professor Laros, agradeço pela disponibilidade em me acolher sem me conhecer e, de modo atencioso e generoso, se dispôs a me ensinar sobre a Psicologia, sobre a Estatística, mas também sobre a vida. Aprendi que precisamos ser criteriosos para escolher cada análise estatística, a depender do objeto. Aprendi a ver beleza nos números e compreendi que as tabelas também têm vida. Aprendi a ser objetiva e que a precisão não deve ser uma característica apenas dos números, como também das palavras. Que essa objetividade exige treino diário e que esse exercício deverá me acompanhar ao longo dos próximos caminhos que trilharei. Mas, principalmente, em meio a tabelas, números e textos objetivos, aprendi a reconhecer o sentido da precisão, ao poder ver a beleza de uma orquídea e ouvir o leve canto dos pássaros. Muito obrigada!

A todos vocês, que seguiram ao meu lado durante essa navegação, a minha gratidão. 


\section{Sumário}

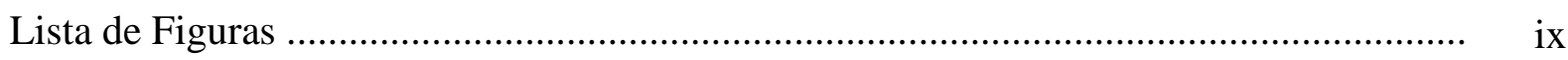

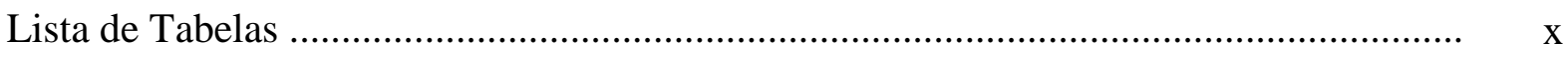

Lista de Abreviações .................................................................................................. xii

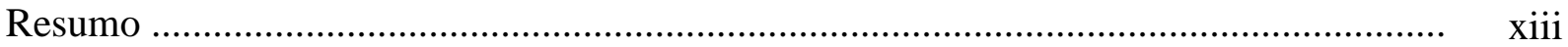

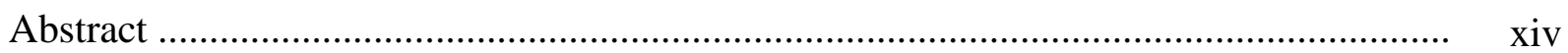

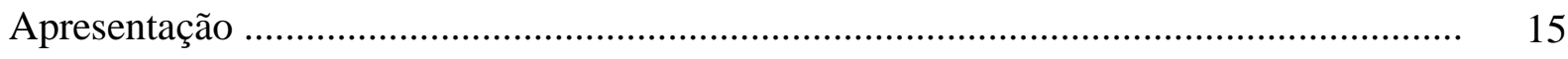

Manuscrito 1. O modelo dos cinco grandes fatores de personalidade: revisão de

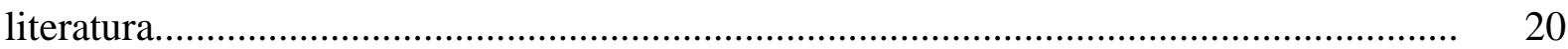

Manuscrito 2. Etapas de elaboração de uma escala de diferencial semântico para avaliação

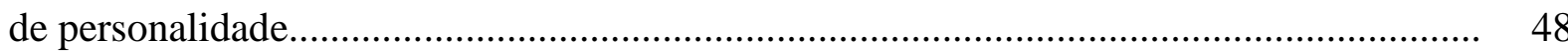

Manuscrito 3. A estrutura fatorial da Escala Reduzida de Cinco Grandes Fatores de

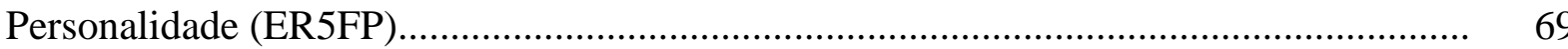

Manuscrito 4. Evidências de validade convergente entre a Escala Reduzida de Diferencial Semântico para Avaliação de Personalidade e o BFI.

Considerações finais

Referências gerais

Anexos 


\section{Lista de Figuras}

Manuscrito 1. O modelo dos cinco grandes fatores de personalidade: revisão de literatura

Figura 1. Distribuição dos artigos pelas grandes áreas - revisão internacional

Figura 2. Aspectos gerais da aplicabilidade do modelo dos Grandes Fatores

Figura 3. Distribuição dos artigos pelas grandes áreas - revisão nacional

Manuscrito 2. Etapas de elaboração de uma escala de diferencial semântico para avaliação de personalidade

Figura 1. Modelo para elaboração do instrumento. 


\section{Lista de Tabelas}

Manuscrito 1. O modelo dos cinco grandes fatores de personalidade: revisão de literatura

Tabela 1. Distribuição dos artigos por ano de publicação e por journal - revisão 28 internacional

Tabela 2. Distribuição dos artigos por ano de publicação e por jornal - revisão nacional

Manuscrito 2. Etapas de elaboração de uma escala de diferencial semântico para avaliação de personalidade

Tabela 1. Modificações realizadas nos pares a partir da análise semântica

Tabela 2. Percentual de concordância entre os psicólogos sobre a condição de oposição de adjetivos e de representação do fator

Tabela 3. - Modificações realizadas nos pares a partir da análise de juízes

Manuscrito 3. A estrutura fatorial da Escala Reduzida de Cinco Grandes Fatores de Personalidade (ER5FP).

Tabela 1. Índices de ajuste dos modelos de mensuração inicial, intermediário e final do instrumento reduzido para avaliar os cinco grandes fatores de personalidade

Tabela 2. Coeficientes de fidedignidade ( $\lambda_{2}$ de Guttman), cargas fatoriais $(\mathrm{CF})$, comunalidades $\left(\mathrm{h}^{2}\right)$, correlações item-resto $\left(\mathrm{r}_{\mathrm{ir}}\right)$, para os cinco fatores do instrumento reduzido de personalidade, as correlações entre os fatores e os índices de ajuste do modelo aos dados $(\mathrm{N}=365)$.

Tabela 3. Médias e Desvios-padrão dos fatores

Tabela 4. Coeficientes Estimados pelo Método da Máxima Verossimilhança e 85 Resultados das Replicações Bootstrap 
Manuscrito 4. Evidências da validade convergente da Escala Reduzida de Cinco Grandes Fatores de Personalidade.

Tabela 1. Dados sociodemográficos dos participantes $(\mathrm{N}=554)$

Tabela 2. Índices de ajuste dos modelos de mensuração iniciais e finais da Escala Reduzida de Cinco Grandes Fatores de Personalidade (ER5FP)

Tabela 3. Cargas fatoriais (CF), comunalidades $\left(h^{2}\right)$ e correlações entre os fatores e índices de ajuste do modelo da Escala Reduzida de Cinco 108 Grandes Fatores de Personalidade (ER5FP) utilizando Análise Fatorial Confirmatória; correlações item-resto (rir), coeficientes de fidedignidade (lambda 2 de Guttman) e correlação média entre os itens por fator $(\mathrm{N}=554)$

Tabela 4. Média, desvio-padrão e variância dos cinco escores fatoriais da Escala Reduzida de Cinco Grandes Fatores de Personalidade (ER5FP) no estudo de construção $(\mathrm{N}=365)$ e no estudo atual de validade convergente $(\mathrm{N}=554)$

Tabela 5. Índices de ajuste dos modelos de mensuração iniciais e finais do Inventário Reduzido dos Cinco Grandes Fatores de Personalidade (IGFP-5R)

Tabela 6. Cargas fatoriais (CF), Comunalidades $\left(\mathrm{h}^{2}\right)$, correlações entre os fatores e índices de ajuste do modelo do Inventário Reduzido dos Cinco Grandes Fatores de Personalidade (IGFP-5R) utilizando Análise Fatorial Confirmatória; correlações item-resto (rir), coeficientes de fidedignidade (lambda 2 de Guttman) e correlação média entre os itens por fator $(\mathrm{N}=554)$

Tabela 7. Média, desvio-padrão e variância dos cinco escores fatoriais Inventário Reduzido dos Cinco Grandes Fatores de Personalidade (IGFP-5R) no estudo atual de validade convergente $(\mathrm{N}=554)$

Tabela 8. Coeficientes de correlação brutos e corrigidos por atenuação entre os fatores da Escala Reduzida de Cinco Grandes Fatores de Personalidade (ER5FP) e os fatores do Inventário de Cinco Grandes Fatores de Personalidade (IGFP-5R) [N=554] 


\section{Lista de Abreviações}

16PF 16 Personality Factors

AF Análise Fatorial

AFC Análise Fatorial Confirmatória

AFE Análise Fatorial Exploratória

$\mathrm{CF}$ Cargas Fatoriais

CFI Comparative Fit Index

CGF Cinco Grandes Fatores de Personalidade

CPS Escala de Personalidade de Comrey

DP Desvio Padrão

EFEx Escala Fatorial de Extroversão

EFN Escala Fatorial de Neuroticismo

EFS Escala Fatorial de Socialização

ER5FP Escala Reduzida dos Cinco Grandes Fatores de Personalidade

FFM Five-Factor Model

GL Graus de Liberdade

GFI Goodness of Fit Index

$\mathrm{h}^{2} \quad$ Comunalidades

IGFP-5R Inventário Reduzido dos Cincos Grandes Fatores de Personalidade

M Média

MEE Modelagem por Equações Estruturais

NEO-PI Neo Revised Personality Inventory

RMSEA Root Mean Square of Error Approximation

SPSS Statistical Package for the Social Sciences

SRMR Standardized Root Mean Square Residual

TCLE Termo de Consentimento Livre e Esclarecido

TLI Tucker-Lewis Index 


\section{Resumo Geral}

A estrutura oferecida pelo modelo dos Cinco Grandes Fatores de Personalidade (CGF) apresenta uma base teórica que permite a incorporação de novos achados empíricos, que tende a disponibilizar uma visão clara do domínio dos traços de personalidade e das relações entre os fatores de personalidade. A presente tese teve por objetivo: (1) verificar como o modelo dos CGF tem sido apoiado pelos estudos empíricos e averiguar a sua aplicabilidade; (2) construir um instrumento reduzido para avaliação dos CGF, utilizando a técnica de diferencial semântico e obter as evidências de validade e de fidedignidade dos seus escores; (3) obter as evidências de validade convergente do novo instrumento. Para o cumprimento dos objetivos, foram elaborados quatro manuscritos: um teórico, um técnico e dois empíricos. A proposta do primeiro manuscrito foi compreender, de modo abrangente, o modelo dos CGF, bem como seus mecanismos de aplicabilidade. Realizou-se uma revisão de literatura de abrangência nacional e internacional a fim de averiguar a produção científica na área. Foram analisados 156 artigos internacionais e 27 artigos nacionais. O segundo manuscrito descreveu, no escopo da avaliação de personalidade com base no modelo dos CGF, as etapas de elaboração de uma escala reduzida, usando a técnica do diferencial semântico. O objetivo do terceiro manuscrito foi verificar as evidências de validade e fidedignidade dos escores do novo instrumento construído, a Escala Reduzida dos Cinco Grandes Fatores de Personalidade - ER5FP. 365 estudantes universitários participaram desta etapa do estudo. No quarto manuscrito, foram apresentados os dados sobre a validade convergente da ER5FP: a escala foi aplicada, junto com o Inventário Reduzido dos Cinco Grandes Fatores de Personalidade (IGFP-5R), em 554 participantes. Os resultados apresentados nos dois últimos manuscritos indicaram evidências satisfatórias de validade e fidedignidade dos escores da ER5FP, especialmente no que se refere aos fatores Extroversão, Neuroticismo e Abertura para Experiência. As evidências de validade da ER5FP são comparáveis com as evidências obtidas por outros instrumentos que se propõem a avaliar o mesmo modelo.

Palavras-chave: cinco grandes fatores de personalidade; escalas reduzidas de personalidade; validade convergente. 


\section{General Abstract}

The structure offered by the Five-Factor Model (FFM) of personality traits presents a theoretical basis that allows the embedding of new empirical findings, and provides a clear vision of the domain of personality traits and of the relationships between personality factors. The objectives of the present thesis were: (1) to ascertain how the FFM has been supported by empirical studies, and to verify the applicability of the model; (2) to construct a reduced instrument assessing the big five personality factors using a semantic differential scale and to obtain evidence of its score validity and score reliability, and (3) to obtain evidence of the convergent validity of the newly constructed instrument. To attain the objectives of the thesis four manuscripts were elaborated: one theoretical, one technical and two empirical. The purpose of the first manuscript was to gain a comprehensive understanding of the FFM and the way in which the model is being applied. This manuscript describes a revision of Brazilian and international scientific literature that was realized to obtain an inventory of the scientific production in the area of personality evaluation. The revision included 156 international and 27 Brazilian scientific articles. The second manuscript describes the development stages of a reduced instrument using a semantic differential scale that was constructed to assess the big five personality factors. The objective of the third manuscript was to verify evidence of the score validity and score reliability of the newly constructed instrument named ER5FP - the Reduced Scale of the Big Five Personality Factors. Therefore, the instrument was administered to 365 university students. In the fourth manuscript data is presented on the convergent validity of ER5FP: the scale was administered to 554 participants together with the reduced version of the Big Five Inventory (IGFP-5R). The results reported in the last two manuscripts indicated that positive evidence of the score validity and the score reliability of the ER5FP was obtained, especially in relation to the factors Extraversion, Neuroticism and Openness to Experience. The evidence of score validity found for the ER5FP is comparable with the evidence obtained for other instruments assessing the big five personality factors.

Keywords: big five personality factors; reduced personality scales; convergent validity. 


\section{Apresentação}

A personalidade, considerada um construto base para a Psicologia como ciência, constitui-se como objeto estudado a partir de diversas perspectivas teóricas, como a psicanálise, a gestalt-terapia, a psicologia junguiana, o behaviorismo e a teoria cognitiva. A personalidade também se configura, ao longo da história, como um construto a ser mensurado, o que resultou na construção de modelos fatoriais de personalidade. Numa outra direção, Cloninger (2009) indica seis perspectivas de compreensão da personalidade: a biológica, a cognitiva, a humanística, a de aprendizagem, a psicodinâmica e a dos traços. A perspectiva dos traços de personalidade se constitui como uma dentre as diversas perspectivas apresentadas para a compreensão do conceito.

Ao tomar como referência um enfoque mais objetivo da personalidade, o recorte do presente estudo é o modelo dos Cinco Grandes Fatores de Personalidade (CGF), sendo a compreensão dos traços de personalidade o ponto de partida para a sua compreensão. Essa perspectiva foi influenciada pelas investigações realizadas por Allport que, em 1927, publicou Concepts of trait and personality e, dez anos depois, publicou Personality: A psychological interpretation. Allport contribuiu para que os traços pudessem ser considerados centrais para o entendimento do conceito de personalidade (Cloninger, 2009).

Em 1936, Allport e Odbert realizaram um estudo psicoléxico com os termos de personalidade. Utilizaram dicionário inglês completo, no qual localizaram 1.800 termos que poderiam ser usados para distinguir o comportamento humano. A partir da análise de terminologias existentes no dicionário, os autores identificaram, como categorias de descrição, os traços de personalidade, os estados temporais, os humores e as atividades, os altos julgamentos avaliativos, as características físicas, as capacidades e os talentos (John, Naumann \& Soto, 2008). Outra importante contribuição ao desenvolvimento da teoria dos traços de 
personalidade, de acordo com John, Naumann \& Soto (2008), foi dada por Murray, em 1938, com a publicação Explorations in personality.

Os estudos dos traços de personalidade também receberam contribuições de Cattell, que adotou procedimentos semânticos e empíricos, chegou a 35 variáveis de personalidade, e eliminou 99\% dos termos, culminando, depois da divisão fatorial, na elaboração do instrumento chamado de 16 PF - 16 Personality Factors - (De Raad, 2009; John, Naumann \& Soto, 2008), que foi traduzido para a realidade brasileira. Segundo De Raad (2009), o 16 PF se configurou como a base para os estudos de análise fatorial de personalidade. No decorrer do tempo, os estudos fatoriais começaram a identificar 5, ao invés de 16 fatores, para sintetizar as várias matrizes de correlação. Os estudos realizados por McCrae e Costa, sobre o 16 PF, identificaram três fatores como ponto de partida para o desenvolvimento da estrutura fatorial do NEO-PI (De Raad, 2009).

Na história da psicologia da personalidade, de acordo com John, Naumann e Soto (2008), as perspectivas de Allport e de Cattell entraram em contradição com as de Murray, uma vez que os dois primeiros consideravam os traços como maiores elementos da personalidade. Ainda sobre as contribuições históricas para o estudo sobre os traços de personalidade, dois exemplos também são considerados relevantes. Em 1952, Eysenck publicou The structure of human personality. Mais recentemente, em 1987, McCrae e Costa apresentaram dados sobre o modelo dos cinco grandes fatores de personalidade (John, Naumann \& Soto, 2008), assim como Hendriks et al (2003), em estudos sobre o Five-Factor Personality Inventory em 13 países.

Em 1981, Goldberg escolheu o nome big five na tentativa de reforçar a amplitude de cada um dos fatores. A ideia defendida era a de que o modelo dos CGF não buscava reduzir a análise da personalidade em apenas cinco traços, mas tais dimensões representam a personalidade no seu amplo nível de abstração, em que cada uma das dimensões sintetiza um grande número de características específicas da personalidade (John, Naumann \& Soto, 2008). 
Os estudos sobre os traços e sobre as questões psicométricas, atreladas à psicologia da personalidade, refletem os esforços dos pesquisadores para seguir os passos das ciências exatas, que gozavam de mais status, graças ao seu nível de precisão (Barenbaum \& Winter, 2009). Um traço pode ser expresso por comportamentos, sentimentos e pensamentos que aparecem com base em uma única causa psicológica. Um traço de personalidade não é simplesmente um hábito que é vinculado a uma situação específica, ele é mostrado em uma variedade de conjunto, em que as pessoas diferem entre si, na maneira em que o traço é expresso. Além disso, há um padrão de comportamento que pode ser observado ao longo do tempo, o que denota a sua estabilidade.

Salienta-se também que, do ponto de vista científico, os traços já ofereceram resultados interessantes no que se refere à definição de características universais de personalidade. Mesmo assim, ao considerar as questões culturais, não há consenso sobre o número de fatores apresentados por meio da linguagem dos traços de personalidade. $\mathrm{O}$ que se observa é que o traço em culturas diferentes é idêntico, mas um fator que é vastamente representado em uma cultura pode ter sido negligenciado em outra cultura (Lee \& Ashton, 2007; McCrae, 2009; McCrae \& Costa, 1997).

Com o intuito de contribuir para os avanços, na discussão dos traços de personalidade, o modelo teórico dos CGF foi sendo estruturado e testado empiricamente, de modo a viabilizar o seu fortalecimento. Foi testado e replicado ao longo do Século XX, e os pesquisadores focaram os seus estudos na tentativa de clarificar os fatores e reanalisar as matrizes de correlação (Barenbaum \& Winter, 2009).

Assim, o modelo dos CGF representa a possibilidade de analisar, de forma objetiva, a personalidade, sem perder a dimensão da sua complexidade. O percurso histórico de estudos realizados sobre o referido modelo revela que as pesquisas têm sido realizadas em três diferentes eixos. O primeiro eixo busca investigar os aspectos referentes à sua estruturação e à 
existência dos CGF. Paralelo a isso, e mais intensificado, o segundo eixo dedica-se aos estudos sobre a qualidade psicométrica de instrumentos para avaliar a personalidade com base no modelo. Já o terceiro eixo é marcado pelo desenvolvimento de pesquisas que são encontradas e que tratam da correlação entre personalidade e outras variáveis, tais como o uso do Facebook (Jenkins-Guarnieri, Wright, \& Johnson, 2013), a dependência química (Nunes, Nunes, Cunha \& Hutz, 2009) e as escolhas amorosas (Gomes, Gouveia, Silva Junior, Coutinho \& Santos, 2013).

Ao considerar a relevância do modelo, a presente tese teve por objetivo elaborar e validar uma escala reduzida de diferencial semântico para avaliação de personalidade. Buscou-se investigar como os CGF se estruturam, de modo a identificar como os estudos empíricos os corroboram. O estudo também averiguou, metodologicamente, como se dá a sua utilização na avaliação de personalidade, considerando os critérios exigidos na construção e na verificação das evidências de validade e de fidedignidade dos escores.

Para o cumprimento desses objetivos, foram organizados quatro manuscritos, um teórico, um técnico e dois empíricos. O primeiro foi estruturado com o propósito de compreender, de modo mais abrangente, o modelo dos CGF, bem como seus mecanismos de aplicabilidade. Foi feita uma revisão de literatura de abrangência nacional e internacional a fim de averiguar a produção científica na área. De modo específico, buscou-se realizar um apanhado dos principais achados na literatura nacional.

O segundo manuscrito se dedicou a apresentar, no escopo da construção de instrumento para avaliação de personalidade com base no modelo dos CGF, as etapas de elaboração de uma escala. A decisão pela inserção do referido manuscrito se deu por se tratar de um modelo fatorial e por ser uma possibilidade de análise da sua estrutura. A técnica de diferencial semântico foi escolhida pela possibilidade de construção de um instrumento mais curto e objetivo, e que 
permita o fácil entendimento por parte dos participantes, contribuindo para que a avaliação seja mais inclusiva.

O terceiro manuscrito, de caráter empírico, tratou das evidências de validade e fidedignidade dos escores apresentados pela Escala Reduzida dos Cinco Grandes Fatores de Personalidade - ER5FP. O quarto, e último manuscrito, dedicou-se a apresentar dados sobre a validade convergente da referida escala com O Big Five Inventory, validado para a realidade brasileira com o nome de Inventário dos Cinco Grandes Fatores de Personalidade - IGFP-5R por Andrade (2008). Por fim, nas considerações finais gerais, foi realizado um apanhado sobre os principais achados, conforme descrito nos quatro manuscritos. Adicionalmente, foram indicados caminhos para o avanço, em estudos futuros, que visem à ampliação da utilização do modelo em pesquisas realizadas no Brasil. 


\title{
Manuscrito 1
}

\section{O modelo dos cinco grandes fatores de personalidade: revisão de literatura}

\begin{abstract}
Resumo
Este estudo é uma revisão do uso do modelo dos Cinco Grandes Fatores (CGF): seu objetivo é mapear os artigos científicos sobre o CGF e ampliar a discussão sobre as características do referido mo delo de personalidade. Foi realizada uma revisão de literatura, utilizando como base de dados a PsicArticles para a pesquisa internacional e as bases de dados Scientific Eletronic Library Online - Scielo e Periódicos Eletrônicos de Psicologia - Pepsic para a pesquisa nacional, no período entre 2008 e 2013. Foram analisados 183 artigos, sendo 156 nas bases internacionais e 27 nas bases nacionais. Os resultados contribuíram para o reconhecimento da qualidade do modelo dos CGF na compreensão dos fenômenos psicológicos. Como agenda de pesquisa futura, é sugerido ampliar o escopo da pesquisa no sentido de usar mais bases de artigos e realizar meta-análises para determinar a robustez dos inventários de personalidade em uma diversidade ampla de condições.
\end{abstract}

Palavras-chave: cinco grandes fatores de personalidade; medida de personalidade; revisão de literatura,

\begin{abstract}
This study is a review of the use of the Five Factor Model (FFM): it aims to map the practical applications of the FFM and to broaden the discussion about its methods and the applicability of this model of personality. A systematic review of the literature published between 2008 and 2013 was conducted, using the PsicArticles database and the Brazilian database of Capes. One hundred eighty three articles were analysed. The NEO-PI-R personality inventory was used in $30.2 \%$ of the articles. The results of the present study indicated the quality of the FFM model as a tool to understand psychological phenomena. A suggestion for a future research agenda involves the realization of several meta-analyses to widen the scope of the investigation and to determine the robustness of the personality inventories in a broad diversity of conditions.
\end{abstract}

Keywords: five-factor model; personality assessment; literature review. 
O modelo dos CGF configura-se como referência no escopo da teoria dos traços de personalidade, e os estudos que o utilizam como base para a compreensão dos fenômenos psicológicos são crescentes (Andrade, 2008; Hutz, Nunes, Silveira, Serra, Anton \& Wieczorek, 1998; McCrae, 2009). Desde a década de 1990, a pesquisa sobre traços de personalidade tem mudado de forma intensa. A teoria do traço é o princípio fundamental do modelo dos CGF, permitindo a avaliação quantitativa. Nesse caso, os indivíduos são caracterizados de acordo com os padrões relativamente duradouros de pensamentos, sentimentos e ações (John, Naumann \& Soto, 2008; McCrae, 2009).

Atualmente, já existe uma extensiva produção científica na esfera internacional que indica que o modelo do CGF apresenta consistência para a compreensão da personalidade (McCrae, 2009; McCrae, Yamagata, Jang, Riemann, Ando, Ono et al., 2008; Perugini, Galluci \& Livi, 2000). Tal consistência também é corroborada pelos estudos transculturais, reiterando a perspectiva de McCrae (2009), que o modelo se configura como um paradigma dominante nas pesquisas sobre personalidade. Além disso, os estudos já indicam que os traços de personalidade nele presentes são preditores de outros aspectos como desempenho no trabalho (Oh \& Berry, 2009; Oh, Wang \& Mount, 2010) e transição para a aposentadoria (Lockenhoff, Terraciano \& Costa Jr, 2009).

O modelo dos CGF funciona como uma estrutura subjacente que serve como referência para a realização de investigações diversas sobre o fenômeno psicológico. Constitui um conjunto bem fundamentado de conceitos básicos com os quais os traços de personalidade podem ser descritos no nível mais abstrato, fornecendo uma estrutura considerável que lhe permite competir com outros modelos (De Raad \& Perugini, 2002).

O modelo do CGF é derivado de duas tradições de pesquisa na área: a abordagem psicoléxica e a elaboração de instrumentos de medidas. A primeira se dedica exaustivamente aos aspectos semânticos para definir a personalidade e recorrer à 
linguagem comum para fazer a identificação das terminologias equivalentes. Já a segunda abordagem indica os estudos sobre o modelo dos CGF que se dedicam ao desenvolvimento de instrumentos de avaliação mais variados e contribuem para que eles fiquem com formatos mais adequados e robustos para a mensuração da personalidade (De Raad \& Perugini, 2002). Dentre os fatores que compõem o modelo dos CGF, estão o Neuroticismo, a Amabilidade, a Conscienciosidade, a Abertura para a Experiência e a Extroversão.

O Neuroticismo refere-se a um traço de personalidade presente em pessoas que vivenciam, de forma negativa, os estados emocionais. Estão mais suscetíveis a apresentar sentimentos como ansiedade, irritabilidade e depressão (Widiger, 2009) e respondem aos eventos estressores de forma pouco proativa. Dentre os domínios que compõem os Cinco Grandes Fatores de personalidade, o Neuroticismo está, junto com a Extroversão e Abertura para Experiências, entre os encontrados na literatura com evidências de validade dos escores mais consistentes nas mais diversas culturas.

A Amabilidade, traduzida para a realidade brasileira por Hutz, Nunes e Nunes (2010) com a terminologia de Socialização, indica a qualidade das relações interpessoais presente no momento da interação de uma pessoa com outra. Indica a possibilidade que uma pessoa tem de construir relações agradáveis, harmoniosas e amistosas. É um fator que revela a diferenciação e a singularidade do indivíduo frente ao contato com as outras pessoas (Graziano \& Tobin, 2009).

A Conscienciosidade, também chamada de Realização na tradução brasileira (Hutz, Nunes \& Nunes, 2010), caracteriza uma pessoa focada em suas metas, seguidora de normas, que busca ter controle sobre seus impulsos. É uma pessoa realizadora, empreendedora e voltada para implementar ações que contribuam para o cumprimento de objetivos da sua vida (Roberts, Jackson, Fayard, Edmon \& Meints, 2009). 
A Abertura para a Experiência revela a disponibilidade de uma pessoa para vivenciar novos ambientes, ter acesso a novos conhecimentos e receber, de forma positiva, ideias mais inovadoras e originais. São curiosos, mais liberais, imaginativos e intelectuais (McCrae \& Sutin, 2009). É um fator permeado pela forma como as pessoas tendem a perceber o ganho de conhecimento e o acesso a novas informações e ideias.

Por último, a Extroversão é característica de pessoas que tendem a apresentar facilidade para interagir com outras pessoas, expor suas ideias em público e fazer novas amizades. Associa-se com alta motivação e com afeto positivo (Wilt \& Revelle, 2009). Em estudos de validade convergente dos cinco fatores de personalidade, o fator Extroversão é um dos que apresenta os coeficientes de validade mais fortes.

Ao considerar os fatores que integram o modelo dos CGF, observa-se que ele não se constitui um único domínio extenso, como uma medida que agrega toda a sua amplitude (Roberts et al., 2009), corroborando com as ideias de McCrae (2009). Ele se estrutura a partir das especificidades e, ao mesmo tempo, das equivalências existentes entre os fatores descritos e, mesmo estes, já são dotados de facetas que indicam a sua complexidade.

Mesmo com o conjunto de esforços realizados para a sua compreensão, ainda há uma série de limitações e críticas ao modelo dos CGF. Os estudiosos indicam que este não oferece uma teoria completa da personalidade (John, Naumann \& Soto, 2008; De Raad, 2009). Apesar de apresentar uma estrutura com um grande número de traços e de ter se tornado um ícone nos estudos de personalidade, para alguns autores, como De Raad (2009), a universalidade atribuída ao modelo é exagerada. Salienta-se que não há questionamentos quanto à aceitabilidade do modelo, mas a visão crítica sobre a sua universalidade configura-se como um ponto de partida para a identificação de outras 
possibilidades de definição dos traços de personalidade e até mesmo de realização de estudos que venham a sustentar o modelo popularmente aceito.

Uma outra crítica refere-se à quantidade de fatores encontrados nas diferentes culturas. Lee e Ashton (2007) sugeriram seis fatores, tendo adicionado o fator de Honestidade, que significa o quanto uma pessoa é justa, sincera, honesta. Os estudos de De Raad e Peabody (2005) relataram análise dos adjetivos que descrevem traços em amostras na Alemanha, Itália, República Checa, Hungria e Polônia e indicaram que existem três fatores robustos, ao invés de cinco.

Há também uma crítica que indica que o modelo dos CGF não se constitui uma teoria completa da personalidade, uma vez que não abarca outros elementos, tais como contexto. Tal aspecto é refutado por McCrae e Costa (1997), com o estudo sobre a universalidade dos traços de personalidade. Os autores identificaram traços similares em seis culturas diferentes. As dimensões básicas da personalidade forneceram uma estrutura para o entendimento dos aspectos singulares que caracterizam cada cultura. Nesse sentido, se o traço representa uma variação na forma como as pessoas agem e vivenciam suas experiências, eles podem ser tratados como universais (McCrae \& Costa, 1997). A universalidade pode ser atribuída tanto a aspectos biológicos quanto às experiências compartilhadas na vida em grupo.

O objetivo desta revisão de literatura é realizar mapeamento de estudos sobre as possibilidades de utilização do CGF, a fim de ampliar a discussão sobre os métodos adotados e a sua aplicabilidade. A escolha por focar esse modelo se deu em função da sua importância para a construção de indicadores de mensuração da personalidade. Verificase a importância de expansão dos estudos por meio do uso do modelo dos CGF, uma vez que ele vem apresentando dados de universalidade e vem sendo largamente estudado em outras culturas. Essa revisão de literatura, portanto, constitui o ponto de partida para a 
identificação de como o modelo vem sendo empregado nos estudos, fornecendo ao leitor informações que subsidiem a construção de problemas de pesquisa com ele relacionados. Em razão disso, as perguntas que norteiam esse estudo são: Como os estudos foram realizados? Quais são os métodos mais usuais, utilizados na análise de dados de estudos sobre personalidade? Em que áreas da psicologia o modelo dos CGF vem sendo aplicado?

\section{Método}

A revisão de literatura, de caráter descritivo, foi realizada nas bases de dados internacional e nacional. A internacional baseou-se nos artigos disponíveis na PsicArticles, integrante da American Psychological Association (APA) e utilizou como palavras-chave big-five e five-factor model. Os artigos inseridos na amostra deveriam apresentar tais palavras em seu título, em seu abstract ou no seu escopo de palavraschave. Os critérios de inclusão adotados foram (i) ter sido publicado no período entre 2008 e 2013 e (ii) ser artigo empírico. Deste modo, foram excluídos todos os artigos teóricos e de meta-análise. Para a pesquisa nacional, foram utilizados os mesmos critérios de análise e de temporalidade e o levantamento de artigos foi efetuado nas bases Scielo e Pepsic.

As categorias de análise da literatura utilizadas no presente estudo foram: desenho de investigação, natureza da pesquisa, quantidade de estudos por artigo, finalidade do estudo, grande área do estudo, tamanho da amostra, características gerais dos participantes, relato de hipóteses, tipo de instrumento utilizado e estratégia de análise de dados adotada. Tais categorias foram baseadas em Borges-Andrade e Pagotto (2010) e adaptadas para a realidade do campo de investigação em questão e para os objetivos do presente estudo. Além disso, a partir da leitura dos artigos, foram indicadas seis categorias de análise para compreensão da expansão de uso do modelo: 
1) elaboração de instrumentos - construção de itens, estudos de evidências de validade fatorial, convergente e divergente e de fidedignidade, replicabilidade de instrumentos;

2) eventos de vida - diferenças entre crianças, jovens e adultos, transição de fases de desenvolvimento, estabilidade dos traços;

3) psicologia organizacional e do trabalho - aspectos atuais dos contextos de trabalho, saúde ocupacional, interesses e trajetórias profissionais;

4) saúde/saúde mental - transtornos de personalidade, estabilidade dos traços, condições de saúde física;

5) social - contingências sociais, fenômenos contemporâneos que atingem os grupos, questões ideológicas, valores, escolhas.

6) Aspectos teóricos - universalidade dos fatores, estrutura da personalidade, definição do número de fatores, diferenças conceituais a partir da denominação dos fatores.

Vale destacar que as categorias "avaliação psicológica" e "teoria da personalidade" se configuram como as duas tradições de pesquisa sobre o modelo dos CGF de personalidade (De Raad \& Perugini, 2002). Outro ponto que merece atenção é que as categorias foram divididas apenas por uma questão didática e de apresentação dos dados. Porém, em muitos artigos, é possível identificar característica de mais de uma categoria. Assim, a decisão foi priorizar o foco principal do estudo. 


\section{Resultados}

\section{A revisão internacional}

Foram identificados 156 artigos que utilizaram o modelo dos CGF entre 2008 e 2013. Ao considerar a faixa temporal estudada, há um aumento considerável do número de publicações de estudos empíricos. Os artigos foram distribuídos em 34 journals, conforme a Tabela 1. Merece destaque ainda a Psychology of Aesthetics, Creativity, and the Arts, que publicou nove artigos que abordam a relação entre a personalidade e a música e outras modalidades de arte (Chamorro-Premuzic, Burke, Hsu \& Swami, 2010; Chamorro-Premuzic, Fagan \& Furnham, 2010; Chamorro-Premuzic, Goma-i-Freixanet, Furnham \& Muro, 2009; Djikic, 2011).

Uma outra evidência é a quantidade de publicações que descrevem as relações existentes entre os CGF e os quadros psicopatológicos. As duas revistas que reúnem a maior quantidade de publicações nesse segmento, a Personality Disorders: Theory, Research and Treatment e o Journal of Abnormal Psychology, juntas, representam 10,2\% das publicações. As demais publicações são de caráter mais pontual, cujos artigos publicados utilizaram o modelo dos CGF para compreensão dos fenômenos tratados das mais variadas formas pelos pesquisadores que tendem a publicar nelas. Um exemplo disso é a Dreaming, que publicou quatro artigos entre 2012 e 2013 sobre a relação entre os CGF e os sonhos (Aumann, Lahl, \& Pietrowsky, 2012; Yu, 2012a; Yu, 2012b; Yu, 2013).

No que se refere ao desenho de investigação, a grande maioria adotou o survey $(78,6 \%)$. O survey foi administrado no formato face-a-face, presencial, online e por $e$ mail. Já os estudos com desenhos experimentais representaram 15,9\% do total de artigos inseridos na amostra. 
Tabela 1. Distribuição dos artigos por ano de publicação e por journal.

\begin{tabular}{lll}
\hline Categorias & $\mathrm{N}$ & $\%$ \\
\hline Ano de publicação & & \\
\hline 2008 & 19 & $12,2 \%$ \\
2009 & 20 & $12,8 \%$ \\
2010 & 21 & $13,5 \%$ \\
2011 & 24 & $15,4 \%$ \\
2012 & 34 & $21,8 \%$ \\
2013 & 38 & $24,3 \%$ \\
\hline Total & 156 & $100,0 \%$ \\
\hline Journal & \multicolumn{2}{|c}{} \\
\hline Journal of Personality and Social Psychology & 33 & $21,2 \%$ \\
Journal of Individual Differences & 16 & $10,3 \%$ \\
European Journal of Psychological Assessment & 12 & $7,7 \%$ \\
Psychological Assessment & 12 & $7,7 \%$ \\
Psychology of Aesthetics, Creativity, and the Arts & 9 & $5,8 \%$ \\
Personality disorders: theory, research and treatment & 8 & $5,1 \%$ \\
Journal of Abnormal Psychology & 8 & $5,1 \%$ \\
Outros (27 journals) & 58 & $37,1 \%$ \\
\hline Total & 156 & $100,0 \%$ \\
\hline
\end{tabular}

Quanto à natureza dos estudos, corroborando com o dado anterior, a grande maioria foi de caráter quantitativo $(64,5 \%)$, seguido dos estudos que adotaram multi-métodos, que representaram $29 \%$ dos artigos analisados. Eles se caracterizaram pela combinação de duas ou mais estratégias de coleta de dados e, em sua maioria (72\%), incorporaram o survey e também se enquadram como estudos quantitativos.

Outro aspecto comum aos artigos é o relato de hipóteses. A grande maioria (80,5\%) indicou as hipóteses a serem testadas em suas pesquisas. Os artigos que não apresentaram hipóteses foram os mais descritivos e os que se dedicaram à obtenção de evidências de validade de escala. Quanto ao método dos estudos, foram localizados 113 artigos de caráter transversal e 43 artigos de caráter longitudinal. Dentre os artigos longitudinais, pode-se citar, como exemplo, o estudo para avaliar a relação entre Neuroticismo e 
satisfação no casamento (Fisher \& McNulty, 2008), cuja coleta de dados foi realizada com um intervalo de seis meses e um ano. No que se refere à quantidade de estudos por artigo, a grande maioria $(74,7 \%)$ é constituída de um estudo. Destaca-se, no entanto, que 39 publicações representam relatos de pesquisa com dois estudos, ou mais.

Quanto às amostras adotadas por estudo, a média encontrada foi de 15.284 participantes. O tamanho elevado da média da amostra deve-se a estudos que apresentaram investigações com amostras populacionais. Por exemplo, um deles buscou investigar as respostas dadas por crianças, adolescentes e jovens adultos ao Big Five Inventory - BFI (Soto, John, Gosling \& Potter, 2008). A amostra de 230.047 voluntários foi obtida pela internet e abrangeu participantes dos Estados Unidos da América e do Canadá.

Quanto aos instrumentos adotados nos estudos analisados nesta revisão, observa-se que há uma prevalência de escalas $(90,3 \%)$ de personalidade e das variáveis escolhidas para a realização de correlações e predições. Dentre as escalas de personalidade mais utilizadas, destaca-se o NEO-PI-R (30,2\%) e NEO-FFI (19\%), em um universo de 30 tipos diferentes de escalas construídas com base no modelo dos CGF.

No que se refere às estratégias de análise de dados adotadas, a análise fatorial $(27,8 \%)$ e a modelagem das equações estruturais $(24,4 \%)$ foram utilizadas principalmente em estudos de evidências de validade e de construção de novos instrumentos de personalidade, conforme indicado na literatura (Laros, 2012). As correlações bivariadas e intraclasse estiveram presentes na grande maioria dos estudos, uma vez que a avaliação do modelo fatorial de personalidade, na interlocução com outras variáveis, constituiu o cerne de muitos estudos.

Os estudos que adotam estratégias mais inferenciais na análise de dados realizaram a interlocução entre os fatores de personalidade e as mais diversas variáveis, tais como 
diferenças de idade (Donnellan \& Lucas, 2008) e transição para aposentadoria (Lockenhoff, Terraciano \& Costa Jr., 2009).

O último tópico abordado refere-se à distribuição dos artigos pelas grandes áreas, de modo a compreender a aplicabilidade do modelo. Como demonstrado na Figura 1, apesar do equilíbrio existente entre as categorias, há uma prevalência dos artigos referentes aos eventos de vida $(21,2 \%)$ e à esfera social $(20,5 \%)$. É importante destacar ainda a avaliação psicológica, pois, apesar de ter aparecido apenas com 18\%, configurase como uma área transversal aos estudos que se dedicam ao entendimento do modelo fatorial de personalidade.

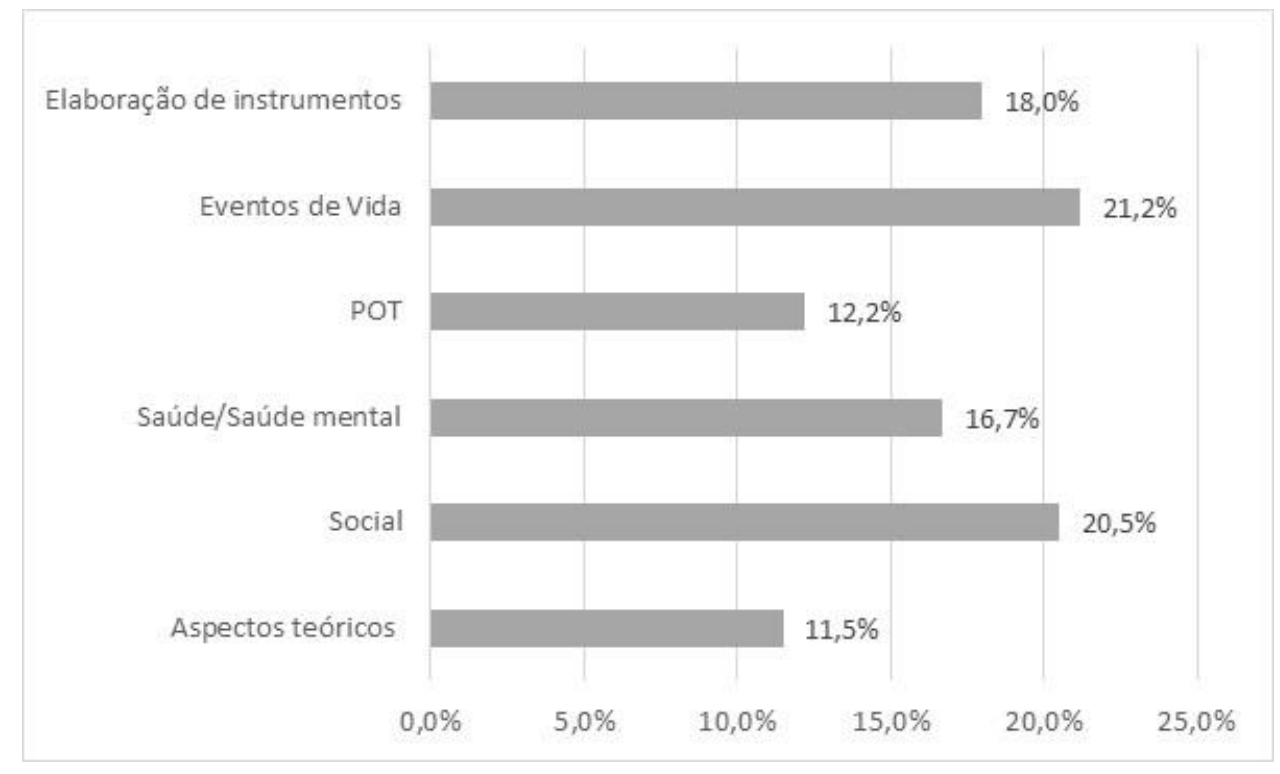

Figura 1. Distribuição dos artigos pelas grandes áreas - revisão internacional

Já a Figura 2 apresenta o mapeamento dos dados gerais encontrados no conjunto de artigos analisados. O que há de predominante entre os artigos é o fomento ao debate sobre os instrumentos. Nesse sentido, a característica geral das pesquisas é dedicar-se a objetos de estudo que abordem, de modo direto ou indireto, a utilização de instrumentos. $\mathrm{O}$ foco foi na realização de pesquisas de validade convergente, divergente e fatorial, na padronização, na verificação das propriedades psicométricas dos instrumentos e na 
realização de comparações entre instrumentos, sejam eles de personalidade ou que mensuram outros construtos.

Ainda sobre os aspectos gerais referentes à aplicabilidade do modelo, foram encontrados estudos que se dedicam à verificação da sua qualidade, com foco na avaliação da dimensionalidade, na estrutura fatorial, na replicação e nos indícios de sua universalidade. Em menor intensidade, foram identificados artigos que falam dos aspectos léxicos da avaliação de personalidade, com base no modelo dos CGF.

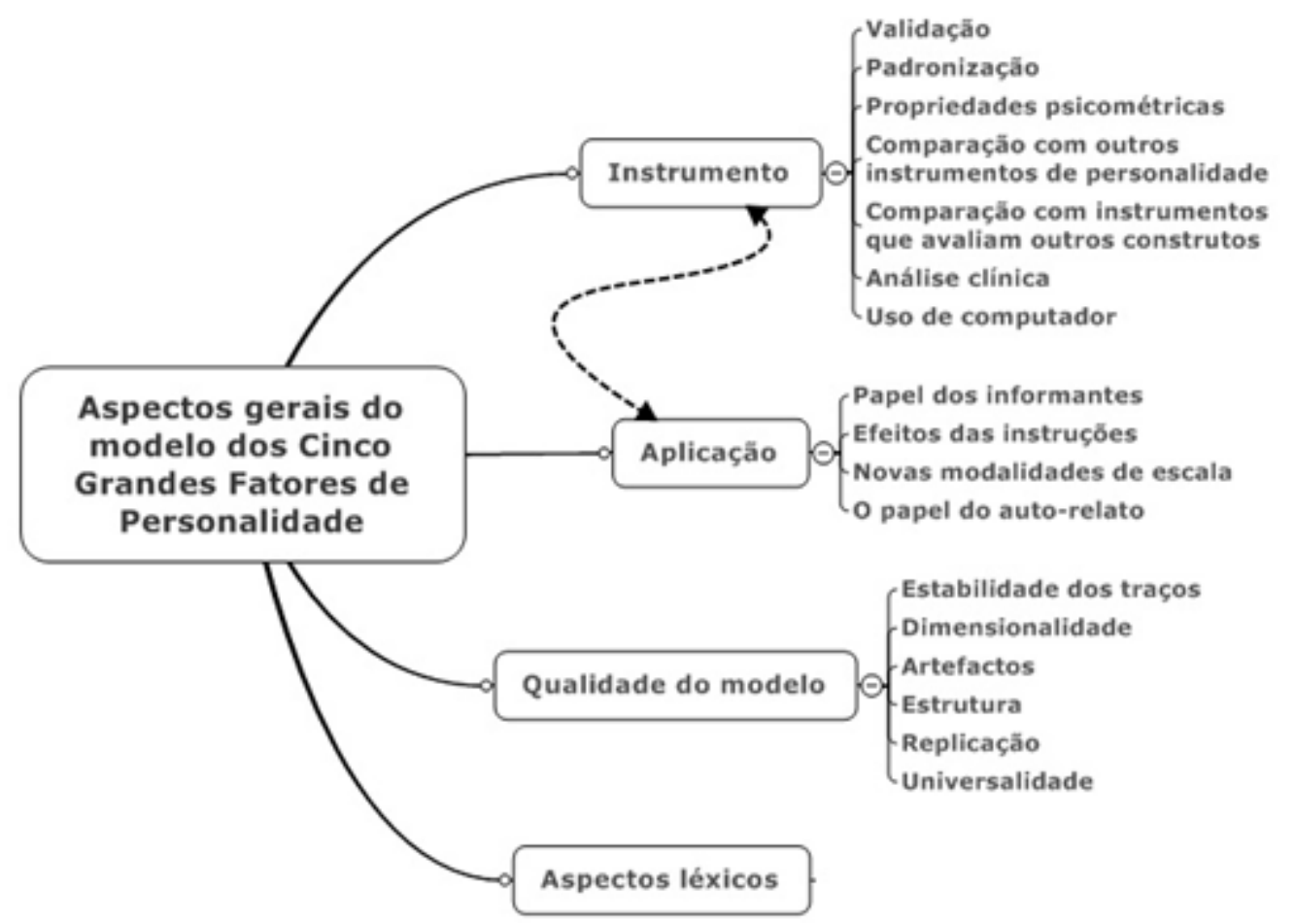

Figura 2. Aspectos gerais da aplicabilidade do modelo dos CGF.

No plano específico, conforme as categorias de análise, os estudos que se dedicam a aprofundar as contribuições para a avaliação psicológica são os mais frequentes, corroborando com o que é demonstrado na Figura 2. No escopo de estudos sobre a avaliação psicológica, merecem destaque os que se dedicam à elaboração de instrumentos para adultos e crianças, estudos transculturais e de comparação de instrumentos de medida para aferição da sua qualidade. O fortalecimento do modelo dos CGF também foi 
evidenciado por meio de pesquisas sobre a verificação da estrutura fatorial do modelo dos CGF, sobre a predição de comportamentos, os estilos de pensamento e os aspectos hereditários.

Um aspecto que também merece ser observado é o do desenvolvimento progressivo de pesquisas ao longo das últimas décadas, mesmo considerando o período de cinco anos. A consequência dos estudos, para o modelo dos CGF, constitui sua sofisticação. Isto pode ser observado de forma mais evidente por meio da reavaliação de testes junto a outras amostras, de países diferentes, a fim de garantir a sua qualidade psicométrica e, nos estudos que se dedicam a realizar, a interlocução da personalidade com as questões contemporâneas, como o fenômeno do Facebook (Jenkins-Guarnieri, Wright, \& Johnson, 2013). Tais correlações evidenciam o reconhecimento da difusão do modelo e sua aplicabilidade na análise de questões sociais e de saúde.

\section{A revisão nacional}

$\mathrm{Na}$ revisão nacional, foram encontrados 27 artigos, conforme apresentados na Tabela 2. Observa-se que o ano com maior número de publicações foi 2012 e que os periódicos com o maior número de artigos publicados sobre o modelo dos CGF foram Avaliação Psicológica, seguido de Psico-USF e Psicologia: Reflexão e Crítica, que são oriundos dos maiores programas que se dedicam às pesquisas sobre avaliação psicológica. 
Tabela 2. Distribuição dos artigos por ano de publicação e por jornal.

\begin{tabular}{lll}
\hline Categorias & $\mathrm{n}$ & $\%$ \\
\hline Ano de publicação & 5 & $18,5 \%$ \\
\hline 2008 & 5 & $18,5 \%$ \\
2009 & 3 & $11,1 \%$ \\
2010 & 2 & $7,4 \%$ \\
2011 & 9 & $33,4 \%$ \\
2012 & 3 & $11,1 \%$ \\
2013 & 27 & $100 \%$ \\
\hline Total & & \\
\hline Jornal & 5 & $18,5 \%$ \\
\hline Avaliação Psicológica & 4 & $14,8 \%$ \\
Psico-USF & 4 & $14,8 \%$ \\
Psicologia: Reflexão e Crítica & 2 & $7,4 \%$ \\
Estudos de Psicologia: Campinas & 2 & $7,4 \%$ \\
Psicologia: Teoria e Pesquisa & 27 & $100,0 \%$ \\
Outros (10 publicações) & 10 & $37,1 \%$ \\
\hline Total & $27 .-1$ \\
\hline
\end{tabular}

Ao avaliar as amostras dos estudos, a média de participantes é de 355,6 e, em sua maioria $(55,6 \%)$, foram compostas por estudantes de ensino médio e universitários. Todos os estudos encontrados foram de corte transversal. Apenas um estudo foi de caráter qualitativo e utilizou entrevista na coleta de dados (Nunes, Nunes, Cunha \& Hutz, 2009). Dentre os instrumentos adotados para coleta de dados sobre o modelo dos CGF, o que mais se destaca é a Bateria Fatorial de Personalidade, que foi adotada em oito estudos. Merece destaque também a utilização da escala de adjetivos, desenvolvida por Hutz et al (1998) e Hauck Filho et al (2008), que se configura como uma alternativa às escalas formadas por itens e que também vem apresentando boa qualidade psicométrica. No que se refere à análise de dados, $26 \%$ dos estudos adotaram a análise fatorial e $41 \%$ utilizaram procedimentos de análise de variância. 
Com relação às áreas dos artigos, a que prevaleceu foi a avaliação psicológica, representando $33,3 \%$ deles. Os artigos encontrados versaram sobre a construção de instrumentos para mensurar cada um dos fatores de modo mais pontual (Vasconcellos \& Hutz, 2008) e sobre a elaboração de instrumentos reduzidos (Carvalho, Nunes, Primi \& Nunes, 2012; Hauck Filho, Machado, Teixeira e Bandeira, 2012; Hauck Filho, Teixeira, Machado \& Bandeira, 2012). Uma outra área que merece atenção é a POT, que abarcou artigos sobre qualidade de vida no trabalho (D’Amico \& Monteiro, 2012), bem-estar nas organizações (Dessen \& Paz, 2010), interesses profissionais e talentos (Ambiel, Noronha \& Nunes, 2012).

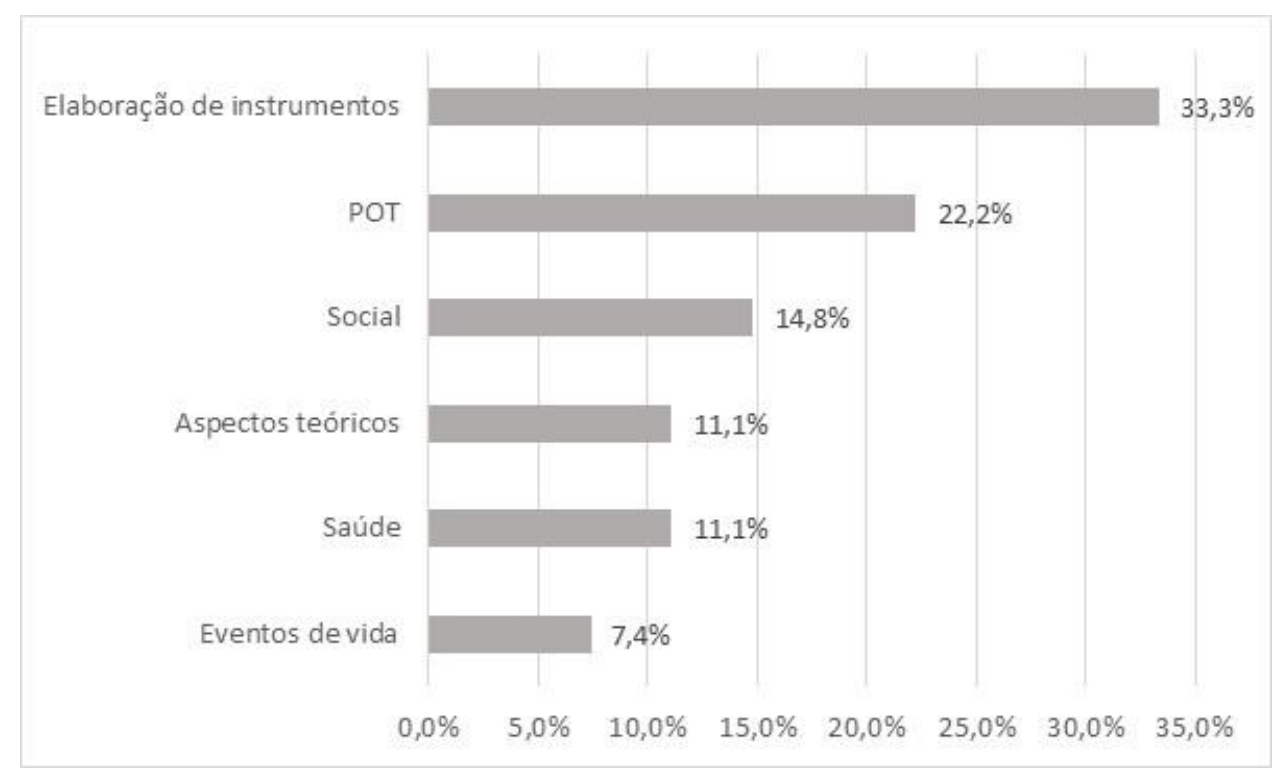

Figura 3. Distribuição dos artigos pelas grandes áreas - revisão nacional

Um outro dado importante refere-se à distribuição dos artigos pelos grupos de pesquisa presentes nas universidades brasileiras. Por meio das publicações, observa-se boa parte dos artigos são advindos das pesquisas realizadas pelos grupos localizados na Universidade Federal do Rio Grande do Sul $(22,2 \%)$ e Universidade São Francisco $(29,7 \%)$ 
Adicionalmente, buscou-se, nos artigos nacionais, analisar, de forma mais sistemática, os resultados encontrados a fim de verificar se refutam ou corroboram os dados empíricos dos estudos anteriores. Assim, Rizatto e Moran (2013), ao realizar um estudo com estudantes universitários sobre empreendedorismo e personalidade, constataram que os empreendedores tendem a apresentar baixa pontuação em Neuroticismo e alta Conscienciosidade, denotando maior equilíbrio emocional, disponibilidade para esforçar-se para buscar realizar seus projetos. Já Oliveira, Natividade e Gomes (2013) ao desenvolver uma escala para mensurar talento, identificaram que profissionais com altos níveis de talento tendem a apresentar índices altos no fator Conscienciosidade. Já o Neuroticismo apresentou correlação negativa com o talento. No estudo sobre qualidade de vida dos gestores do Rio Grande do Sul, D'Amico e Monteiro (2012) identificaram correlação positiva entre Extroversão e Qualidade de Vida dos Gestores. Além disso, gestores com maior ajustamento social e que demonstram ter maior estabilidade emocional tendem a ser mais saudáveis.

Foram localizados três estudos que discutiam a relação entre interesses profissionais e personalidade. Os achados indicam que existem correlações positivas entre o tipo profissional artístico e o fator Abertura e o tipo profissional empreendedor e o fator Conscienciosidade (Noronha, Mansão \& Nunes, 2012). O fator Abertura para experiências apresentou correlações positivas com as áreas de artes e comunicação e ciências humanas e sociais (Ambiel, Noronha \& Nunes, 2012). Amabilidade, Extroversão e Abertura interferem na demonstração de interesses por determinadas profissões. Realização está atrelada ao fazer esforços para conseguir cumprir objetivos. E altos índices de Neuroticismo denotam dificuldades para tomar decisões (Nunes \& Noronha, 2009). Como pode ser observado nesses estudos, o fator Abertura tende a se configurar 
como um elemento norteador das escolhas das profissões relacionadas às artes e comunicação.

Outra categoria analisada em correlação com os cinco grandes fatores foi o bemestar. Dessen e Paz (2010), ao pesquisar sobre bem-estar nas organizações, identificaram que trabalhadores com alto grau de Conscienciosidade, mais organizados, persistentes, decididos e ambiciosos demonstram maior bem-estar no trabalho. Já Nunes, Hutz e Giacomi (2009), ao associar bem-estar subjetivo com o modelo dos CGF, encontraram que pessoas com altos níveis de depressão tendem a apresentar uma avaliação negativa sobre si mesmos e a ter mais dificuldades para lidar com aspectos negativos que ocorrem em sua vida.

Natividade, Aguirre, Bizarro e Hutz (2012), em estudo realizado com estudantes universitários sobre a relação entre traços de personalidade e consumo de álcool identificaram que os que consomem álcool com mais frequência tendem a apresentar maiores índices no fator Extroversão. As menores médias foram apresentadas para os fatores Amabilidade e Conscienciosidade. Em um estudo com estudantes do ensino médio universitário, Vasconcelos, Gouveia, Pimentel e Pessoa (2008) buscaram avaliar os aspectos que predizem as condutas antissociais. Os resultados encontrados indicaram que o Neuroticismo explica tais condutas. Pimentel e Donnelly (2008), ao avaliarem a relação entre preferência musical e o modelo dos CGF, identificaram que "a música de massa se relacionou positivamente com Extroversão e negativamente com Abertura à Experiência; Música Refinada se relacionou negativamente com Neuroticismo e positivamente com Abertura à Experiência; Música Alternativa se relacionou negativamente com Neuroticismo (p.706)".

Ainda sobre as correlações entre personalidade e outras variáveis, foram encontrados estudos sobre coping em adolescentes (Diniz \& Zanini, 2010), em que foi 
constatado que adolescentes mais jovens tendem a apresentar maiores índices nos fatores Socialização e Abertura. Os autores, ao realizarem a correlação com a variável sexo, identificaram que meninos apresentaram maiores índices no fator Neuroticismo. Já as meninas tendem a usar mais as estratégias de coping, do tipo análise lógica, que os meninos.

No que se refere à construção de escalas, pode-se citar como exemplo o estudo realizado por Nunes, Muniz, Nunes, Primi e Miguel (2010), que elaboraram a versão reduzida da Escala Fatorial de Socialização, e Vasconcellos e Hutz (2008), que apresentaram dados sobre a construção de escala para avaliação da Abertura para Experiência. No primeiro estudo, de acordo com os autores, foi possível preservar as propriedades psicométricas da escala, tendo apenas ocorrido uma pequena perda na precisão da escala. Já no segundo estudo, os autores afirmaram que as dimensões encontradas na Escala de Abertura para Experiência estão em consonância com as já existentes e que utilizam como referencial a mesma abordagem teórica.

Outras escalas tiveram suas evidências de validade avaliadas. Este aspecto se reflete nos estudos realizados por Carvalho, Nunes, Primi e Nunes (2012), que identificaram que escalas com dez itens não sustentam o modelo dos CGF. Numa direção mais favorável, Hauck Filho, Machado, Teixeira e Bandeira (2012) constataram, ao estudarem as evidências de validade dos marcadores reduzidos para personalidade, que a consistência interna foi favorável e comparável às apresentadas pelos instrumentos reduzidos.

Gomes (2012) apresentou a estrutura fatorial do Inventário de Características de Personalidade - ICP, composto por 50 adjetivos. As análises foram feitas por meio de estudo com estudantes do ensino fundamental. O autor considerou o ICP como um instrumento promissor, mas que ainda merece ser aprimorado antes de ser adotado em processos de avaliação. 
Outro estudo foi o realizado por Carvalho, Gurgel e Primi (2011), que buscou verificar as evidências de validade do Inventário Dimensional dos Transtornos de Personalidade - IDTP, elaborado com base na Teoria de Theodore Millon. Para tanto, os autores utilizaram a Ten Item Personality Inventory. Os resultados indicaram que a escala avaliada apresenta boa qualidade psicométrica e que os dois modelos de personalidade apresentam aspectos convergentes.

Trentini et al (2009), em um estudo com 72 adultos, identificaram correlações positivas existentes entre a Escala Fatorial de Neuroticismo, construída com base no modelo dos CGF e o Inventário Fatorial de Personalidade - IFP, elaborado a partir do modelo das necessidades de Murray.

Mônego e Teodoro (2011) estudaram a Teoria Triangular do Amor de Stenberg e sua correlação com o Modelo dos CGF. Os autores identificaram correlações entre Amabilidade e os aspectos românticos. As pessoas casadas ou que estão namorando ou noivas e apresentam médias mais altas para Amabilidade tendem a perceber suas relações de modo mais positivo. Carvalho, Bueno e Kebleris (2008) realizaram estudo com estudantes universitários para avaliar a qualidade psicométrica do Inventário de Ciúme Romântico - ICR. Apesar de identificarem correlação positiva entre Neuroticismo e ocorrência de ciúme, afirmaram que a escala apresentou propriedades psicométricas que ainda precisam ser aprimoradas.

Na direção de avaliação do modelo de personalidade, Gomes e Golino (2012) se dedicaram a desenvolver um modelo teórico para compreensão do modelo dos CGF, por meio de estudos com alunos do ensino fundamental. Os autores identificaram "evidências favoráveis de um novo modelo teórico no qual os traços amplos do Big Five apresentam uma estrutura hierárquica de quatro níveis, contendo as polaridades Extroversão, 
Introversão, Estabilidade, Mutabilidade, Foco no Objeto, Foco no Objetivo, Foco nas Relações Humanas e Abertura a Novas Experiências (p.454)”.

Por fim, dois dos vinte e sete estudos se dedicaram a estudar os traços de personalidade e fizeram análise do grupo de estudantes universitários (Bartolomeu, Nunes e Machado, 2008; Figueiró, Souza, Martins, Leite, Ziliotto e Bacha, 2010). Os estudos indicam que as mulheres que evidenciaram altos índices para o fator Amabilidade tendem a expressar com mais facilidade os sentimentos positivos. Revelaram cuidado com as pessoas, bondade, altruísmo, empatia, responsividade e confiança nos indivíduos. Os homens expressaram resultados mais elevados no fator autocontrole da agressividade. Além disso, estão mais abertos a viverem novas situações. Os casados e os que trabalham tendem a possuir características de competência, ordem, responsabilidade, motivação de desempenho, ou autodisciplina, porém apresentam-se mais ansiosos, preocupados, com tendência a apresentar depressão, desencorajamento, ou impulsividade.

A partir dos achados, ao comparar as duas bases de dados, nacional e internacional, observa-se que, apesar do número de estudos realizados na realidade brasileira ser menor, há uma consonância entre os tipos de estudo e métodos adotados. No entanto, ainda observa-se a necessidade, no contexto brasileiro, de expansão de estudos de caráter longitudinal e pesquisas com mais de um estudo.

\section{Discussão}

O presente estudo teve como objetivo realizar revisão de literatura sobre os Cinco Grandes Fatores de Personalidade, considerando as bases nacionais e internacionais. Na revisão da literatura internacional, os dados indicam que, mesmo com as tentativas de realização de pesquisas com métodos diferenciados, o survey ainda se configura como a representação da tradição de pesquisa na área. Porém, os estudos multimétodos também se fizeram presentes na literatura internacional e viabilizaram a utilização de estratégias 
de coletas de dados diferenciadas e a comparação entre os resultados obtidos pelos diversos métodos. Já na literatura nacional, os artigos foram elaborados a partir de um estudo e basearam-se na aplicação de escalas. Além disso, não foram encontrados estudos longitudinais.

A análise dos artigos referentes ao modelo dos CGF contribuiu em duas direções: teórica e prática. No que se refere à primeira esfera, observa-se, por meio dos estudos transculturais, que os cinco fatores foram corroborados em diversos contextos sociais e culturais. Nesse sentido, há o reconhecimento de que o modelo dos CGF é consistente e seus fatores apresentam dados de confiabilidade, contribuindo, assim, para a compreensão da personalidade (McCrae, 2009) e favorecendo o entendimento desse construto na interlocução com outros fenômenos psicológicos. Porém, tanto o número de fatores quanto a sua universalidade devem ser mais explorados nos diversos contextos socioculturais.

Na esfera prática, observou-se a versatilidade do modelo que, por meio da variedade de instrumentos construídos, facilitam a realização dos estudos que apresentam os fatores de personalidade como preditores de comportamentos. Isso revela que a sua flexibilidade pode viabilizar a construção de modelos de investigação mais complexos que ultrapassem a correlação apenas entre duas variáveis, possibilitando a sua utilização como base para a realização de procedimentos e de desenhos de intervenção. Este aspecto pode ser observado nos estudos que se dedicam a estudar fenômenos sociais atuais, como é o exemplo do Facebook (Jenkins-Guarnieri, Wright, \& Johnson, 2013).

Além disso, ao realizar comparação entre as duas bases, constatou-se que há uma consonância entre o que vem sendo estudado nas esferas nacional e internacional. No Brasil, no entanto, há ainda uma grande concentração de estudos na região Sul e Sudeste e um outro grupo de pesquisa localizado no Nordeste. Assim, verifica-se a importância 
do desenvolvimento de um maior número de estudos em outras regiões, a fim de verificar a abrangência nacional do modelo. Destaca-se ainda a necessidade de

Quanto às limitações do estudo, a primeira delas refere-se à restrição da fonte de dados, que não abrangeu a inserção de teses e dissertações, handbooks e de outras revistas de divulgação que apresentam apenas o abstract dos seus estudos. A segunda limitação refere-se ao fato de ser um estudo descritivo. Mesmo reconhecendo a sua importância para a obtenção de um conhecimento mais abrangente sobre uma determinada variável, no caso em questão, o modelo dos CGF, tal estudo restringiu a possibilidade de uma análise mais aprofundada dos resultados.

Como agenda de pesquisa, sugere-se, no escopo da revisão de literatura, a realização de subdivisão para análise mais específica da contribuição do modelo para cada área de investigação. Uma outra proposta é realizar recortes, dentro dessa amostra de artigos, para a realização de estudos de meta-análise, que visem à aferição, por exemplo, de quão robustos são os instrumentos de avaliação de personalidade que apresentam um menor número de itens. Sugere-se, ainda, o desenvolvimento de pesquisas que incorporem um ou mais fatores do modelo como moderadores ou mediadores, a fim de viabilizar a expansão dos estudos inferenciais no campo da personalidade e a indicação de evidências sobre a funcionalidade do modelo dos CGF.

Conclui-se que o modelo dos CGF, mesmo com todos os questionamentos sobre a sua universalidade, se configura como um referencial consistente da personalidade, que permite a expansão da utilização desse construto para a análise dos diversos fenômenos sociais. Observa-se que os aspectos teóricos que embasam o modelo são fortalecidos por meio da qualidade dos ajustes dos modelos de investigação propostos pelos diversos estudos. 


\section{Referências}

Ambiel, R. A. M, Noronha, A. P. P, \& Nunes, F. O. (2012). Interesses profissionais e personalidade: um aporte para a Integração dos construtos. Avaliação Psicológica, 11(2), 191-201.

Andrade, J. M. (2008). Evidências de validade do inventário dos cinco grandes fatores de personalidade para o Brasil. Tese de Doutorado, Universidade de Brasília, Brasília.

Aumann, C., Lahl, O., \& Pietrowsky, R. (2012). Relationship between dream structure, boundary structure and the big five personality dimensions. Dreaming, 22(2), 124135.

Bartolomeu, D., Nunes, C. H. S. S., \& Machado, A. (2008). Traços de personalidade e habilidades sociais em universitários. Psico-USF, 13(1), 41-50.

Borges-Andrade, J., \& Pagotto, C. (2010). O estado da arte da pesquisa brasileira em Psicologia do Trabalho e Organizacional. Psicologia: Teoria e Pesquisa, 26, 37-50.

Carvalho, L. F., Bueno, M. H., \& Kebleris, F. (2008). Estudos psicométricos preliminares do Inventário de Ciúme Romântico. Avaliação Psicológica, 7(3), 335-346.

Carvalho, L. F., Gurgel, M. G. A., \& Primi, R. (2011). Evidências de validade do IDTP por meio da versão brasileira do TIPI. Psicologia Hospitalar, 9(1), 2- 23.

Carvalho L. F., Nunes M. F. O., Primi R., \& Nunes, C. H. S. S., (2012). Evidências desfavoráveis para avaliação da personalidade com um instrumento de 10 itens. Paidéia, 22(51), 63-71.

Chamorro-Premuzic, T., Burke, C., Hsu, A., \& Swami, V. (2010). Personality predictors of artistic preferences as a function of emotional valence and perceived complexity of paints. Psychology of Aesthetics, Creativity and the Arts, 4, 196-204.

Chamorro-Premuzic, T., Fagan, P., \& Furnham, A. (2010). Personality and uses of music as predictors of preference for music consensually classified as happy, sad, complex and social. Psychology of Aesthetics, Creativity and the Arts, 4, 205-213.

Chamorro-Premuzic, T., Goma-i-Freixanet, M., Furnham, A., \& Muro, A. (2009). Personality, self-estimated intelligence and uses of music: A Spanish replication and 
extension using structural equation modeling. Psychology of Aesthetics, Creativity and the Arts, 3, 149-155.

D’Amico, M., \& Monteiro, J. K. (2012). Características de personalidade e qualidade de vida de gestores no Rio Grande do Sul. Revista de Administração Contemporânea. 16(3), 381-396.

De Raad, B. (2009). Structural models of personality. In P. Corr \& G. Matthews (Eds.), The Cambridge handbook of personality psychology (pp. 127-147). New York: Cambridge University Press.

De Raad, B., \& Perugini, M. (2002). Big five assessment: Introduction. In B. De Raad \& M. Perugini (Eds.), Big five assessment (pp.1-26). Germany: Hogrefe \& Huber Publishers.

De Raad, B., \& Peabody, D. (2005). Cross-culturally recurrent personality factors: Analyses of three factors. European Journal of Psychology, 19, 451-474.

Dessen, M. C., \& Paz, M. G. T. (2010). Bem-estar pessoal nas organizações: o impacto de configurações de poder e características de personalidade. Psicologia: Teoria e Pesquisa. 26(3), 549-556.

Diniz, S. S, \& Zanini, D. S (2010). Relação entre fatores de personalidade e estratégias de coping em adolescentes. Psico-USF, 15(1), $71-80$.

Djikic, M. (2011). The effect of music and lyrics on personality. Psychology of Aesthetics, Creativity, and the Arts, 5, 237-240.

Donnellan, M. B., \& Lucas, R. (2008). Age differences in the big five across life span: Evidence from two national samples. Psychology and Aging, 23, 558-566.

Figueiró, M. T., Souza J. C., Martins, L. N. T., Leite, L. R. C., Ziliotto, J. M. B., \& Bacha, M. (2010). Traços de personalidade de estudantes de Psicologia. Psicólogo inFormação, 14(14), 13-28.

Fisher, T., \& McNulty, J. (2008). Neuroticism and marital satisfaction: The mediating role played by the sexual relationship. Journal of Family Psychology, 22, 112-122.

Graziano, W., \& Tobin, R. (2009). Agreeableness. In M. Leary \& R. Hoyle (Eds.), Handbook of individual differences in social behavior (pp. 46-61). New York: The Guilford Press. 
Gomes, C. M. A. (2012). A estrutura fatorial do inventário de características da personalidade. Estudos de Psicologia (Campinas), 29(2), 209-220.

Gomes, C., Gouveia, V., Silva Junior, N. A., Coutinho, M. \& Santos, L. C. (2013). Escolha do(a) parceiro(a) ideal por heterossexuais: são seus valores e traços de personalidade uma explicação? Psicologia: Reflexão e Crítica, 26(1), 29-37.

Gomes, C. M. A., \& Golino, H. F., (2012). Relações hierárquicas entre os traços amplos do Big Five. Psicologia: Reflexão e Crítica, 25(3), 445-456.

Hauck Filho, N., Machado, W. L., Teixeira, M. A. P., \& Bandeira, D. R. (2012). Evidências de validade de marcadores reduzidos para a avaliação da personalidade no modelo dos cinco grandes fatores. Psicologia: Teoria e Pesquisa, 28(4), 417-423.

Hauck Filho, N., Teixeira, M. A. P., Machado, W. L., \& Bandeira, D. R. (2012). Marcadores reduzidos para a avaliação da personalidade em adolescentes. PsicoUSF, 17(2), 253-260.

Hutz, C.S., Nunes, C., Silveira, A. D., Serra, J., Anton, M., \& Wieczorek, L. (1998). O desenvolvimento de marcadores para a avaliação da personalidade no modelo dos cinco grandes fatores. Psicologia: Reflexão e Crítica, 11, 395-411.

Hutz, C., Nunes, C. H., \& Nunes, M. (2010). Manual da Bateria Fatorial de Personalidade. São Paulo: Casa do Psicólogo.

Jenkins-Guarnieri, M. Wright, S. \& Johnson, B. (2013). The interrelationships among attachment style, personality traits, interpersonal competency, and facebook use. Psychology of Popular Media Culture, 2, 117-131.

John, O. P., Naumann, L. P., \& Soto, C. J. (2008). Paradigm shift to the integrative big five trait taxonomy: History, measurement, and conceptual issues. In O. P. John, R. W. Robins \& L. A. Pervin (Eds.), Handbook of personality: Theory and research (pp. 114-158). New York: The Guilford Press.

Laros, J. A. (2012). O uso da análise fatorial: algumas diretrizes para pesquisadores. In L. Pasquali (Ed.), Análise fatorial para pesquisadores (pp. 141-160). Brasília: LabPAM Saber e Tecnologia.

Lee, K., \& Ashton, M. (2007). Factor analysis in personality research. In R.W. Robins, R.C. Fraley \& R.F. Kruger (Eds.), Handbook of research methods in personality psychology (pp. 429-443). New York: Guilford Press. 
Lockenhoff, C., Terraciano, A., \& Costa Jr., P. (2009). Five-factor model personality traits and the retirement transition: Longitudinal and cross-sectional associations. Psychology and Aging, 24, 722-728.

McCrae, R. (2009). The five-factor model of personality traits: Consensus and controversy. In P. Corr \& G. Matthews (Eds.), The Cambridge handbook of personality psychology (pp. 148-161). Cambridge: University Press.

McCrae, R., \& Costa, P. (1997). Personality trait structure as a human universal. American Psychologist, 52(5), 509-516.

McCrae, R., \& Sutin, A. (2009). Openness to experience. In M. Leary \& R. Hoyle (Eds.), Handbook of individual differences in social behavior (pp. 257-273). New York: The Guilford Press.

McCrae, R., Yamagata, S., Jang, K., Riemann, R., Ando, J., Ono, Y., Angleitner, A., \& Spinath, F. (2008). Substance and artifact in the higher-order factors of the big five. Journal of Personality and Social Psychology, 95, 442-455.

Monego, B. G., \& Teodoro, M. L. M. (2011). A teoria triangular do amor de Sternberg e o modelo dos cinco grandes fatores. Psico-USF, 16 (1), 97 -105.

Natividade, J. C., Aguirre, A. R, Bizarro, L., \& Hutz, C. S. (2012). Fatores de personalidade como preditores do consumo de álcool por estudantes universitários. Cadernos de Saúde Pública, 28(6), 1091-1100.

Noronha, A. P. P., Mansão, C. S. M., \& Nunes, M. F. O. (2012). Interesses profissionais e personalidade: análise correlacional a partir do ATPH e BFP. Actualidades en Psicologia. 26, 73-86.

Nunes, C. H. S., Hutz, C. S., \& Giacomi, C. H. (2009). Associação entre bem-estar subjetivo e personalidade no modelo dos CGF. Avaliação Psicológica, 8(1), 99-108.

Nunes, M. F. O., Muniz, M., Nunes, C. H. S. S. Primi, R., \& Miguel, F. K, (2010). Escala Fatorial de Socialização- Versão Reduzida: seleção de itens e propriedades psicométricas. 23(2), 345-353.

Nunes, M. F. O., \& Noronha, A. P. P (2009). Relações entre interesses, personalidade e habilidades cognitivas: um estudo com adolescentes. Psico-USF, 14(2), 131-141. 
Nunes, C. H. S. S., Nunes, M. F. O., Cunha, T. F. C., \& Hutz, C. S. (2009). Chemical dependence and personality. Revista Interamericana de Psicología. 43(1), 68-76.

Oh, I. S., \& Berry, C. (2009). The five-factor model of personality and managerial performance: Validity gains through the use of 360 degree performance ratings. Journal of Applied Psychology, 94(6), 1498-1513.

Oh, I. S., \& Wang, G., \& Mount, M. K. (2010). Validity of observer ratings of the fivefactor model of personality traits: A meta-analysis. Journal of Applied Psychology. Advance online publication. DOI: 10.1037/a0021832.

Oliveira, M. Z., Natividade, J. C., \& Gomes, W. B. (2013). A medida do talento: evidências de validade de uma escala para aferir talento em organizações. Temas em Psicologia, 21(2), 419-437.

Perugini, M., Galluci, M., \& Livi, S. (2000). Looking for a simple big five factorial structure in the domain of adjectives. European Journal of Psychological Assessment, 16, 87-97.

Pimentel, C. E., \& Donnely, E. D. O. P (2008). A relação da preferência musical com os cinco grandes fatores da personalidade. Psicologia: Ciência e Profissão. 28 (4), 696713.

Rizzatto, S. C. C., \& Moran, M. C. (2013). Empreendedorismo e personalidade: o perfil em estudantes brasileiros. Psicologia: Organizações e Trabalho, 13(3), 279-292.

Roberts, B., Jackson, J., Fayard, J., Edmonds, G., \& Meints, J. (2009). Conscientiousness. In M. Leary \& R. Hoyle (Eds.), Handbook of individual differences in social behavior (pp. 369-381). New York: The Guilford Press.

Soto, C., John, O., Gosling, S., \& Potter, J. (2008). The developmental psychometrics of big five self-reports: Acquiescence, factor structure, coherence and differentiation from ages 10 to 20. Journal of Personality and Social Psychology, 94, 718-737.

Trentini, C., Hutz, C., Bandeira, D. R., Teixeira, M. A., Gonçalves, M. T., \& Tomazoni, A. R. (2009). Correlações entre a EFN e o IFP. Avaliação Psicológica. 8(2), 209217.

Vasconcellos, S. J. L., \& Hutz, C. S. (2008). Construção e validação de uma escala de abertura à experiência. Avaliação Psicológica, 7(2), 135-141. 
Vasconcelos, T., Gouveia, V., Pimentel, C., \& Pessoa, V. (2008). Condutas desviantes e traços de personalidade: testagem de um modelo causal. Estudos de Psicologia: Campinas, 25(1), 55-65.

Widiger, T. (2009). Neuroticism. In M. Leary \& R. Hoyle (Eds.), Handbook of individual differences in social behavior (pp. 129-148). New York: The Guilford Press.

Wilt, J., \& Revelle, W. (2009). Extraversion. In M. Leary \& R. Hoyle (Eds.), Handbook of individual differences in social behavior (pp. 27-45). New York: The Guilford Press.

Yu, C. K. (2012a). Testing the factorial structure of the dream intensity scale. Dreaming, 22, 284-309.

Yu, C. K. (2012b). The effect of sleep position on dream experiences. Dreaming, 22, 212221.

Yu, C. K. (2013). The structural relations between the superego, instinctual affect, and dreams. Dreaming, 23, 145-155. 


\title{
Manuscrito 2
}

\section{Etapas de elaboração de uma escala de diferencial semântico}

\author{
para avaliação de personalidade
}

\begin{abstract}
Resumo
A elaboração de escalas para avaliação de personalidade demanda o cumprimento de etapas e de estabelecimento de critérios para escolha de técnicas e construção dos itens. Seguir os passos necessários pode garantir que a escala seja construída de modo consistente, de modo a apresentar evidências de validade e fidedignidade compatíveis com o que se espera de uma escala. O presente artigo teve como objetivo descrever as etapas de elaboração para construção de uma escala de avaliação de personalidade. Tal descrição baseou-se no processo de construção da Escala Reduzida de Diferencial Semântico para Avaliação de Personalidade. A técnica de diferencial semântico demonstrou ser simples, de fácil entendimento e passível de ser utilizada para avaliação de personalidade que utiliza como referencial teórico o modelo dos Cinco Grandes Fatores de Personalidade.
\end{abstract}

Palavras-chaves: construção de escala reduzida; cinco grandes fatores de personalidade; diferencial semântico. 


\begin{abstract}
The construction of a scale to assess personality traits demands the compliance of consecutive stages and the establishment of criteria for the formulation of the items. Following the necessary steps during the construction process of a scale will guarantee that the scale will be developed in a solid way, and will increase the chance that the scale will present evidence of score validity and score reliability compatible with the expectations for the scale. The purpose of the present article is to describe the elaboration stages during the construction process of a personality scale. The description is based on the construction of the Reduced Scale of the Big Five Personality Factors (ER5FP). The ER5FP was elaborated using the technique of a semantic differential. This technique showed to be simple, and adequate in the development of a personality scale that uses the Five-Factor Model as theoretical reference.
\end{abstract}

Keywords: scale construction; five-factor model; semantic differential 
Os instrumentos de mensuração psicológica são largamente utilizados para a avaliação de personalidade. A literatura (Günther, 2008; Hogan, 2006; Pasquali, 2010; Saucier \& Goldberg, 2002) sinaliza a necessidade de alguns cuidados na elaboração de instrumentos a serem utilizados em pesquisa, como o foco no que se propõe a mensurar, a escolha do referencial teórico, a clareza e a objetividade das perguntas e o tempo de resposta. Assim, uma escala psicométrica precisa representar o construto psicológico por meio de um conjunto de itens, que funciona como um estímulo para que o respondente atribua valor conforme as suas características (Pasquali, 2010).

Assim, a construção de uma escala demanda tomada de decisões, em função dos seus objetivos. Por exemplo, se serão elaborados itens ou se será constituída por pares de adjetivos, se será dicotômica ou se será do tipo Likert. Um outro aspecto a ser destacado no processo de construção de escala refere-se ao número de itens. Os instrumentos de avaliação de personalidade tendem a ser mais extensos, com mais de 100 itens, como é o caso da Escala de Personalidade de Comrey - CPS, que possui 155 itens e a Bateria Fatorial de Personalidade - BFP, com 126 itens. Tradicionalmente, a sua extensão se deve ao número de fatores que busca abarcar. No entanto, uma tendência entre os estudos tem sido a possibilidade de construção de escalas mais curtas (Hauck Filho, Machado, Teixeira \& Bandeira; Herzberg \& Brähler, 2006; Rammsted, 2007).

Na realidade brasileira, foram identificadas algumas tentativas de construção ou de tradução de escalas já existentes, como se observa nos estudos de Hauck Filho, Machado, Teixeira e Bandeira (2012) e Carvalho, Nunes, Primi e Nunes (2012). Os resultados da pesquisa realizada pelos primeiros autores, que construíram uma lista de marcadores reduzidos para avaliação de personalidade, reforçam a possibilidade de construção de instrumento reduzido. Já a segunda pesquisa, que se dedicou a avaliar a qualidade psicométrica de uma escala com 10 itens, identificou evidências desfavoráveis para 
avaliação de personalidade. Diante dos achados que ainda evidenciam resultados que precisam ser ainda mais investigados, busca-se, por meio da construção de uma escala de pares de adjetivos, verificar se a escala reduzida constitui um meio eficiente de avaliação de personalidade.

\section{O diferencial semântico}

O diferencial semântico configura-se como uma "técnica de mensuração altamente generalizável" (Osgood, Suci \& Tannenbaum, 1957, p. 76), que se propõe a avaliar percepção afetiva, por meio da atribuição de uma série de qualificações quantitativas a pares adjetivos bipolares e que estão correlacionados com um dado atributo do fenômeno a ser avaliado (Andrade, Cruz, Stephan, \& Bitencourt, 2009; Ignacio, 2009). Busca, ainda, explicar a natureza de um dado significado em meio a um contexto marcado por heterogeneidade e diversidade (Ignacio, 2009) e se estrutura a partir de características advindas dos métodos escalares e associacionistas, indicados por Osgood (1952) ${ }^{1}$.

A técnica de diferencial semântico foi pensada por Osgood, Suci e Tannenbaum na década de 50 e utilizou como base o sentido da linguagem. Foram pioneiros em estabelecer uma interlocução da concepção teórica da natureza do significado e suas técnicas de mensuração (Ignacio, 2009; Salor, 1979). Para Osgood (1952), o processo de comunicação pode ser visto como um nível de interação de dois sistemas paralelos de organização comportamental. O primeiro refere-se à sequência de eventos centrais ou ideias e o segundo constitui a sequência de habilidades instrumentais, sejam elas vocais, gestuais ou ortográficas. O autor afirma que o conteúdo da mensagem vai refletir os determinantes de um sistema semântico.

\footnotetext{
${ }^{1}$ Osgood (1952) descreve cinco métodos (fisiológicos, aprendizagem, percepção, associação e escalares) para compreender o significado e propõe um sexto, o de diferencial semântico.
} 
Para compreender o diferencial semântico, dois conceitos são considerados como referência. O primeiro é o de significado e o segundo é o de espaço semântico (Ignacio, 2009; Osgood, 1952; Osgood, Suci e Tannenbaum, 1957; Pasquali, 2010; Salor, 1979). Afirma-se que a unidade do diferencial semântico é a palavra. De modo geral, o significado de uma determinada palavra é visto a partir de um contexto em particular, que envolve uma pessoa e deve ser definido como um processo representacional que revela uma pequena parcela de todo o comportamento (Ignacio, 2009). O significado, no diferencial semântico, pode ser analisado de dois modos: o denotativo, que se refere ao que uma determinada palavra quer dizer no sentido strictu e vinculado à realidade; e o conotativo, que incorpora as reações emocionais e as interpretações que uma pessoa pode vir a fazer de uma dada palavra a partir das suas vivências.

De acordo com Ignacio (2009), o espaço semântico é de dimensionalidade desconhecida e de natureza matemática. O espaço semântico é o espaço do significado, de caráter multidimensional e que deve se situar a partir das três dimensões: avaliação, potência e atividade. (Andrade, 2007; Ignacio, 2009; Osgood, 1952; Osgood, Suci e Tannenbaum, 1957; Pasquali, 2010; Salor, 1979). O ponto no espaço que se configura como uma definição operacional, apresenta duas propriedades: direção (qualidade) e distância (intensidade). A direção de um ponto em um espaço semântico pode corresponder a reações que são eliciadas pelo sinal e a distância vai corresponder à intensidade de tais reações (Osgood, Suci \& Tannenbaum, 1957). Assim, o que constitui a técnica do diferencial semântico como um processo de mediação representacional que determina o significado são as operações de mensuração, como a análise fatorial.

O diferencial semântico baseia-se em modelos que formam uma tríade que o apóia do ponto de vista teórico: o condutista, o espacial e o métrico. O modelo condutista consiste na forma como é atribuído significado a um dado objeto, em função da 
representação interna que o indivíduo tem sobre o referido objeto. O modelo espacial indica como o objeto se insere em um dado espaço e se forma a partir de $n$ dimensões, que são a avaliação, a potência e a atividade. Já o modelo métrico refere-se ao aspecto operacional, uma vez que busca estimar e quantificar as dimensões do objeto (Andrade, 2007; Osgood, Suci e Tannenbaum, 1957).

Construir uma escala reduzida, com base no diferencial semântico se justifica por várias razões, que podem ser compreendidas em científicas, práticas e sociais. No campo científico, o diferencial semântico tem proporcionado melhor ajuste dos modelos, facilidade na utilização e interpretação dos escores, adequação para mensuração de construtos, reconhecimento de que se trata de uma técnica confiável, sensível e discriminativa. Bradley e Lang (1994) investigaram a eficácia de instrumentos para mensurar prazer, dominância e atração associados à reação afetiva que uma pessoa pode ter frente a um conjunto de estímulos. Compararam uma avaliação não verbal baseada em figuras com um instrumento de diferencial semântico com 18 pares de adjetivos e encontraram alta correlações entre esses instrumentos.

Um outro exemplo de comparação entre escalas foi descrito no estudo desenvolvido por Friborg, Martinussen e Rosenvinge (2006). Os autores, ao avaliarem o construto resiliência, compararam uma escala tipo Likert com um instrumento de diferencial semântico. Demonstraram preocupação com os erros sistemáticos que tendem a ocorrer com instrumentos de autorrelato e citaram como um dos principais exemplos a aquiescência, que consiste na possibilidade de emissão de respostas positivas independente do conteúdo apresentado pelos itens. Nesse estudo, com base na Modelagem por Equações Estruturais - MEE, o instrumento de diferencial semântico apresentou um modelo com um ajuste melhor. Adicionalmente, os autores afirmaram que os escores são mais fáceis de serem interpretados. 
A técnica do diferencial semântico foi utilizada ainda em estudos nas mais diversas áreas do conhecimento, cujo aspecto em comum constitui a mensuração de atitudes. Assim, foram identificados estudos sobre necessidades e aspirações de usuários sobre o design de máquinas (Mondragón, Company \& Vergara, 2005), significados afetivos atribuídos pelos moradores e visitantes à cidade de Brasília (Maniscalco, 1994), avaliação de fenômenos acústicos no interior de aeronaves (Andrade, Cruz, Stephan \& Bitencourt, 2009), percepção dos pacientes hospitalizados sobre o banho (Lopes, Nogueira-Martins, Andrade \& Barros, 2011), avaliação das atitudes frente ao envelhecimento (Mikusinski \& Urteaga, 1982; Posada, 1997), mensuração da qualidade dos relacionamentos românticos (Andrade \& Garcia, 2011), avaliação dos efeitos da psicoterapia (Escudero \& Zafra, 2012) e verificação da utilidade do diferencial semântico para avaliação de personalidade (Mikusinski, Urteaga, Quintana \& Andrade, 1980).

Na esfera prática, o estudo que aborda a questão da avaliação dos efeitos da psicoterapia (Escudero \& Zafra, 2012) indicou a contribuição da técnica no processo de reconhecimento, por parte do paciente, das principais mudanças que foram desencadeadas em função do espaço psicoterapêutico. Ao explorar o significado conotativo, o diferencial semântico estimula a reflexão sobre as reações das pessoas frente às diversas situações.

$\mathrm{Na}$ esfera social, trata-se de um instrumento que demonstra ser facilmente adaptado aos contextos culturais, podendo propiciar menor viés nos processos de tradução de escalas (Andrade \& Garcia, 2011). É considerado flexível e de fácil quantificação, e o valor afetivo mensurado por essa técnica tende a ser comum a um grupo de pessoas, considerando os aspectos culturais e regionais (Andrade, Cruz, Stephan \& Bitencourt, 2009). A contextualização cumpre o papel de reconhecer a multidimensionalidade do conceito, que deixa de ser considerado universal e passa a incorporar os aspectos que incrementam o significado. Permite ainda a ampliação de participantes que apresentam 
mais dificuldades para entendimento de sentenças mais longas, o que pode vir a proporcionar maior fidedignidade dos escores dos fatores analisados.

Tomando esses elementos como base, o presente estudo teve como objetivo descrever as principais etapas de elaboração para construção de uma escala reduzida de diferencial semântico, tomando como caso ilustrativo a construção de escala para avaliação de personalidade. Tal descrição foi estruturada com base nas estratégias adotadas pelos pesquisadores em estudos anteriores para este fim.

\section{Etapas de elaboração}

As etapas descritas para a construção da escala baseiam-se na problematização realizada por Osgood, Suci e Tannenbaum e nos estudos realizados por Andrade (2007), Mondragón, Company e Vergara (2005), Mikusinski, Urteaga, Quintana e Andrade (1980), Al-Hindawe (1996) e Lopes, Nogueira-Martins, Andrade e Barros (2011). Além dos teóricos que discutem essa técnica (Osgood, Suci \& Tannenbaum, 1957; Andrade, 2007; Mondragón, Company \& Vergara, 2005; Mikusinski, Urteaga, Quintana \& Andrade, 1980; Al-Hindawe, 1996; Lopes, Nogueira-Martins, Andrade \& Barros, 2011), tomou-se como referência os estudos realizados por Andrade, Cruz, Stephan, \& Bitencourt (2009), Babbie (2003), Pasquali (2010), Peres-dos-Santos \& Laros (2007), Lopes, Nogueira-Martins, Andrade, \& Barros (2011). A Figura 1 indica os passos a serem seguidos para elaboração do instrumento. 


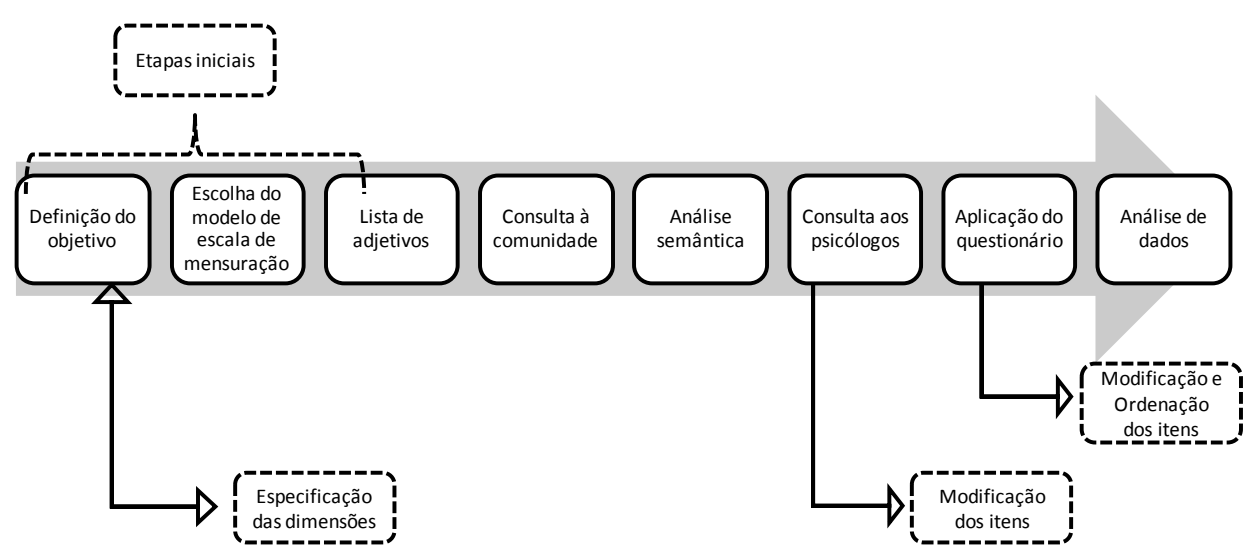

Figura 1. Modelo para elaboração do instrumento

a. Etapa exploratória sobre o construto a ser investigado

Essa etapa, de caráter exploratório, tem como objetivo obter uma avaliação geral sobre como as pessoas veem o determinado construto. Constitui-se de uma lista de adjetivos para verificar qual o grau de entendimento das pessoas sobre um determinado construto. Pode ser ainda uma lista de perguntas que conduzam o pesquisador a elaborar os pares de adjetivos opostos. Uma outra técnica utilizada nesta etapa é a solicitação de que os respondentes indiquem adjetivos para descrever um determinado construto.

b. Análise realizada pelo profissional de semântica.

O objetivo desta etapa é efetuar a análise detalhada dos conceitos, a fim de verificar a qualidade e grau de oposição dos pares. Nesse processo, também é importante comparar significados das palavras, a fim de localizar redundâncias e incoerências e aferir se os antônimos estavam coerentes, para prosseguir com as modificações necessárias no conjunto de pares.

c. Avaliação de juízes.

A avaliação de juízes costuma ser realizada por especialistas que apresentam domínio na área de investigação. Demonstram habilidades e competências para tecer considerações sobre a relação técnica entre o instrumento construído e o construto. Nesse 
momento, tende a ser atribuído sentido teórico à análise conceitual realizada pelo profissional de semântica.

d. Coleta de dados

Antes de realizar a coleta propriamente dita, são realizados os ajustes na escala. Consiste na revisão e na reestruturação de todos os pontos que foram considerados críticos pelos juízes. É uma etapa crucial para evitar possíveis erros e fazer com que a escala pudesse apresentar o maior grau de clareza para os participantes. Nesta etapa, é importante que haja também um estudo piloto, a fim verificar o grau de entendimento e a necessidade de realização de novos ajustes antes da aplicação em si.

Esta é uma etapa em que alguns cuidados precisam ser tomados, como populaçãoalvo, definição e representatividade da amostra. Além disso, ao longo da coleta de dados, é importante manter as condições adequadas para a participação do respondente, como também fornecer explicações com qualidade, a fim de diminuir viés no processo de resposta.

\section{Caso ilustrativo}

A proposta do referido estudo foi apresentar um caso, para ilustrar as etapas de elaboração de um instrumento de diferencial semântico para avaliação de personalidade. No caso em questão, foi definido que seria elaborada uma lista para consulta sobre as palavras que viriam a compor o instrumento de diferencial semântico para avaliação de personalidade. O modelo dos cinco grandes fatores de personalidade e os estudos anteriormente realizados na área foram utilizados como referência para elaboração da lista inicial, formada com 383 palavras. Também foi utilizada como ferramenta auxiliar dois dicionários de sinônimos e antônimos. Feita essa lista, foi realizada uma verificação do grau de popularidade das palavras. Para a realização de tal etapa, foi utilizada como ferramenta o Google AdWords, um aplicativo que apresenta a popularidade da palavra 
por meio de dados sobre acessos e número de páginas que contêm as referidas palavras. Apesar de não ser a ferramenta mais eficaz, funcionou como um ponto de partida necessário para o cumprimento das demais etapas de pesquisa.

Dessa lista, foram escolhidas 149 palavras em função do seu grau de popularidade, por ser esse um indicador de que o respondente poderia compreender de forma mais equivalente o significado dos adjetivos. Além disso, buscou-se realizar a distribuição dos pares da forma mais equitativa, em termos numéricos, entre os fatores. Os participantes foram convidados a responder, para cada um dos adjetivos, duas perguntas "Você sabe o que significa esta palavra?" e "Essa palavra define você?". Em função da amostra reduzida e do objetivo da etapa, não foi utilizada no presente estudo (Anexo 1). Participaram desta etapa 29 pessoas. A aplicação foi realizada em uma sala de aula de alunos já graduados que estavam se dedicando a estudar para concursos.

Após a aplicação, foram escolhidos os adjetivos que apresentaram maior facilidade para serem compreendidos pelos participantes. Em seguida, os adjetivos foram organizados, junto com os que poderiam ser considerados opostos, a fim de seguir para as demais avaliações: a do profissional de semântica e a de juízes.

A partir dos dados apresentados, foi elaborado um conjunto de pares de adjetivos supostamente opostos, com base no referencial teórico, no grau de compreensão do significado, identificado por meio da consulta a leigos, conforme descrito na etapa b e no grau de popularidade fornecido pela ferramenta Google Adwords. Para tanto, foram elaborados 51 pares de adjetivos opostos.

O processo de avaliação semântica foi realizado por um profissional especialista na área e consistiu na realização de análise detalhada dos conceitos, a fim de verificar a qualidade, grau de oposição dos pares e a relação com os fatores de personalidade. A análise foi iniciada por meio da consulta ao significado de cada um dos adjetivos. Em 
seguida, foi realizada a comparação dos significados dos adjetivos, a fim de indicar presença mais forte dos fatores de personalidade, buscando identificar redundâncias e incoerências. Por fim, foram sugeridas as modificações para garantir o melhor ajuste dos pares aos fatores de personalidade. A análise de pares feita pelo profissional de semântica baseou-se na análise de sinônimos, de antônimos, de homônimos e da polissemia (AlHindawe, 1994).

A análise foi realizada com base nos princípios da semântica, tomando o cuidado para identificar todos os elementos que tendem a dificultar quando se trata de conceitos. Foram retirados três pares (Determinado/Indeciso, Agitador/Pacificador e Cooperativo/ Competitivo). Ademais, foram feitas sete modificações, conforme Tabela 1.

Tabela 1. Modificações realizadas nos pares a partir da análise semântica

\begin{tabular}{lll}
\hline \multicolumn{1}{c}{ Fator correspondente } & Sugestão de par inicial & Sugestão de par final \\
\hline Neuroticismo & Triste / Feliz & Triste / Alegre \\
Neuroticismo & Vulnerável / Inatacável & Vulnerável / Resistente \\
Neuroticismo & Emotivo / Sereno & Emotivo / Racional \\
Amabilidade & Gentil / Indelicado & Gentil / Rude \\
Amabilidade & Negligente / Protetor & Negligente /Cuidadoso \\
Abertura & Autêntico / Forçado & Autêntico /Fingido \\
Abertura & Entusiasta / Desencantado & Entusiasta / Apático \\
\hline
\end{tabular}

O modelo final, que foi encaminhado para os juízes, constou de 48 pares de adjetivos opostos. Apesar de ter sido sinalizada a necessidade de retirada de pares em função da sua redundância, a decisão tomada para o cumprimento das próximas etapas foi deixar o maior número de pares possíveis para aferição da sua qualidade junto aos especialistas em psicologia e à comunidade, de modo geral, no momento da realização da realização do estudo sobre as evidências de validade da escala. 
Assim, após as modificações realizadas, em função das sugestões apresentadas pelo referido profissional, foi elaborado um questionário online, no site Survey Monkey, para que os psicólogos pudessem realizar a avaliação de cada par de adjetivos, assim como a sua relação com cada fator. Houve também, a partir da análise semântica, uma mudança na distribuição do número de pares por fator, sendo que o fator Amabilidade ficou com oito pares, Extroversão ficou com nove pares, os fatores Neuroticismo e Conscienciosidade ficaram com 10 pares e o fator Abertura para Experiências ficou com 11 pares.

O questionário foi enviado para 24 psicólogos e foi estruturado com uma parte inicial a fim de buscar dados sobre o tempo de formação de tais profissionais, se já haviam trabalhado com avaliação e, de modo mais específico, com testes de personalidade. Foram inseridas perguntas sobre a opinião dos psicólogos sobre os testes. A taxa de retorno dos respondentes foi de 58,3\%, totalizando 14 participantes. O tempo médio de formação dos profissionais foi de 11,5 anos. Dos profissionais que avaliaram o instrumento, nove responderam que já haviam trabalhado com testes de personalidade.

Os itens foram divididos pelos fatores, em consonância com o modelo dos CGF e com a avaliação prévia realizada pelo profissional de semântica. As perguntas feitas aos psicólogos foram: “Os adjetivos são realmente opostos?" e "O par de adjetivos representa o fator?”. A Tabela 2 apresenta o percentual de concordância entre os psicólogos sobre as duas perguntas.

No que se refere à oposição dos adjetivos, os dados indicaram que o maior grau de concordância ocorreu nos itens que compõem o fator Conscienciosidade. Nesse caso, em sete dos 10 itens, houve concordância de $100 \%$ entre os psicólogos. Já o fator Abertura para Experiências foi o que mais apresentou discordância entre os profissionais. 
Tabela 2. Percentual de concordância entre os psicólogos sobre a condição de oposição de adjetivos e de representação do fator

\begin{tabular}{|c|c|c|c|}
\hline \multirow{2}{*}{ Fatores } & \multirow{2}{*}{ Par original } & \multicolumn{2}{|c|}{$\begin{array}{l}\text { Percentual de concordância entre os } \\
\text { psicólogos }\end{array}$} \\
\hline & & $\begin{array}{c}\text { Oposição dos } \\
\text { adjetivos }\end{array}$ & Representação do fator \\
\hline \multirow{10}{*}{$\begin{array}{l}\text { Neuroticismo } \\
(\mathrm{n} \text { itens }=10)\end{array}$} & Vulnerável / Resistente & 83,3 & 91,7 \\
\hline & Nervoso / Calmo & 100 & 100 \\
\hline & Triste / Alegre & 100 & 91,7 \\
\hline & Impaciente / Paciente & 100 & 100 \\
\hline & Oscilante / Equilibrado & 83,3 & 91,7 \\
\hline & Emotivo / Racional & 100 & 83,3 \\
\hline & Temperamental / Controlado & 75 & 83,3 \\
\hline & Ansioso / Tranquilo & 91,7 & 100 \\
\hline & Instável / Estável & 100 & 100 \\
\hline & Depressivo / Animado & 58,3 & 83,3 \\
\hline \multirow{9}{*}{$\begin{array}{l}\text { Extroversão } \\
(\mathrm{n} \text { itens }=9)\end{array}$} & Sociável / Reservado & 100 & 100 \\
\hline & Expansivo / Contido & 100 & 100 \\
\hline & Extrovertido / Tímido & 100 & 100 \\
\hline & Receptivo / Intransigente & 50 & 33,3 \\
\hline & Comunicativo / Calado & 91,7 & 91,7 \\
\hline & Ativo / Passivo & 91,7 & 58,3 \\
\hline & Dinâmico / Acomodado & 66,7 & 66,7 \\
\hline & Otimista / Pessimista & 100 & 75 \\
\hline & Desinibido / Retraído & 91,7 & 91,7 \\
\hline \multirow{8}{*}{$\begin{array}{l}\text { Amabilidade } \\
(\mathrm{n} \text { itens }=8)\end{array}$} & Prudente / Impulsivo & 91,7 & 75 \\
\hline & Amigável / Hostil & 91,7 & 100 \\
\hline & Tolerante / Intolerante & 100 & 100 \\
\hline & Simpático / Antipático & 100 & 100 \\
\hline & Altruísta / Individualista & 83,3 & 91,7 \\
\hline & Cuidadoso / Negligente & 100 & 83,3 \\
\hline & Gentil / Rude & 100 & 100 \\
\hline & Amoroso / Indiferente & 58,3 & 83,3 \\
\hline \multirow{11}{*}{$\begin{array}{l}\text { Abertura para } \\
\text { Experiências } \\
(\mathrm{n} \text { itens }=11)\end{array}$} & Curioso / Desinteressado & 91,7 & 91,7 \\
\hline & Aberto / Inacessível & 75 & 91,7 \\
\hline & Aventureiro / Hesitante & 58,3 & 83,3 \\
\hline & Inquieto / Conformado & 50 & 75 \\
\hline & Questionador / Alienado & 91,7 & 91,7 \\
\hline & Ousado / Temeroso & 100 & 100 \\
\hline & Autêntico / Fingido & 75 & 66,7 \\
\hline & Entusiasta / Apático & 91,7 & 91,7 \\
\hline & Criativo / Prosaico & 75 & 72,7 \\
\hline & Inovador / Conservador & 100 & 100 \\
\hline & Flexível / Rígido & 100 & 100 \\
\hline \multirow{10}{*}{$\begin{array}{l}\text { Conscienciosidade } \\
\quad(\mathrm{n} \text { itens }=10)\end{array}$} & Organizado / Desorganizado & 100 & 91,7 \\
\hline & Persistente / Inconstante & 58,3 & 66,7 \\
\hline & Ambicioso / Modesto & 75 & 75 \\
\hline & Decidido / Indeciso & 100 & 100 \\
\hline & Responsável / Irresponsável & 100 & 100 \\
\hline & Construtivo / Destrutivo & 100 & 75 \\
\hline & Obstinado / Desistente & 83,3 & 91,7 \\
\hline & Motivado / Desmotivado & 100 & 91,7 \\
\hline & Eficiente / Ineficiente & 100 & 100 \\
\hline & Eficaz / Ineficaz & 100 & 100 \\
\hline
\end{tabular}


Com relação à segunda pergunta, a Tabela 2 indica que a Conscienciosidade foi novamente o fator que apresentou os maiores percentuais de concordância, que variaram entre $91,7 \%$ e $100 \%$ para sete dos 10 itens. Para a referida pergunta, os itens do fator Extroversão apresentaram os percentuais mais baixos de concordância entre os psicólogos (Receptivo/Intransigente, com 33,3\% e Ativo/Passivo, com 58,3\%).

Foi destinado aos juízes um espaço livre para comentários sobre cada um dos itens. Tais comentários foram utilizados na realização de ajustes na escala. A reestruturação dos itens se deu conforme disposto na Tabela 3. Os juízes apresentaram justificativas, a fim endossar as mudanças sugeridas.

Tabela 3. Modificações realizadas nos pares a partir da análise de juízes

\begin{tabular}{lll}
\hline Fator correspondente & \multicolumn{1}{c}{ Sugestão de par inicial } & Sugestão de par final \\
\hline Neuroticismo & Depressivo / Animado & Depressivo / Eufórico/Excitado \\
Amabilidade & Prudente / Impulsivo & Prudente / Inconsequente \\
Abertura & Aberto / Inaccessível & Aberto / Fechado \\
Abertura & Aventureiro / Hesitante & Aventureiro / Inativo \\
Abertura & Autêntico / Fingido & Autêntico / Simulado \\
Conscienciosidade & Persistente / Inconstante & Persistente / Desistente \\
Conscienciosidade & Obstinado / Desistente & Obstinado / Inconstante \\
\hline
\end{tabular}

O par de adjetivo Depressivo/Animado não foi considerado equilibrado. Assim, a indicação da palavra "Eufórico" foi acatada, porém foi assegurada a necessidade de avaliação do referido par sobre o nível de compreensão pelos participantes. Já a substituição de Inacessível por Fechado se deu uma vez que o primeiro adjetivo pode evidenciar maior consonância com o fator Socialização.

No que se refere ao número de pares de adjetivos, a proposta, tanto na avaliação do profissional de semântica como na avaliação de juízes, foi a de permanecer com o maior 
número de pares possíveis. Esta decisão foi tomada por considerar que, por meio da coleta de dados e da realização de análise fatorial, a tendência do número de pares seria diminuir. Assim, o único par de adjetivos retirado nesta etapa foi o Construtivo/Destrutivo, considerado pelos juízes como inadequado para avaliação de personalidade, dada a sua conotação pejorativa. No que se refere aos pares mantidos, ressalta-se o "Receptivo/Intransigente" e o "Amoroso/Indiferente", que permaneceram com o intuito de verificar se, de fato pertencem ao fator indicado ou se serão retirados, corroborando as impressões realizadas pelos psicólogos.

A escala final para aplicação foi composta de 47 pares de adjetivos opostos, separados por sete pontos. Os questionários foram aplicados em duas faculdades localizadas no Distrito Federal, em salas de aula e com alunos de diversos cursos de graduação (Direito, Administração e Sistemas de Informação). Participaram desta etapa 365 estudantes universitários com idade média de 29,1 anos ( $\mathrm{DP}=8,6)$, sendo 53,7 \% da amostra composta por mulheres.

Durante a aplicação, observou-se que os participantes apresentaram bom entendimento sobre o instrumento. O diferencial semântico também se configurou como uma estratégia de fácil compreensão, podendo abarcar participantes de vários níveis de escolaridade.

\section{Discussão}

O presente artigo buscou descrever as etapas de elaboração de instrumentos construídos com base na técnica de diferencial semântico, em pesquisas de avaliação de personalidade. Apesar de ser uma técnica aparentemente simples, para garantir a sua eficácia, a construção da escala precisa acontecer de forma criteriosa, considerando um conjunto de etapas. 
A aplicação do instrumento transcorreu sem dificuldades e os participantes apresentaram bom entendimento das instruções para responder aos itens da escala. Além disso, evidenciaram boa compreensão dos adjetivos apresentados. Demonstrou ser uma técnica de fácil aplicação, o que pode garantir melhor qualidade de resposta entre os que apresentam menor nível de escolaridade. Além disso, apresenta boa capacidade de discriminação dos itens e tende a apresentar menor viés do respondente.

Destaca-se, na construção da escala, a participação da comunidade, do profissional de semântica e dos juízes. Os atores envolvidos deram contribuições importantes para a formação dos pares de adjetivos opostos e na avaliação da consonância existente entre os pares e relação entre eles e os fatores. Os diversos olhares sob o mesmo objeto, no caso em questão, os pares de adjetivos, se complementaram, garantindo a construção de uma escala que tende a apresentar maior relação com o que se pretende mensurar, conforme sinalizado na literatura (Hogan, 2006; Pasquali, 2010; Saucier \& Goldberg, 2002).

Os pares, ao serem observados pelos psicólogos, foram modificados, a fim de viabilizar maior adequação com a perspectiva teórica de avaliação de personalidade. Enquanto o profissional de semântica se deteve a analisar a qualidade da oposição entre os pares, os juízes se dedicaram a aferir a capacidade apresentada pelo par de adjetivo para pertencer a um dado fator.

Outro ponto a ser salientado no presente relato refere-se à importância da análise fatorial e do cálculo de validade e de fidedignidade dos escores. As dúvidas sobre a permanência de determinados itens foram esclarecidas no momento em que as análises estatísticas foram realizadas. Pares de adjetivos que haviam sido mantidos, como foi o caso de "Receptivo/Intransigente", que apresentou um baixo grau de concordância entre os juízes, quanto ao seu pertencimento a um dado fator e que tal análise foi corroborada pela baixa carga fatorial demonstrada pelo referido par $(<0,40)$. Tais dados corroboram o 
modelo métrico que integra a tríade de sustentação do diferencial semântico (Andrade, 2007; Osgood, Succi \& Tannenbaum, 1957)

Algumas limitações foram identificadas na realização do estudo. Muitas vezes é difícil compor antônimos com precisão para adjetivos e frases, o que vai depender da habilidade do pesquisador e do cumprimento das etapas de construção da escala. Outra limitação refere-se à restrição no método para construção dos pares de adjetivos opostos. Apesar de Andrade e Garcia (2011) afirmarem que as escalas de diferencial semântico são mais facilmente adaptadas às diversas culturas, realizar entrevistas e grupos focais podem contribuir para a ampliação da investigação dos aspectos culturais sobre a popularidade e significado dos adjetivos.

Ainda ressalta-se como limitação a restrição do público participante. A coleta foi realizada por acessibilidade e o público foi de estudantes universitários, que tendem a apresentar maior grau de entendimento sobre os adjetivos. Ao considerar que a escala se caracteriza pela sua simplicidade e objetividade, faz-se necessário realizar estudos com outras faixas etárias, a fim de verificar níveis de aceitação e aplicabilidade a esse modelo de escala.

Sugere-se que outros estudos sejam realizados para aferir a aplicabilidade da escala nos diversos contextos e obter as evidências de validade e fidedignidade dos escores dos fatores. Ademais, é importante avançar em estudos que utilizem a covariável nível de escolaridade para verificar se há diferença no modo de compreensão, e em estudos de escalas que adotam diferencial semântico com outras que avaliem os níveis de desejabilidade social.

Conclui-se que, mesmo com as limitações indicadas, a escala de diferencial semântico demonstrou ser uma ferramenta eficaz para avaliação de personalidade. Apesar 
da necessidade de novos estudos, apresenta condições favoráveis para ser adotada em estudos que tenham como variável a personalidade. 


\section{Referências}

Al-Hindawe, J. (1996). Considerations when constructing a differential semantic scale. La Trobe Working Papers in Linguistics, 9, 1-9.

Andrade, A. L. (2007). A técnica do diferencial semântico para avaliação de fenômenos acústicos no interior de aeronaves. Dissertação de Mestrado, Universidade Federal de Santa Catarina, Florianópolis.

Andrade, A. L., Cruz, R. M., Stephan, P., \& Bitencourt, R. F. (2009). Construção de escalas de diferencial semântico: medidas de avaliação de sons no interior de aeronaves. Avaliação Psicológica, 8(2), 197-208.

Andrade, A. L., \& Garcia, A. (2011). Desenvolvimento de uma medida multidimensional para avaliação de qualidade em relacionamentos românticos - Aquarela-R, Psicologia: Reflexão e Crítica, 25(4), 634-643.

Babbie, E. (2003). Métodos de pesquisas de survey. Belo Horizonte: UFMG.

Bradley, M., \& Lang, P. L. (1994). Measuring emotion: The self-assessment manikin and the semantic differential. Journal of Behavioral Therapy and Experimental Psychiatry, 25(1), 49-59.

Carvalho L. F., Nunes M. F. O., Primi R., \& Nunes, C. H. S. S., (2012). Evidências desfavoráveis para avaliação da personalidade com um instrumento de 10 itens. Paidéia, 22(51), 63-71.

Escudero, G., \& Zafra, M. (2012). Cambio conceptual en los grupos de crecimiento personal. Miscelánea Comillas, 70(137), 397-442.

Friborg, O., Martinussen, M., \& Rosenvinge (2006). Likert-based vs. semantic differential-based scorings of positive psychological constructs: A psychometric comparison of two versions of a scale measuring resilience. Personality and Individual Differences, 40, 873-884.

Günther, H. (2008). Como elaborar um questionário. In J. Q. Pinheiro \& H. Günther (Eds.), Métodos de pesquisa nos estudos pessoa-ambiente (pp. 105-149). São Paulo: Casa do Psicólogo. 
Hauck Filho, N., Teixeira, M. A. P., Machado, W. L., \& Bandeira, D. R. (2012). Marcadores reduzidos para a avaliação da personalidade em adolescentes. Psico$U S F, 17(2), 253-260$.

Herzberg, P., \& Brähler, E. (2006). Assessing the big-five personality domains via short forms: A cautionary note and a proposal. European Journal of Psychological Assessment, 22(3),139-148.

Hogan, T. (2006). Introdução à prática dos testes psicológicos. Rio de Janeiro, LTC.

Ignacio, G. (2009). El diferencial semántico: un espacio universal de ordem psicologico. Signos Linguisticos, 9, 111-122.

Maniscalco, A. P. C. (1994). Avaliação de Brasília entre moradores e visitantes. Série: Textos de Alunos de Psicologia Ambiental, 6, 1-4.

Mikusinski, E. B., \& Urteaga, A. G. (1982). La imagen de la vejez explorada mediante el diferencial semântico. Revista Latinoamericana de Psicología, 14(1), 37-53.

Mikusinski, E. B., Urteaga, A. G., Quintana, M. E., \& Andrade, M. C. (1980). Exploración de las dimenciones Eysenckianas de personalidad mediante el diferencial semântico. Revista Latinoamericana de Psicología, 12(3), 425- 440.

Mondragón, S., Company, P., \& Vergara, M. (2005). Semantic differential applied to the evaluation of machine tool design. International Journal of Industry Ergonomics, 35, 1021-1029.

Osgood, C. E. (1952). The nature and measurement of meaning. Psychological Bulletin, 49(3), 197-237.

Osgood, C. E., Suci, G. J., \& Tannenbaum, P. H. (1957). The measurement of meaning. Urbana, IL: University of Illinois Press.

Pasquali, L. (2010). Diferencial semântico. In L. Pasquali (Ed.), Instrumentação Psicológica (pp. 262-272). Petrópolis, RJ: Vozes.

Peres-dos-Santos, L. B. F., \& Laros J. A. (2007). Avaliação da prática pedagógica do professor de ensino superior. Estudos em Avaliação Educacional, 18(36),75-95.

Posada, F. (1997). Construcción y evaluación en diferentes cohortes del DSE (Diferencial semántico del envejecimiento). Anales de Psicología, 13(1), 31-37. 
Rammstedt, B. (2007). The 10-item Big Five Inventory: Norm values and investigation of sociodemographic effects based on a German population representative sample. European Journal of Psychological Assessment 23(3), 193-201.

Salor, S. S. (1979). Diferencial semántico e actitudes: un estudio sociologico entre estudiantes de bachirellato. El Basilisco, 6, 9-17.

Saucier, G. \& Goldberg, L. (2002). Assessing the Big Five: Applications of 10 psychometric criteria to development of marker scales. In B. De Raad \& M. Perugini (Eds.), Big five assessment (pp.29-58). Germany: Hogrefe \& Huber Publishers. 


\title{
Manuscrito 3
}

\section{A estrutura fatorial da Escala Reduzida de Cinco Grandes Fatores}

\author{
de Personalidade (ER5FP)
}

\begin{abstract}
Resumo
O presente estudo visou verificar as evidências de fidedignidade e validade dos escores derivados de um novo instrumento reduzido para avaliar os cinco grandes fatores de personalidade utilizando o diferencial semântico. Elaborou-se um conjunto de 47 itens que foi aplicado para uma amostra de 365 estudantes universitários do Distrito Federal, com idade média de 29,1 anos $(D P=8,6)$, sendo 53,7\% de mulheres. O modelo de cinco fatores de personalidade foi testado usando análise fatorial confirmatória. Uma vez que o modelo inicial com todos os 47 itens não mostrou um bom ajuste, foram excluídos 27 itens com base nas cargas fatoriais e nos índices de modificação. O modelo final com 20 itens apresentou um bom ajuste aos dados. Foram encontrados coeficientes de fidedignidade dos cinco fatores com valores entre 0,71 e 0,85 . Os resultados desse estudo mostram evidências satisfatórias de fidedignidade do novo instrumento na amostra pesquisada.
\end{abstract}

Palavras-chave: avaliação da personalidade; escala de diferencial semântico; análise fatorial confirmatória. 


\begin{abstract}
The purpose of this study was to verify evidence of the score reliability and score validity of a new reduced instrument assessing the big five personality factors using a semantic differential scale. A set of 47 items was elaborated and administered to a sample of 365 university students of the Federal District in Brazil, with a mean age of 29.1 years $(S D=8.6), 53.7 \%$ being women. The five-factor model of personality was tested using confirmatory factor analysis. Since the initial model with all 47 items did not exhibit an adequate fit to the data, 20 items were excluded on the basis of factor loadings and modification indices. The final model consisting of 20 items showed a good fit to the data. The five factors showed reliability coefficients ranging from .71 to .85 . The results of this study show satisfactory reliability evidence of the new instrument in the investigated sample.
\end{abstract}

Keywords: personality assessment, semantic differential scale, confirmatory factor analysis. 
No campo da personalidade, são numerosos os instrumentos que vêm sendo elaborados e validados para a realidade de diversos contextos sociais e culturais (Costa \& McCrae, 2007; Rammstedt, 2007; Hauck Filho, Machado, Teixeira \& Bandeira, 2012; Rodríguez-Fornells, Lorenzo-Seva, \& Andrés-Pueyo, 2001). Observa-se, por meio dos relatos de pesquisa, que o modelo dos Cinco Grandes Fatores (CGF) vem sendo também largamente utilizado como base teórica para a construção dos instrumentos e para o aprofundamento na discussão sobre os traços de personalidade e a sua interlocução com outros construtos (Bäccman \& Carlstedt, 2010; Jenkins-Guarnieri, Wright, \& Johnson, 2013).

O modelo dos CGF é estruturado com os fatores Neuroticismo, Extroversão, Abertura para experiências, Conscienciosidade e Amabilidade. O Neuroticismo consiste na forma como uma pessoa vivencia as experiências negativas, indicando o seu grau de estabilidade emocional (Widiger, 2009). A Extroversão representa o quanto uma pessoa é comunicativa, ativa e que tem facilidade para estabelecer interações sociais dinâmicas (Wilt \& Revelle, 2009). A Abertura para experiências é um fator que avalia em que medida uma pessoa é curiosa e tem disponibilidade para vivenciar situações novas, desconhecidas, que demandem dela uma postura mais criativa (McCrae \& Sutin, 2009). A Conscienciosidade configura-se como um fator que avalia o quanto a pessoa é focada, tem disposição para buscar suas metas, é realizadora e apresenta autocontrole (Roberts, Jackson, Fayard, Edmonds, \& Meints, 2009). Por fim, a Amabilidade, também traduzida para a realidade brasileira como Socialização (Nunes, Hutz, \& Nunes, 2010; Nunes \& Hutz, 2007c), revela em que medida a pessoa tem capacidade para estabelecer relações com qualidade, de forma harmoniosa, agradável, empática (Graziano \& Tobin, 2009).

No Brasil, existem grupos de pesquisa em avaliação psicológica, vinculados a instituições de ensino superior e a editoras que têm buscado desenvolver escalas de 
personalidade com base nos CGF e que apresentem boa qualidade psicométrica. Dentre os instrumentos validados no Brasil, que utilizam como referência o CGF, existem o Inventário de Personalidade NEO Revisado - NEO-PI-R (Flores-Mendoza, 2007), NEOFFI (Flores-Mendoza, 2007), a Bateria Fatorial de Personalidade - BFP (Nunes, Hutz, \& Nunes, 2010) e as escalas de construtos específicos, como a Escala Fatorial de Neuroticismo - EFN (Hutz \& Nunes, 2001), a Escala Fatorial de Extroversão - EFEx (Nunes \& Hutz, 2007a) e a Escala Fatorial de Socialização - EFS (Nunes \& Hutz, 2007b).

Ainda, sobre o contexto brasileiro, observa-se a necessidade de continuar atendendo à demanda de construção de instrumentos que gerem escores fidedignos e válidos, necessários para a mensuração de um aspecto tão complexo, que é a personalidade. Além da qualidade psicométrica dos escores dos instrumentos de personalidade, uma questão enfrentada nesse segmento de avaliação é o fato de que os instrumentos tendem a ser estruturados com mais de 100 itens, podendo interferir diretamente na qualidade de resposta dos respondentes.

Deste modo, fica evidente que o campo da avaliação psicológica em personalidade ainda pode ser aprimorado por meio de estudos, na realidade brasileira. Tais estudos podem focar no aprofundamento da discussão sobre o CGF, assim como podem ser sobre as evidências de validade e de aplicabilidade dos instrumentos que o utilizam como referência teórica sobre a modalidade de instrumentos utilizados e sobre o número ideal de itens em um instrumento.

A eficácia dos instrumentos com número reduzido de itens, sejam eles construídos com base em instrumentos existentes mais extensos ou elaborados já com tal característica, ainda carece de investigações. Na pesquisa desenvolvida por Carvalho, Nunes, Primi, e Nunes (2012), não foi possível sustentar os cinco fatores de personalidade em um instrumento com 10 itens. Os autores também não encontraram dados favoráveis 
na avaliação da consistência interna, denotando, assim, a inadequação do instrumento para avaliação de personalidade. No entanto, Hauck Filho et al (2012), ao estudarem uma medida reduzida, com 25 marcadores de avaliação de personalidade, construída com base nos 64 marcadores desenvolvidos por Hutz, Nunes, Silveira, Serra, Antón e Wieczoneck (1998), encontraram dados de consistência interna compatíveis com os achados da literatura.

Ademais, estudar a elaboração de instrumento reduzido para avaliação de personalidade se sustenta na ampliação de estudos sobre personalidade na correlação com outros construtos. Apesar de já ser uma prática no campo da personalidade, a construção de instrumentos reduzidos pode facilitar o processo de estabelecimento de correlações entre variáveis. A personalidade já é largamente estudada na correlação com outras variáveis tais como transição para aposentadoria (Lockenhoff, Terraciano, \& Costa Jr, 2009) e estilo de apego, competências interpessoais e uso do Facebook (JenkinsGuarnieri et al, 2013). A construção de um instrumento mais curto pode vir a contribuir para a ampliação de estudos e a obtenção de dados mais consistentes sobre tais correlações.

No presente estudo, pretende-se agregar duas características à escala: que ela seja reduzida e que adote a técnica do diferencial semântico que busca avaliar características de personalidade por meio de pares de adjetivos opostos. Conforme afirma Kashiwagi (2002), existem algumas vantagens que podem estimular um pesquisador a escolher uma escala de adjetivos. A primeira delas é o tempo que se leva em um processo avaliativo. Segundo o autor, uma escala dessa natureza pode reduzir o tempo de aplicação, o que pode vir a garantir maior qualidade da resposta do participante. A segunda é a maior possibilidade de compreensão entre públicos com diversas características, seja escolaridade, seja a condição de ser estrangeiro ou não, por exemplo. Kashiwagi (2002) 
recorreu aos estudos realizados por ele em 1999, e por outros autores, para reforçar que a maior vantagem dos testes de adjetivos refere-se aos escores de fidedignidade, que tendem a ser altos.

Com o intuito de testar um instrumento com 50 adjetivos, Perugini e Di Blas (2002), fizeram uma pesquisa com 1.029 participantes na Itália e encontraram coeficientes de consistência interna dos fatores entre 0,73 e 0,89. Ao utilizar como covariáveis a idade e o sexo, observaram que não há grandes diferenças entre os grupos para os fatores Extroversão e Abertura para experiências. No entanto, com a inserção da covariável idade, identificaram diferenças no fator Conscienciosidade, em que pessoas mais velhas tendem a apresentar maiores escores nesse fator. No que se refere à variável sexo, os dados do referido estudo indicam que as mulheres tendem a apresentar maiores escores médios no fator Neuroticismo. Já a Amabilidade recebe interferências tanto da idade como do sexo. Nesse caso, as mulheres apresentam maiores escores, assim como os participantes mais velhos.

Conforme sinalizado, além de ser uma escala reduzida, a escala elaborada nesse estudo utiliza a técnica do diferencial semântico. Tal técnica que usa escalas bipolares foi desenvolvida por Osgood, Suci, e Tannenbaum na década de 50. Foram pioneiros em estabelecer uma interlocução da concepção teórica da natureza do significado e suas técnicas de mensuração (Ignacio, 2009; Pasquali, 2010; Salor, 1979). A técnica de diferencial semântico foi criada por Osgood, Suci, e Tannenbaun (1957), ao perceberem a necessidade de avaliar o significado afetivo das atitudes, opiniões, percepções, imagem social, personalidade, preferências e interesses das pessoas frente a conteúdos que não são diretamente mensuráveis.

Nesse contexto, o objetivo de presente estudo é construir e averiguar as evidências de validade de uma escala reduzida de diferencial semântico para avaliação de 
personalidade, utilizando como base o modelo dos cinco grandes fatores de personalidade.

\section{Método}

\section{Construção do instrumento}

Para a construção da escala reduzida de diferencial semântico, para avaliação de personalidade, tomou-se como referência os estudos realizados por Andrade, Cruz, Stephan, \& Bitencourt (2009), Pasquali (2010), Peres-dos-Santos \& Laros (2007), Lopes, Nogueira-Martins, Andrade, \& Barros (2011). A partir desses estudos, foram realizadas as seguintes etapas: (1) Elaboração de lista de adjetivos. Para a construção da lista inicial com 51 pares de adjetivos, foram utilizados, como referência, os estudos sobre os descritores de traços de personalidade (Peabody \& De Raad, 2002). A lista inicial foi composta por 149 adjetivos. Foram excluídas, após consulta à comunidade, que contou com a participação de 29 participantes, e com o suporte de dicionários de sinônimos e antônimos, as palavras que foram consideradas de difícil compreensão, denotaram duplo sentido ou que indicaram características da forma de linguagem de uma determinada região (Hutz et al., 1998). (2) Análise realizada pela profissional de semântica. O processo de avaliação semântica consistiu na realização de análise detalhada dos conceitos a fim de verificar a qualidade e grau de oposição dos pares. Dos 51 pares de adjetivos, três foram retirados e sete modificações foram feitas nos demais. (3) Avaliação de juízes. Após as modificações realizadas em função das sugestões apresentadas pela profissional de semântica, foi elaborado um questionário online, via Survey Monkey, para que os juízes pudessem realizar a avaliação de cada par de adjetivos, assim como a sua relação com cada fator. As modificações sugeridas pelos 14 juízes, com formação em psicologia e experiência de 9,4 anos em avaliação psicológica, foram acatadas e culminaram na elaboração da versão final do instrumento, com 47 itens. 


\section{Participantes}

Participaram do estudo 365 estudantes universitários dos cursos de Direito, Administração e Sistemas de Informação, sendo a maioria de mulheres, representando $53,7 \%$ da amostra. As mulheres apresentaram idade média de 29,7 anos $(D P=8,58)$ e os homens apresentaram idade média de 28,4 anos $(D P=8,65)$. A idade dos participantes variou entre 17 e 70 anos $(M=29,02 ; D P=8,62)$. A variação e o valor mais elevado da média de idade são características das turmas que estudam no turno noturno, período em que a maior parte da coleta de dados foi realizada.

\section{Procedimentos}

\section{Coleta de dados}

O instrumento de diferencial semântico com 47 itens foi aplicado em duas faculdades localizadas no Distrito Federal, em salas de aula e com alunos de diversos cursos de graduação. Inicialmente, foi realizado contato com os coordenadores dos cursos de graduação, a fim de solicitar anuência para realizar aplicação em sala de aula. A coleta de dados só foi realizada mediante a referida autorização.

No processo de realização deste estudo, foram consideradas as questões éticas que envolvem pesquisa com seres humanos. Assim, todos os participantes foram orientados quanto aos objetivos da pesquisa e quanto ao sigilo dos dados a serem obtidos, e que, sob nenhuma hipótese, teriam a sua identidade revelada. Cientes dessas informações, os participantes foram convidados a assinar o Termo de Consentimento Livre e Esclarecido, antes de iniciar a participação da pesquisa. O tempo médio de aplicação do questionário foi de 6 minutos, tendo variado entre 4 e 10 minutos. O tempo médio de permanência em cada sala de aula levou aproximadamente 30 minutos, entre explicação, leitura do termo de consentimento e aplicação do questionário. 


\section{Análise de Dados}

Para a análise fatorial confirmatória, utilizou-se o software Amos 18.0 (Arbuckle, 2009). A verificação da normalidade univariada e multivariada foi realizada com o programa FACTOR na sua versão 9.2 (Lorenzo-Seva \& Ferrando, 2013). O SPSS foi utilizado em sua versão 18 para o tratamento de dados ausentes, o cálculo do coeficiente de fidedignidade dos fatores e o cálculo das estatísticas descritivas. Por meio dos programas, foram adotados procedimentos para análise exploratória dos dados, análise fatorial confirmatória e análise de fidedignidade.

\section{Análise exploratória dos dados.}

Por meio da análise exploratória, verificou-se a ocorrência de erros de digitação, a marcação de mais de que uma categoria de resposta e de dados ausentes, assim como a análise de pressupostos para a realização da análise fatorial confirmatória. Foram utilizadas, como referência, as recomendações de Weston, Gore, Chan, e Catalano (2008), que indicam a verificação inicial do pressuposto de normalidade univariada, por meio da inspeção dos índices de assimetria (skewness) e curtose (kurtosis) dos itens.

O critério para considerar um item com distribuição não-normal foi assimetria e curtose superior a 2,0 (Miles \& Shelvin, 2001). Os autores argumentam que variáveis com valores abaixo de 2 não costumam afetar as análises substancialmente. Posteriormente, a normalidade multivariada dos itens foi verificada, usando o coeficiente de assimetria e curtose multivariada de Mardia (1970).

\section{Análise Fatorial Confirmatória.}

Inicialmente, buscou-se testar se a estrutura fatorial do novo instrumento, na sua forma integral, com todos os 47 itens, estava de acordo com o modelo de cinco grandes 
fatores de personalidade. Na modificação do modelo inicial, foi utilizada como critério a exclusão dos itens que mostravam uma carga fatorial relativamente fraca $(<0,40)$. Os itens também foram excluídos com base nos índices de modificação. Para avaliar o ajuste dos modelos aos dados, foram utilizados os seguintes índices sugeridos por Byrne (2005): o qui-quadrado $\left(\chi^{2}\right)$ acompanhado com os graus de liberdade (gl), o Comparative Fit Index (CFI), o Tucker-Lewis Index (TLI), o Root Mean Square Error of Approximation (RMSEA) com o intervalo de confiança de $90 \%$ e o Standardized Root Mean Square Residual (SRMR). A interpretação dos índices de ajuste foi baseada nos critérios sugeridos por Weston et al (2008) que recomendam os seguintes valores para um bom ajuste: CFI $\geq 0,95, \mathrm{TLI} \geq 0,95, \mathrm{RMSEA} \leq 0,06$ e SRMR $\leq 0,08$. As análises foram realizadas com o software Amos utilizando o método Maximum Likelihood.

\section{Análise de fidedignidade.}

A fidedignidade foi avaliada para cada fator separadamente, utilizando o coeficiente lambda 2 de Guttman $\left(\lambda_{2}\right)$. Existem amplas evidências de que o lambda 2 de Guttman é mais adequado do que o coeficiente de alfa de Cronbach, principalmente em situações que envolvem uma quantidade menor de itens (Sijtsma, 2012; Tellegen \& Laros, 2014). 


\section{Resultados}

\section{Análise Exploratória dos dados}

Como primeiro passo, foram excluídos do banco de dados os respondentes $(\mathrm{N}=47)$ que assinalaram mais do que uma categoria de resposta em um dos itens do instrumento de personalidade. Em seguida, os valores ausentes foram substituídos pelos valores preditos por regressão (linear point at trend), uma vez que a quantidade de dados ausentes não ultrapassou 5\% (Tabachnick \& Fidell, 2007). No terceiro passo, foi verificada a normalidade univariada das distribuições das respostas nos 47 itens do novo instrumento por meio da assimetria e curtose univariadas. Essa análise revelou que todos os valores ficaram abaixo de |2|, indicando não existe um problema relevante de normalidade univariada (Miles \& Shevlin, 2001).

Como último passo, foi verificada a normalidade multivariada com base dos índices de assimetria e curtose multivariada de Mardia (1970). A assimetria multivariada mostrou um valor de 73,0 ( $p>0,05)$ e o valor da curtose multivariada foi de 562,13 ( $p<0,05)$. Deste modo, os dados apresentaram assimetria multivariada normal e curtose multivariada não normal. Consequentemente, foi necessário realizar uso da técnica de bootstrap para resolver efeito da não normalidade na estimação dos parâmetros (Byrne, 2010).

\section{Análise fatorial confirmatória}

O primeiro modelo que foi testado foi o modelo inicial com o conjunto completo de 47 itens distribuídos entre os cinco construtos latentes, sendo: Neuroticismo e Amabilidade cada um com 10 indicadores, Extroversão, Abertura para experiências e Conscienciosidade cada um nove indicadores. Seguindo as recomendações do Thompson (2005), as variâncias dos construtos latentes foram fixadas em um valor de 1. Os 
resultados da testagem do modelo inicial indicaram um ajuste aos dados, não satisfatório, com os seguintes valores dos índices de ajuste: $\mathrm{TLI}=0,66, \mathrm{CFI}=0,68, \mathrm{RMSEA}=0,075$ e $\operatorname{SRMR}=0,111$.

Tabela 1. Índices de ajuste dos modelos de mensuração inicial, intermediário e final do instrumento reduzido para avaliar os cinco grandes fatores de personalidade.

\begin{tabular}{llllllll}
\hline Modelo & $\mathrm{n}$ itens & $\chi^{2}$ & Gl & TLI & CFI & RMSEA (IC 90\%) & SRMR \\
\hline Modelo inicial & 47 & $3.145,91$ & 1.024 & 0,66 & 0,68 & $0,075(0,072-0,078)$ & 0,111 \\
Modelo & 34 & $1.540,23$ & 517 & 0,78 & 0,80 & $0,074(0,070-0,078)$ & 0,101 \\
intermediário & 20 & 304,53 & 160 & 0,94 & 0,95 & $0,050(0,041-0,058)$ & 0,062 \\
Modelo final & 20 &
\end{tabular}

Notas. $\chi^{2}=$ qui-quadrado; $\mathrm{gl}=$ graus de liberdade; TLI $=$ Tucker-Lewis Index, $\mathrm{CFI}=$ Comparative Fit Index; RMSEA (IC 90\%) = Root Mean Square Error of Approximation com intervalo de confiança de 90\%; SRMR = Standardized Root Mean Square Residual.

Para melhorar o ajuste do modelo aos dados, foram realizadas modificações no modelo original. Os 13 itens que tinham uma carga fatorial menor do que 0,40 foram excluídos do modelo. As cargas dos itens excluídos tinham valores entre 0,13 e 0,39. Depois da exclusão dos referidos itens, o modelo intermediário com 34 itens foi avaliado.

O ajuste deste segundo modelo aos dados melhorou em relação ao modelo anterior, mas ainda não foi satisfatório uma vez que os índices de ajuste não atingiram os valores estabelecidos para um bom ajuste: $\mathrm{TLI}=0,78, \mathrm{CFI}=0,80, \mathrm{RMSEA}=0,074$ e SRMR $=$ 0,101. Assim, foi decidido realizar mais alterações baseadas nos índices de modificação fornecidos no programa Amos.

Os índices de modificação, com um maior impacto na melhoria do ajuste, sugeriram adicionar uma correlação entre os erros de vários itens de um mesmo fator. Segundo Byrne (2010), uma correlação entre os erros de itens significa que eles são muito semelhantes em termos de conteúdo. Para evitar a existência desse tipo de itens no modelo, foi decidido excluir um dos dois itens (o item com menor carga fatorial), para qual o índice de modificação sugeriu incluir uma correlação entre os erros. 
Com base nesse procedimento, foram excluídos 14 itens. Depois da exclusão desses itens, o modelo final com 20 itens foi avaliado. Conforme pode ser observado na Tabela 1, o modelo apresentou índices que indicam um bom ajuste aos dados (TLI = 0,94, CFI = $0,95, \operatorname{RMSEA}=0,050$ e SRMR $=0,062$.

$\mathrm{Na}$ Tabela 2, são apresentadas algumas propriedades psicométricas dos cinco fatores do modelo final. Na sua inspeção, observa-se que o fator Extroversão mostrou as cargas fatoriais mais elevadas, tendo apresentado uma média no valor de 0,77 . Já o fator Abertura para experiências manifestou as cargas mais baixas com uma média de 0,62. Assim, apesar das cargas fatoriais satisfatórias apresentadas pelos itens, alguns apresentaram cargas fatoriais mais baixas, que ficaram entre 0,44 e 0,59 (flexível / rígido, obstinado / inconstante, amoroso / indiferente e instável / estável).

Ainda na inspeção da Tabela 2, no que se refere às correlações entre os cinco fatores, as que se apresentaram mais forte foram entre F2 (Conscienciosidade) e F5 (Abertura para experiências) e entre F2 (Conscienciosidade) e F3 (Amabilidade). As correlações mais fracas foram entre F1 (Extroversão) e F4 (Neuroticismo) e entre F4 (Neuroticismo) e F5 (Abertura para experiências). 
Tabela 2. Coeficientes de fidedignidade ( $\lambda_{2}$ de Guttman), cargas fatoriais (CF), comunalidades $\left(h^{2}\right)$, correlações item-resto $\left(r_{i r}\right)$, para os cinco fatores do instrumento reduzido de personalidade, as correlações entre os fatores e os índices de ajuste do modelo aos dados $(\mathrm{N}=365)$.

\begin{tabular}{|c|c|c|c|}
\hline Fator 1 - Extroversão - Fidedignidade $\left(\lambda_{2}\right)=0,85$ & $\mathrm{CF}$ & $h^{2}$ & rir \\
\hline Item 13. Extrovertido / Tímido & 0,90 & 0,81 & 0,78 \\
\hline Item 14. Comunicativo / Calado & 0,90 & 0,81 & 0,77 \\
\hline Item 12. Expansivo / Contido & 0,66 & 0,44 & 0,63 \\
\hline Item 11. Sociável / Reservado & 0,60 & 0,36 & 0,57 \\
\hline Média & 0,77 & 0,59 & 0,69 \\
\hline Fator 2 - Conscienciosidade - Fidedignidade $\left(\lambda_{2}\right)=0,78$ & $\mathrm{CF}$ & $\mathrm{h}^{2}$ & rir \\
\hline Item 44. Motivado / Desmotivado & 0,78 & 0,61 & 0,65 \\
\hline Item 45. Persistente / Desistente & 0,75 & 0,56 & 0,65 \\
\hline Item 43. Eficiente / Ineficiente & 0,64 & 0,41 & 0,54 \\
\hline Item 46. Obstinado / Inconstante & 0,59 & 0,35 & 0,51 \\
\hline Média & 0,69 & 0,48 & 0,59 \\
\hline Fator 3 - Amabilidade - Fidedignidade $\left(\lambda_{2}\right)=0,81$ & $\mathrm{CF}$ & $h^{2}$ & rir \\
\hline Item 22. Simpático / Antipático & 0,76 & 0,58 & 0,66 \\
\hline Item 23. Gentil / Rude & 0,76 & 0,58 & 0,67 \\
\hline Item 26. Amigável / Hostil & 0,76 & 0,58 & 0,64 \\
\hline Item 29. Amoroso / Indiferente & 0,59 & 0,35 & 0,52 \\
\hline Média & 0,72 & 0,52 & 0,62 \\
\hline Fator 4 - Neuroticismo - Fidedignidade $\left(\lambda_{2}\right)=0,80$ & $\mathrm{CF}$ & $\mathrm{h}^{2}$ & rir \\
\hline Item 1. Nervoso / Calmo & 0,82 & 0,67 & 0,71 \\
\hline Item 2. Impaciente / Paciente & 0,82 & 0,67 & 0,70 \\
\hline Item 3. Ansioso / Tranquilo & 0,71 & 0,50 & 0,60 \\
\hline Item 5. Instável / Estável & 0,44 & 0,19 & 0,38 \\
\hline Média & 0,70 & 0,49 & 0,60 \\
\hline Fator 5 - Abertura para experiências - Fidedignidade $\left(\lambda_{2}\right)=0,71$ & $\mathrm{CF}$ & $\mathrm{h}^{2}$ & rir \\
\hline Item 36. Criativo / Prosaico & 0,69 & 0,69 & 0,58 \\
\hline Item 35. Entusiasta / Apático & 0,67 & 0,67 & 0,52 \\
\hline Item 38. Autêntico / Simulado & 0,67 & 0,67 & 0,51 \\
\hline Item 31. Flexível / Rígido & 0,44 & 0,44 & 0,35 \\
\hline Média & 0,62 & 0,62 & 0,49 \\
\hline
\end{tabular}

Correlação entre os fatores: F1-F2 = 0,26; F1-F3 = 0,23; F1-F4 = 0,09; F1-F5 = 0,32; F2-F3 = 0,62; F2-F4 = -0,11; F2-F5 = 0,79; F3-F4 = -0,25; F3-F5 = 0,67; F4-F5 = -0,14.

Índices de ajuste: $\chi^{2}=304,53 ; \mathrm{gl}=160 ; \mathrm{TLI}=0,94 ; \mathrm{CFI}=0,95 ; \mathrm{RMSEA}=0,050 ; \mathrm{SRMR}=0,062$.

\section{Análise de fidedignidade dos escores}

A análise de fidedignidade dos cinco fatores foi realizada com base do coeficiente lambda2 de Guttman. Ainda, na Tabela 2, pode ser observado que os coeficientes de 
fidedignidade variaram entre 0,71 e 0,85 . O coeficiente do fator Abertura para experiências foi o mais baixo e o de fator Extroversão foi o mais alto.

Um outro dado a ser salientado refere-se às médias encontradas para cada um dos fatores. Observa-se, na Tabela 3, que os participantes atribuíram valores mais elevados para os fatores Amabilidade, Conscienciosidade, Abertura para experiências e Extroversão. O Neuroticismo foi o único fator que apresentou valor mais baixo em sua média.

Tabela 3. Médias e desvios-padrão dos fatores

\begin{tabular}{lll}
\hline Fatores & Média & DP \\
\hline Extroversão & 4,29 & 1,97 \\
Conscienciosidade & 5,65 & 1,36 \\
Amabilidade & 5,91 & 1,28 \\
Neuroticismo & 3,71 & 1,86 \\
Abertura para Experiências & 5,29 & 1,46 \\
\hline
\end{tabular}

Por fim, Na Tabela 4, são apresentados os coeficientes estimados pelo método da máxima verossimilhança e os resultados das replicações bootstrap. Segundo as recomendações de Byrne (2010), optou-se para realizar 500 replicações. As médias das cargas fatoriais estimadas pelo método da máxima verossimilhança e as médias das cargas fatoriais estimadas pelo método bootstrap são iguais. 
Tabela 4. Coeficientes estimados pelo método da Máxima Verossimilhança e resultados das replicações bootstrap

\begin{tabular}{|c|c|c|c|c|c|c|c|}
\hline \multirow{2}{*}{ Itens } & \multicolumn{4}{|c|}{ Máxima Verossimilhança } & \multicolumn{3}{|c|}{ Bootstrap } \\
\hline & $\mathrm{CF}$ & EP & $z$ & $p$ & Média & EP & Bias \\
\hline Item 13. Extrovertido / Tímido & 0,905 & 0,08 & 21,12 & $<0,01$ & 0,904 & 0,021 & 0,000 \\
\hline Item 14. Comunicativo / Calado & 0,896 & 0,08 & 20,82 & $<0,01$ & 0,896 & 0,018 & 0,000 \\
\hline Item 12. Expansivo / Contido & 0,658 & 0,09 & 13,63 & $<0,01$ & 0,658 & 0,041 & 0,000 \\
\hline Item 11. Sociável / Reservado & 0,595 & 0,10 & 12,01 & $<0,01$ & 0,591 & 0,049 & 0,005 \\
\hline Item 44. Motivado / Desmotivado & 0,780 & 0,06 & 16,26 & $<0,01$ & 0,779 & 0,032 & 0,001 \\
\hline Item 45. Persistente / Desistente & 0,750 & 0,07 & 15,43 & $<0,01$ & 0,749 & 0,049 & 0,001 \\
\hline Item 43. Eficiente / Ineficiente & 0,644 & 0,06 & 12,69 & $<0,01$ & 0,644 & 0,054 & 0,001 \\
\hline Item 46. Obstinado / Inconstante & 0,590 & 0,08 & 11,38 & $<0,01$ & 0,589 & 0,057 & 0,001 \\
\hline Item 22. Simpático / Antipático & 0,762 & 0,06 & 15,86 & $<0,01$ & 0,764 & 0,050 & 0,002 \\
\hline Item 23. Gentil / Rude & 0,759 & 0,06 & 15,78 & $<0,01$ & 0,763 & 0,052 & 0,004 \\
\hline Item 26. Amigável / Hostil & 0,757 & 0,05 & 15,73 & $<0,01$ & 0,755 & 0,042 & 0,003 \\
\hline Item 29. Amoroso / Indiferente & 0,591 & 0,07 & 11,45 & $<0,01$ & 0,593 & 0,050 & 0,001 \\
\hline Item 1. Nervoso / Calmo & 0,819 & 0,09 & 17,19 & $<0,01$ & 0,820 & 0,034 & 0,000 \\
\hline Item 2. Impaciente / Paciente & 0,823 & 0,09 & 17,28 & $<0,01$ & 0,823 & 0,034 & 0,000 \\
\hline Item 3. Ansioso / Tranquilo & 0,706 & 0,09 & 14,29 & $<0,01$ & 0,704 & 0,044 & 0,002 \\
\hline Item 5. Instável / Estável & 0,435 & 0,09 & 8,04 & $<0,01$ & 0,431 & 0,065 & 0,004 \\
\hline Item 36. Criativo / Prosaico & 0,694 & 0,08 & 13,58 & $<0,01$ & 0,692 & 0,047 & 0,001 \\
\hline Item 35. Entusiasta / Apático & 0,666 & 0,07 & 12,92 & $<0,01$ & 0,667 & 0,055 & 0,001 \\
\hline Item 38. Autêntico / Simulado & 0,672 & 0,08 & 13,07 & $<0,01$ & 0,675 & 0,055 & 0,003 \\
\hline Item 31. Flexível / Rígido & 0,442 & 0,08 & 8,01 & $<0,01$ & 0,437 & 0,060 & 0,005 \\
\hline
\end{tabular}

Notas. Foram realizadas 500 amostras bootstrap; $\mathrm{CF}=$ carga fatorial; $\mathrm{EP}=$ erro-padrão; Média = valor médio dos cargas fatoriais no procedimento bootstrap; Bias = diferença entre a estimativa do $\mathrm{ML}$ e estimativa bootstrap.

Também fica evidente que as estimativas do bootstrap são estáveis dada a baixa variação nas suas 500 amostras. Assim, pode-se concluir que a não normalidade das distribuições dos escores dos itens não sofreram influência relevante na estimação das cargas fatoriais. 


\section{Discussão}

O objetivo do presente estudo foi elaborar uma escala reduzida de diferencial semântico para avaliação de personalidade. Tal escala foi elaborada com base em pressupostos teóricos dos cinco grandes fatores de personalidade, nos critérios para estruturação de escala de diferencial semântico e nos parâmetros estatísticos de referência para verificação da qualidade psicométrica da medida (Hauck Filho et al., 2012).

A escala reduzida demonstrou ser um instrumento de fácil entendimento, aplicação e que demanda um tempo reduzido para que o participante possa responder. Reforçou o que Kashiwagi (2002) e Perugini e Di Blas (2002) evidenciam como vantagens das escalas de adjetivos.

Os índices de ajuste do modelo aos dados encontrados atendem aos critérios recomendados por Weston, Gore, Chan, e Catalano (2008), indicando a qualidade da escala e o seu reconhecimento como uma alternativa viável para realização de estudos que incorporem a personalidade como variável a ser estudada, mas que ainda demandam outras pesquisas, uma vez que se trata de um tema recente na realidade brasileira (Carvalho et al., 2012; Hauck Filho et al., 2012). É importante destacar que nesse estudo, conforme afirma Byrne (2005), o modelo original passou por modificações, e assim começou a trabalhar no modo exploratório e não mais no modo confirmatório. Deste modo, os resultados encontrados neste estudo ainda necessitam ser corroborados em futuras pesquisas.

Os dados apresentados na Análise Fatorial Confirmatória indicaram que a escala apresentou coeficientes de fidedignidade compatíveis com os encontrados na literatura que tratam de versões reduzidas de instrumentos de avaliação de personalidade (McCrae \& Costa, 2007). Segundo os critérios do Hogan (2006), esses valores (no caso do presente estudo, entre 0,71 e 0,85 ) são suficientemente bons para a maioria das pesquisas básicas. 
Dentre as médias das cargas fatoriais, a mais baixa foi a do fator Abertura para experiências, dado que também foi corroborado pela literatura (Hauck Filho et al, 2012; McCrae \& Costa, 2007).

Outro aspecto relevante refere-se às médias encontradas para cada fator. Observase que as médias mais altas foram apresentadas pelos fatores Extroversão, Amabilidade, Conscienciosidade e Abertura para experiências, que denotam a capacidade de adaptação do indivíduo ao meio social. A média mais baixa foi a apresentada pelo fator Neuroticismo, que se caracteriza por ser o único fator que pode evidenciar as experiências negativas, que avalia a estabilidade emocional, conforme sinaliza Widiger (2009), indicando a dificuldade de ajuste do indivíduo ao meio social. Estes dados são corroborados pelos achados de Hauck Filho et al. (2012).

Como uma das limitações do estudo, destaca-se a restrição da amostra, uma vez que não se constituiu de forma aleatória. Identifica-se ainda como limitação a restrição geográfica da aplicação, pois o estudo foi realizado apenas em Brasília. Apesar de ser uma cidade que agrega uma população advinda de todas as regiões, conforme pode ser identificado no dado de naturalidade, este dado não é suficiente para atender o critério de generalização. Uma outra limitação refere-se à pouca variabilidade do público-alvo, já que a amostra foi composta por estudantes universitários.

Como agenda de pesquisa, identifica-se a necessidade de expandir para outras cidades, de modo a abarcar as cinco regiões do Brasil, a fim de garantir maior precisão na generalização dos dados. São recomendados estudos com pessoas que apresentem outros níveis de escolaridade, a fim de abarcar participantes do ensino médio à pósgraduação (Rammstedt, 2007), para verificar se há interferência no grau de entendimento dos participantes. 
Sugere-se ainda a realização de estudos de validade convergente com instrumentos já validados para a realidade brasileira a fim de aferir a consistência dos fatores. Outros estudos que podem ser realizados são os que envolvem a correlação entre a variável personalidade e outros construtos, uma vez que a literatura sugere que os instrumentos reduzidos tendem a cumprir importante papel nesse tipo de estudo (Costa \& McCrae, 2007).

O avanço de estudos sobre instrumentos reduzidos para avaliação dos CGF configura-se como um eixo importante de investigação, pois contribui tanto para a ampliação dos modos de avaliação já existentes como para a difusão do modelo na realidade brasileira. Conclui-se que o referido estudo apresentou resultados que, junto aos esforços já realizados por outros estudos no Brasil (Carvalho et al., 2012; Hauck Filho et al., 2012), reforçam a necessidade de aprofundamento do debate sobre a eficácia dos instrumentos reduzidos e sobre que critérios podem ser utilizados para o estabelecimento do número de itens em instrumentos de avaliação de personalidade. 


\section{Referências}

Andrade, A., Cruz, R. M., Stephan, P., \& Bitencourt, R. F. (2009). Construção de escalas de diferencial semântico: medidas de avaliação de sons no interior de aeronaves. Avaliação Psicológica, 8(2), 197-208.

Arbuckle, J. L. (2009). Amos ${ }^{\mathrm{TM}} 18$ User's Guide. Chicago, IL: SPSS Inc.

Bäccman, C., \& Carlstedt, B. (2010). A construct validation of a profession-focused personality questionnaire (PQ) versus the FFPI and the SIMP. European Journal of Psychological Assessment 26(2), 136-142.

Byrne, B. M. (2005). Factor analytic models: Viewing the structure of an assessment instrument from three perspectives. Journal of Personality Assessment, 85(1), 1732.

Byrne, B. M. (2010). Structural Equation Modeling with AMOS: Basic concepts, applications and programming. New York: Routledge, Taylor \& Francis.

Carvalho, L. F., Nunes, M., Primi, R., \& Nunes, C. H. S. (2012). Evidências desfavoráveis para avaliação da personalidade com um instrumento de 10 itens. Paidéia, 22(51), 63-71.

McCrae, R., \& Costa, P. (2007). Brief versions of the NEO-PI-3. Journal of Individual Differences 8(3), 116-128.

Flores-Mendoza, C. (2007). Manual do NEO-PI-R e NEO-FFI. São Paulo: Vetor Editora.

Graziano, W., \& Tobin, R. (2009). Agreeableness. In M. Leary \& R. Hoyle (Eds.), Handbook of individual differences in social behavior (pp. 46-61). New York: The Guilford Press.

Hauck Filho, N., Machado, W., Teixeira, M. A, \& Bandeira, D. R. (2012). Evidências de validade de marcadores reduzidos para a avaliação da personalidade no modelo dos cinco grandes fatores. Psicologia: Teoria e Pesquisa, 28(4), 417-423.

Hogan, T. P. (2006). Introdução à Prática de Testes Psicológicos. Rio de Janeiro: LTC.

Hutz, C. S., Nunes, C. H., Silveira, A. D., Serra, J., Antón, M., \& Wieczoneck, L. S. (1998). O desenvolvimento de marcadores para a avaliação da personalidade no modelo dos cinco grandes fatores. Psicologia: Reflexão e Crítica, 11(2), 395-410. 
Hutz, C. S., \& Nunes, C. H. S. (2001). Escala Fatorial de Neuroticismo. São Paulo: Casa do Psicólogo.

Ignacio, G. (2009). El diferencial semántico: un espacio universal de orden psicológico. Signos Linguisticos, 9(5), 111-122.

Jenkins-Guarnieri, M. Wright, S., \& Johnson, B. (2013). The interrelationships among attachment style, personality traits, interpersonal competency, and facebook use. Psychology of Popular Media Culture, 2(2), 117-131.

Kashiwagi, S. (2002). Japanese adjective list for the Big Five. In B. De Raad \& M. Perugini (Eds.), Big five assessment (pp.305-326). Germany: Hogrefe \& Huber Publishers.

Lockenhoff, C., Terraciano, A., \& Costa Jr, P. (2009). Five factor model personality traits and the retirement transition: Longitudinal and cross-sectional associations. Psychology and Aging, 24(3), 722-728.

Lopes, J. L., Nogueira-Martins, L. A., Andrade, A. L., \& Barros, A. L. B. L. (2011). Escala de diferencial semântico para avaliação da percepção de pacientes hospitalizados frente ao banho. Acta Paulista de Enfermagem, 24(6), 815-20.

Lorenzo-Seva, U., Ferrando, P. J. (2013). FACTOR: A computer program to fit the exploratory factor analysis model. Behavior Research Methods, 38(1), 88-91.

Mardia, K. V. (1970), Measures of multivariate skewness and kurtosis with applications. Biometrika, 57(3), 519-530.

McCrae, R., \& Sutin, A. (2009). Openness to experience. In M. Leary \& R. Hoyle (Eds.), Handbook of individual differences in social behavior (pp. 257-273). New York: The Guilford Press.

Miles, J., \& Shevlin, M. (2001). Applying regression \& correlation. A guide for students and researchers. London: Sage Publications.

Nunes, C. H. S., \& Hutz, C. S. (2007a). Escala Fatorial de Extroversão. São Paulo: Casa do Psicólogo.

Nunes, C. H. S., \& Hutz, C. S. (2007b). Escala Fatorial de Socialização. São Paulo: Casa do Psicólogo. 
Nunes, C. H. S., Hutz, C. S., \& Nunes, M. (2010). Bateria Fatorial de Personalidade (BFP): Manual Técnico. São Paulo: Casa do Psicólogo.

Nunes, C. H. S., \& Hutz, C. S. (2007c). Construção e validação da escala fatorial de Socialização no modelo dos Cinco Grandes Fatores de Personalidade. Psicologia. Reflexão e Crítica, 20(1), 20-25.

Osgood, C. E., Suci, G. J., \& Tannenbaum, P. H. (1957). The measurement of meaning. Urbana, IL: University of Illinois Press.

Pasquali, L. (2010). Diferencial semântico. In L. Pasquali (Ed.), Instrumentação Psicológica (pp. 262-272). Petrópolis, RJ: Vozes.

Peabody, D., \& De Raad, B. (2002). The substantive nature of psycholexical personality factors: A comparison across languages. Journal of Personality and Social Psychology, 83(4), 983-997.

Peres-dos-Santos, L. B. F., \& Laros J. A. (2007). Avaliação da prática pedagógica do professor de ensino superior. Estudos em Avaliação Educacional, 18(36), 75-95.

Perugini, M., \& Di Blas, L. (2002). The Big Five Markers Scales (BFMS) and the Italian AB5C taxonomy: Analysis from an etic-emic perspective. In B. De Raad \& M. Perugini (Eds.), Big five assessment (pp.281-304). Germany: Hogrefe \& Huber Publishers.

Rammstedt, B. (2007). The 10-item Big Five Inventory: Norm values and investigation of sociodemographic effects based on a German population representative sample. European Journal of Psychological Assessment 23(3), 193-201.

Roberts, B., Jackson, J., Fayard, J., Edmonds, G., \& Meints, J. (2009). Conscientiousness. In M. Leary \& R. Hoyle (Eds.), Handbook of individual differences in social behavior (pp. 369-381). New York: The Guilford Press.

Rodríguez-Fornells, A., Lorenzo-Seva, U., \& Andrés-Pueyo, A. (2001). Psychometric properties of the Spanish adaptation of the Five Factor Personality Inventory. European Journal of Psychological Assessment, 17(2), 145-153.

Salor, S. S. (1979). Diferencial semántico e actitudes: un estudio sociologico entre estudiantes de bachirellato. El Basilisco, 6(1), 9-17. 
Sijtsma, K. (2012). Future of psychometrics: Ask what psychometrics can do for psychology. Psychometrika, 77(1), 4-20.

Tellegen, P. J., \& Laros J. A. (2014). SON-R 6-40. Snijders-Oomen Non-verbal intelligence test. Volume I: Research report. Hogrefe: Göttingen, Germany.

Thompson, B. (2005). Exploratory and confirmatory factor analysis: Understanding concepts and applications. Washington, DC: American Psychological Association.

Weston, R, Gore, P. A., Shan, F., \& Catalano, D. (2008). An introduction to using Structural Equation Models in rehabilitation psychology. Rehabilitation Psychology, 53(3), 340-356.

Widiger, T. (2009). Neuroticism. In M. Leary \& R. Hoyle (Eds.), Handbook of individual differences in social behavior (pp. 129-148). New York: The Guilford Press.

Wilt, J., \& Revelle, W. (2009). Extraversion. In M. Leary \& R. Hoyle (Eds.), Handbook of individual differences in social behavior (pp. 27-45). New York: The Guilford Press. 


\title{
Manuscrito 4
}

\section{Evidências da validade convergente da Escala Reduzida de Cinco Grandes Fatores de Personalidade.}

\begin{abstract}
Resumo
O objetivo deste estudo foi obter evidências de validade convergente da Escala Reduzida de Cinco Grandes Fatores de Personalidade (ER5FP). Assim, a ER5FP foi aplicada em 554 participantes com idades entre 16 e 69 anos $(M=30,6$; $D P=8,6)$ junto com o Inventário Reduzido dos Cinco Grandes Fatores de Personalidade (IGFP-5R). Ambos os instrumentos visam medir os cinco grandes fatores de personalidade: a ER5FP consiste de 20 itens e o IGFP-5R contém 32 itens. Depois de testar o modelo de mensuração de ambos os instrumentos, usando Modelagem por Equações Estruturais, as correlações entre os cinco fatores dos instrumentos foram obtidas. Para os fatores Extroversão, Neuroticismo e Abertura para Novas Experiências foram encontradas evidências fortes de validade convergente (correlações entre 0,60 e 0,80); os fatores Amabilidade e Conscienciosidade mostraram evidências menos fortes (correlações entre 0,43 e 0,48). Os valores encontrados de validade convergente dos cinco fatores estão em consonância com os apresentados na literatura internacional.
\end{abstract}

Palavras-chave: evidências de validade convergente; cinco grandes fatores de personalidade; escalas reduzidas de personalidade 


\begin{abstract}
This study was realized to obtain evidence of the convergent validity of the Reduced Scale of the Big Five Personality Factors (ER5FP). To attain this objective the scale was administered to 554 participants with ages between 16 and 69 years $(M=30.6 ; S D=8.6)$ together with the reduced version of the Big Five Inventory (IGFP-5R). Both instruments aim to measure the big five personality factors. The ER5FP consists of 20 items and the IGFP-5R has 32 items. After testing the measurement model of both instruments with Structural Equation Modeling the correlations between the five factors of the two instruments were calculated. Strong evidence of the convergent validity was found for the factors Extraversion, Neuroticism and Openness to Experience (correlations between .60 and .80). For the factors Agreeableness and Conscientiousness moderate strong evidence was found (correlations between .43 and .48). The results found in this study of the convergent validity of the five personality factors are in accordance with the results reported in the international literature.
\end{abstract}

Keywords: convergent validity; big five personality factors; reduced personality scales 
O modelo dos Cinco Grandes Fatores de Personalidade (CGF) - formado pela Extroversão, Conscienciosidade, Amabilidade, Neuroticismo e Abertura para Novas Experiências - ganhou notoriedade, ao longo do século XX. McCrae e Costa, com o desenvolvimento do NEO-PI (McCrae \& Costa, 1997) e a expansão dos estudos lexicais (De Raad \& Perugini, 2002; Hofstee, Kiers, De Raad, Goldberg \& Ostendorf, 1997) contribuíram para a sustentação do modelo e para busca de consolidação de uma linguagem comum, nos diversos contextos culturais, para a descrição da personalidade.

Se, por um lado, os estudos têm contribuído para a sustentação do modelo, por outro, o crescimento de pesquisas também acaba por identificar as suas fragilidades, o que demanda a continuidade de estudos na área (Lee, Sudom \& McCreary, 2011). Uma questão que é identificada como fragilidade consiste na conceituação das diferentes dimensões. Por exemplo, na realidade brasileira, o fator Agradabilidade pode ser encontrado como Amabilidade ou denominado de Socialização (Nunes \& Hutz, 2007). A polissemia também é observada para o fator Abertura para Experiência, que é alcunhado de Intelecto. Uma sugestão recorrente nos artigos identificados na literatura brasileira é a realização de pesquisas de validade convergente, a fim de aferir qualidade psicométrica dos instrumentos elaborados (Gomes, 2012; Hauck Filho, Machado, Teixeira \& Bandeira, 2012). Os estudos de validade convergente também cumprem o papel de contribuir para o desenvolvimento e o aperfeiçoamento do modelo teórico subjacente.

O presente artigo tem como objetivo relatar evidências de validade convergente da Escala Reduzida de Cinco Grandes Fatores de Personalidade (ER5FP). A utilização do referido procedimento na avaliação de instrumentos reduzidos tende a contribuir, em conjunto com a verificação dos coeficientes de fidedignidade dos escores, para os avanços sobre as alternativas para mensuração de personalidade. Assim, para a realização do referido estudo, foi utilizada a versão reduzida do Inventário dos Cinco Grandes Fatores 
de Personalidade (IGFP-5R). Andrade (2008) propôs essa versão com base em análises estatísticas, cuja versão final foi estruturada com itens. Inicialmente, buscou-se checar o modelo de mensuração dos dois instrumentos, a fim de verificar os valores das cargas fatoriais de cada um dos fatores, as correlações entre os itens e entre os fatores. Em seguida, buscou-se construir a matriz de correlação correspondente à integração dos fatores, a partir dos dados obtidos por meio dos dois instrumentos.

Na busca pela obtenção de instrumentos de mensuração com maiores índices de fidedignidade dos escores, pesquisadores sinalizam preocupações quanto à sua elaboração. Donnellan, Oswald, Baird e Lucas (2006) ponderam que instrumentos longos tendem a ser cansativos para os participantes e que podem produzir erros de mensuração. Afirmam, ainda, que os instrumentos reduzidos tendem a contribuir não só para a redução do tempo de realização da pesquisa como para a diminuição dos custos financeiros da pesquisa. Assim, desenvolveram um instrumento com 20 itens e verificaram a fidedignidade dos escores dos fatores em estudo com estudantes da Universidade de Michigan. Os valores encontrados variaram entre 0,65, para Abertura para Novas Experiências e 0,77 para Extroversão. Os autores também verificaram as evidências de validade convergente do instrumento reduzido com dois outros instrumentos, um com 50 itens e o outro com 120 itens, cujas evidências de validade já tinham sido aferidas com outras amostras. Os resultados encontrados indicaram correlações elevadas (entre 0,85 e 0,93) com o instrumento de 50 itens, com destaque para Extroversão, que apresentou correlação de 0,93 . Os valores que demarcam a validade convergente com o instrumento de 120 itens foram menores, mas dentro de um patamar aceitável, uma vez que variaram entre 0,52 para Amabilidade e 0,73, para Neuroticismo.

Ainda sobre os instrumentos reduzidos, Laverdiere, Diguer, Gamache e Evans (2010) utilizaram a forma reduzida desenvolvida por Donnellan, Oswald, Baird e Lucas 
(2006). Encontraram coeficientes de fidedignidade dos escores de 0,76 para Extroversão, 0,69 para Amabilidade, 0,81 para Conscienciosidade, 0,81 para Neuroticismo e 0,72 para Abertura para Novas Experiências.

Os dados encontrados nos estudos citados indicam que a Extroversão e o Neuroticismo tendem a apresentar os coeficientes de fidedignidade dos escores mais elevados, assim como, em estudos de validade convergente, constituem os fatores que apresentam as correlações mais fortes. Um outro achado importante refere-se à importância de uma base teórica consolidada para a construção de um instrumento (Donnellan, Oswald, Baird \& Lucas, 2006)

Ainda no que se refere à quantidade de itens que compõem um instrumento, há uma tendência de que, de modo geral, espera-se que um úmero maior de itens apresente um incremento no coeficiente de fidedignidade e uma redução no erro de mensuração. Essa é a visão convencional que indica a obtenção de resultados de forma efetiva (Thalmayer, Saucier \& Eigenhuis, 2011). Frazier, Naugle e Harggety (2006), ao realizar comparações entre versões curtas e longas de um instrumento de personalidade constataram que existem alguns cuidados que precisam ser tomados com medidas mais curtas, como, por exemplo, a cobertura do conteúdo por meio dos itens.

Dentre os estudos realizados no contexto brasileiro, foram identificados dois que abordaram a discussão sobre questionários com número reduzido de itens. Hauck Filho et al. (2012) desenvolveram um instrumento reduzido, com base nos adjetivos marcadores para avaliação de personalidade, desenvolvido por Hutz et al. (1998). A sua amostra foi composta de 674 estudantes universitários. A versão final foi estruturada com cinco itens para cada fator e os valores de coeficientes de fidedignidade dos escores variaram entre 0,61 e 0,80. Os autores indicam, no entanto, a necessidade de realização de outros estudos de validade convergente para melhor aferição do modelo. 
Um outro estudo foi realizado por Carvalho et al. (2012), por meio do qual os autores indicam a inadequação do Ten Item Personality Inventory (TIPI), uma medida reduzida utilizada em outros estudos internacionais (Herzberg \& Bahler, 2006). Assim como no contexto internacional, os autores não identificaram valores consideráveis dos coeficientes de fidedignidade dos escores nos fatores, nem denotaram a existência dos cinco grandes fatores de personalidade.

Ao considerar tais aspectos, faz-se necessário avançar nos estudos de evidências de validade convergente para contribuir para o debate sobre o desenvolvimento de instrumentos reduzidos para avaliação de personalidade. Assim, o objetivo geral deste estudo foi obter evidências de validade convergente da Escala Reduzida de Cinco Grandes Fatores de Personalidade (ER5FP), aplicando o ER5FP com um outro instrumento que visa mensurar os cinco fatores de personalidade, a saber, o Inventário Reduzido dos Cinco Grandes Fatores de Personalidade (IGFP-5R).

\section{Método}

\section{Participantes}

Participaram do estudo 554 estudantes distribuídos por três níveis de escolaridade: médio/técnico, graduação e pós-graduação. Possuem idade média de 30,6 anos $(\mathrm{DP}=8,61)$. As mulheres foram maioria no presente estudo, perfazendo um total de $58,9 \%$. No que se refere à escolaridade, $51,5 \%$ estão cursando ou concluíram o ensino superior.

A coleta de dados foi realizada no Distrito Federal e na Região Metropolitana de Salvador-Bahia. Ao considerar as características do Distrito Federal, por ter uma grande quantidade de moradores advindos de outros Estados, foi inserida uma pergunta no questionário sobre a região de origem dos respondentes. Assim, observa-se que a amostra 
é formada por $47,5 \%$ de participantes advindos do Centro-Oeste, $39,2 \%$ do Nordeste e $13,3 \%$ são de outras regiões do país.

Tabela 1. Dados sociodemográficos dos participantes $(\mathrm{N}=554)$

\begin{tabular}{llll}
\hline Variável & Categoria & N & $\%$ \\
\hline Sexo & Masculino & 226 & 40,8 \\
& Feminino & 324 & 58,5 \\
& Sem informação & 4 & 0,7 \\
\hline Idade & Até 20 anos & 41 & 7,4 \\
& De 21 a 25 anos & 122 & 22,0 \\
& De 26 a 30 anos & 164 & 29,6 \\
& De 31 a 35 anos & 92 & 16,6 \\
& De 36 anos em diante & 134 & 24,2 \\
& Sem informação & 1 & 0,2 \\
\hline Estado Civil & Casado & 289 & 52,2 \\
& Solteiro & 210 & 37,9 \\
& Outro & 55 & 9,9 \\
& Sem informação & 0 & 0 \\
\hline Escolaridade & Ensino Fundamental & 7 & 1,2 \\
& Ensino Médio/Técnico & 131 & 23,6 \\
& Ensino Superior & 282 & 50,4 \\
& Pós-graduação & 128 & 23,1 \\
& Sem informação & 5 & 0,9 \\
\hline Norte & 17 & 3,1 \\
\hline Região & Nordeste & 217 & 39,2 \\
& Centro-Oeste & 263 & 47,5 \\
& Sudeste & 52 & 0,9 \\
\hline$---1-50$ & 4 & \\
\hline
\end{tabular}

\section{Modelo de mensuração}

A verificação dos ajustes dos modelos das duas escalas permitiu a comparação das dimensões que as formam. Em que pese as semelhanças nas concepções dos fatores, os resultados das correlações podem indicar diferenças, em função da estrutura de cada escala. Apesar de, em geral, haver uma tendência de afirmar que instrumentos com maior número de itens contribuem para o incremento dos coeficientes de fidedignidade dos 
escores e para a redução dos erros de mensuração, a literatura já apresenta evidências de que os instrumentos reduzidos são alternativas para avaliação de personalidade (Donnellan, Oswald, Baird \& Lucas, 2006; Laverdiere et al, 2010; Rammsted, 2007).

Buscou-se, no presente estudo, a identificação das correlações entre as duas escalas construídas com base nos CGF, mas também o foco foi analisar o papel das covariáveis na descrição dos fatores que compõem a escala. Para a realização da comparação entre grupos, foram utilizadas como covariáveis o sexo, a idade, o fato de ter ou não filhos, a escolaridade e o estado civil.

A covariável sexo foi escolhida em função dos estudos já realizados e que indicam que há diferenças entre homens e mulheres no que se refere aos traços de personalidade. É o que afirmam Schmitt Realo, Voracek e Allik (2008), em seu estudo com 55 nações. Os achados indicaram que, em sociedades mais prósperas e igualitárias, os traços de personalidade de homens e mulheres tendem a ser menos similares. Um dado relevante encontrado neste estudo é que as mulheres apresentaram maiores índices de Neuroticismo em 49 nações estudadas, demonstrando ser o traço de personalidade que apresenta maior uniformidade.

O efeito da idade na definição dos traços de personalidade também tem sido abarcado em diversos estudos (Donnellan \& Lucas, 2008; Rammsted, 2007; Srivastava, John, Gosling \& Potter, 2003). Na elaboração de uma versão reduzida do Big Five Inventory - BFI, o BFI-10, Rammsted (2007) afirmou que os mais jovens tendem a apresentar maiores escores para o fator Extroversão, enquanto que os mais velhos apresentam os maiores escores nos fatores Amabilidade e Conscienciosidade.

Sobre o efeito da escolaridade, adotado aqui também como covariável para a realização das comparações de médias dos grupos, os achados nos estudos de Rammsted (2007) indicaram que pessoas com maior escolaridade tendem a apresentar escores mais 
elevados no fator Abertura para Novas Experiências. Além das covariáveis citadas anteriormente, que são as mais comumente estudadas, foram inseridas também aquelas relacionadas ao fato de ter filhos ou não e estado civil, a fim de verificar se há algum efeito de ambas na definição dos traços de personalidade.

\section{Procedimentos}

\section{Instrumentos}

Escala Reduzida de Cinco Grandes Fatores de Personalidade (ER5FP).

A ER5FP é uma escala reduzida de diferencial semântico, composta por 20 pares de adjetivos bipolares, com escalas de resposta tipo Likert de 7 pontos, que foi elaborada por Passos e Laros (2014). Apresentou coeficientes satisfatórios de fidedignidade dos escores dos fatores (Extroversão $=0,85$; Conscienciosidade $=0,78$; Amabilidade $=0,81$; Neuroticismo $=0,80$ e Abertura para Novas Experiências $=0,71)$. Esses indices de fidedignidade são compatíveis com os valores encontrados em estudos nacionais e internacionais realizados com base no modelo dos CGF. A ER5FP não foi elaborada para a comercialização, e sim, para a realização de pesquisas e para colaborar com o incentivo ao uso de instrumentos reduzidos em estudos que adotem como referencial teórico o modelo dos cinco grandes fatores de personalidade. $\mathrm{O}$ estudo para obtenção das evidências de validade da referida escala indicou um bom ajuste do modelo. 
Inventário Reduzido dos Cinco Grandes Fatores de Personalidade (IGFP-5R)

O IGFP-5R constitui um instrumento baseado no Big Five Inventory (BFI) que foi submetido a um processo de validação para a realidade brasileira por Andrade (2008). Configura-se como uma medida alternativa para avaliação de personalidade com base no modelo dos CGF. Formado originalmente por 44 itens, no processo de validação brasileira permaneceu com 32 itens, cujo padrão de resposta é tipo Likert de 5 pontos, que variam entre $1=$ discordo totalmente e $5=$ concordo totalmente. Os coeficientes de fidedignidade dos escores fatoriais, encontrados no estudo de Andrade (2008), foram considerados aceitáveis (Extroversão $=0,76$; Conscienciosidade $=0,66$; Amabilidade $=$ 0,74; Neuroticismo = 0,75; e Abertura para Novas Experiências = 0,68).

É importante destacar que o BFI já foi utilizada, no cenário internacional, por outros estudos de evidências de validade convergente, com escalas reduzidas (Donnellan Oswald, Baird \& Lucas, 2006) e os valores encontrados das correlações entre os fatores dos dois instrumentos foram fortes para Extroversão e Neuroticismo $(r=0,81$ e $r=0,80$ respectivamente), aceitáveis para Conscienciosidade e Abertura para Novas Experiências $(\mathrm{r}=0,66$ e $\mathrm{r}=0,68$ respectivamente $)$. A correlação mais baixa foi encontrada para o fator Amabilidade $(\mathrm{r}=0,49)$.

O BFI também foi adotado como escala de um estudo transcultural para verificação das diferenças entre homens e mulheres no que se refere à disposição dos traços de personalidade (Schmitt, Realo, Voracek \& Allik, 2008). Os autores incorporaram tal escala ao estudo por ser considerada uma ferramenta eficiente e rápida no processo de avaliação dos CGF.

\section{Coleta de dados}

A coleta de dados foi realizada em uma instituição pública e em duas instituições particulares. Na instituição pública, os questionários foram aplicados em alunos do nível 
técnico e da graduação. Já nas instituições privadas, a coleta de dados fora realizada com alunos da graduação e da pós-graduação. Duas das instituições escolhidas estão localizadas na região do Distrito Federal e a terceira encontra-se na Região Metropolitana de Salvador-Bahia. A escolha das referidas instituições se deu por acessibilidade às instituições nessas regiões.

Antes da aplicação, foi solicitada autorização aos dirigentes das instituições de ensino. Foram apresentados os objetivos da pesquisa, assim como o processo de aplicação do questionário. Recebida a autorização, a coleta de dados foi realizada em sala de aula. Inicialmente, os objetivos da pesquisa foram explicados e todos os estudantes inicialmente foram convidados a fazer a leitura do Termo de Consentimento Livre e Esclarecido (TCLE). Ao se disponibilizarem a participar da pesquisa, os estudantes foram solicitados a registrar a sua participação por meio da sua assinatura no referido termo. Esse momento também foi destinado ao esclarecimento de dúvidas sobre o questionário.

Após a assinatura do consentimento, foi dado o início à aplicação. Por se tratar de um questionário de autorrelato, no primeiro momento, os estudantes receberam as instruções básicas e depois foram orientados a responder individualmente. O tempo de resposta do questionário variou entre 10 e 30 minutos.

\section{Análise de dados}

Para as análises exploratórias e para as análises descritivas, foi utilizado o pacote estatístico SPPS (Statistical Package for the Social Sciences) versão 18.0. Para a verificação da normalidade univariada e multivariada, para o desenho dos modelos e para a análise fatorial confirmatória utilizou-se o software Amos 18.0 (Arbuckle, 2009). Na análise fatorial confirmatória foram seguidas as recomendações indicadas por Byrne (2005; 2010), McDonald e Ho (2002), Thompson (2004) e Weston, Gore, Chan e Catalano (2008). 
Os seguintes procedimentos de análise de dados foram utilizados:

\section{Análise exploratória dos dados.}

A fim de garantir a qualidade das análises, o banco foi revisado. Do banco de dados inicial $(\mathrm{N}=605)$ foram retiradas: (1) as pessoas que não responderam a um dos dois instrumentos de personalidade; (2) as pessoas que não informaram nenhum dos dados sociodemográficos e (3) pessoas consideradas como outliers com base da distância Mahalanobis. Como resultado da análise exploratória, 9,2\% dos casos foram excluídos, restando 554 casos válidos.

\section{Análise de pressupostos para realização da Análise Fatorial Confirmatória.}

Depois da análise exploratória, os dados foram submetidos à verificação de pressupostos para a realização da análise fatorial confirmatória. Seguindo as recomendações de Weston, Gore, Chan e Catalano (2008) primeiramente foi verificado o pressuposto de normalidade univariada através da inspeção de assimetria e curtose dos itens. O critério para considerar um item com distribuição não-normal foi assimetria superior a 1,0 e curtose superior a 2,0 (Miles \& Shevlin, 2001; Osborne, 2002). Miles \& Shevlin (2001) definem valores absolutos de assimetria e curtose acima de 2 como problemáticos. Nenhum dos itens dos dois instrumentos de personalidade mostrou nãonormalidade univariada. Em seguida, a normalidade multivariada dos itens foi verificada usando o coeficiente de curtose multivariada de Mardia (McDonald \& Ho, 2002; Brown, 2006; Schumacker \& Lomax, 2010). 


\section{Tratamento dos dados ausentes}

Uma vez que a análise fatorial confirmatória não permite a ocorrência de dados ausentes nos instrumentos analisados, os itens dos dois instrumentos que apresentaram dados ausentes foram estimados usando a técnica de linear trend at point. Esta técnica é considerada uma das melhores para lidar com dados ausentes (Tabachnick \& Fidell, 2007), porque tende a estimar os dados ausentes a partir do conjunto de dados apresentados pela variável em questão.

\section{Análise Fatorial Confirmatória.}

Foram testados os modelos de mensuração dos dois instrumentos de personalidade. Nos modelos iniciais, foram realizadas alterações baseadas nos índices de modificação (modification indexes) fornecidos no programa Amos. Os índices de modificação que indicavam um maior impacto na melhoria do ajuste sugeriram incluir uma correlação entre os termos de erro de vários itens de um mesmo fator. Byrne (2010) afirma que a inclusão de uma correlação entre os erros de dois itens no modelo significa, na maioria dos casos, que os itens são muito semelhantes em termos de conteúdo. Quando dois itens são muito semelhantes em termos de conteúdo, sugere-se excluir um dos dois, uma vez que o segundo item não acrescenta informação. Dessa forma, foi decidido excluir um dos itens (o item com menor carga fatorial) para os quais o índice de modificação sugeriu a correlação entre os erros. Na testagem dos modelos utilizou-se o método Maximum

\section{Likelihood.}

\section{Estimação da consistência interna dos escores fatoriais.}

Foi utilizado o coeficiente de lambda 2 de Guttman $\left(\lambda_{2}\right)$ para avaliação da consistência interna dos escores em cada fator. Este coeficiente foi adotado porque se mostra mais apropriado em estudos que tenham utilizado instrumento com número 
reduzido de itens para cada componente (Tellegen \& Laros, 2014; Sijtsma, 2012; Ten Berge \& Zegers, 1978).

\section{Cálculo dos coeficientes de validade brutos e corrigidos}

Foram utilizadas as correlações de Pearson para obter evidências da validade convergente dos dois instrumentos de personalidade. Para corrigir os coeficientes brutos, para o efeito de erros de mensuração, foi utilizada a fórmula de correção dupla para atenuação (Hogan, 2006; Nunnally \& Bernstein, 1994), que é a seguinte: $r_{x}^{\prime} y^{\prime}=r_{x y} \div \sqrt{ }$ $\left(r_{x x} \cdot r_{y y}\right)$. Na referida fórmula, o $r_{x}{ }^{\prime}$ é o coeficiente de validade corrigido pelo erro de mensuração tanto no teste quanto no critério, $r_{x x}$ é a fidedignidade do teste e $r_{y y}$ é a fidedignidade do critério.

\section{Resultados}

As duas escalas foram submetidas à Análise Fatorial Confirmatória - AFC, cuja condução foi realizada por meio da Modelagem por Equações Estruturais - MEE. O modelo de mensuração definido para as duas escalas previu a identificação dos CGF, inter-relacionados entre si: Extroversão, Conscienciosidade, Amabilidade, Neuroticismo e Abertura para Novas Experiências. Primeiramente serão apresentados os índices de ajuste dos modelos de mensuração iniciais e finais. Em seguida, os resultados da testagem do modelo de mensuração em nível de item serão apresentados separadamente para os dois instrumentos de personalidade. Finalmente, os coeficientes de validade entre os fatores dos dois instrumentos serão descritos.

\section{Resultados da ER5FP}

Como pode ser observado na Tabela 2, o modelo inicial da ER5FP mostrou um valor de RMSEA maior do que 0,06 e um valor de SRMR maior do que 0,08 , que não é 
considerado um ajuste satisfatório. As recomendações de Weston, Gore, Chan e Catalano (2008) sugerem o RMSEA $\leq 0,06$ e o $\mathrm{SRMR} \leq 0,08$ como critérios mínimos para garantia de qualidade no ajuste do modelo. Os valores de CFI e de GFI do modelo inicial da ER5FP também indicaram um ajuste não satisfatório, uma vez que ficaram abaixo do critério de 0,95 .

A fim de melhorar a qualidade do ajuste do modelo, foram realizadas modificações baseadas nos índices de modificação (Modification indexes), disponibilizados pelo programa Amos. Seguindo o procedimento descrito na seção de método, dos 20 itens, cinco foram retirados do modelo de mensuração inicial da ER5FP. O ajuste do modelo de mensuração final com 15 itens ficou satisfatório com um valor de RMSEA de 0,059 e um valor de SRMR de 0,054 e valores de CFI e GFI ao redor de 0,95. Assim, todos os índices de ajuste indicam que o modelo de mensuração final da ER5FP é um modelo adequado.

Tabela 2. Índices de ajuste dos modelos de mensuração iniciais e finais da Escala Reduzida de Cinco Grandes Fatores de Personalidade (ER5FP).

\begin{tabular}{lccccccc}
\hline Modelo & $\mathrm{n}$ itens & $\chi^{2}$ & $\chi^{2} / \mathrm{gl}$ & CFI & GFI & RMSEA & SRMR \\
\hline ER5FP inicial & 20 & 710,91 & 4,43 & 0,83 & 0,88 & 0,079 & 0,088 \\
ER5FP final & 15 & 233,57 & 2,92 & 0,93 & 0,95 & 0,059 & 0,054 \\
\hline
\end{tabular}

Notas. $\chi^{2}=$ qui-quadrado; $\mathrm{gl}=$ graus de liberdade; $\mathrm{CFI}=$ Comparative Fix Index $; \mathrm{GFI}=$ Goodness of Fit Index; RMSEA = Root Mean Square Error of Approximation; SRMR = Standardized Root mean Square Residual.

Na Tabela 3, são exibidas as cargas fatoriais, as comunalidades, as correlações entre os fatores da ER5FP baseados na análise com Amos e as correlações item-resto ( $\mathrm{r}_{\mathrm{ir}}$ ) dos itens, a correlação média entre os itens e os índices de consistência interna dos escores nos fatores, baseados na análise dos itens com SPSS.

Merece destaque os resultados da Tabela 3, o fato de que, mesmo com um número reduzido de itens, a consistência interna dos escores fatoriais é razoável com exceção do último fator, Abertura para Novas Experiências, que mostrou um índice de consistência 
interna de 0,58. Os índices dos demais fatores ficaram entre 0,67 e 0,79, sendo que este último valor foi apresentado pelo fator Extroversão, que também apresentou a maior correlação média entre os seus itens $(r=0,56)$.

Tabela 3. Cargas fatoriais (CF), comunalidades $\left(h^{2}\right)$ e correlações entre os fatores e índices de ajuste do modelo aos dados da ER5FP utilizando Análise Fatorial Confirmatória; correlações item-resto (rir), coeficientes de fidedignidade (lambda 2 de Guttman) e correlação média entre os itens por fator $(\mathrm{N}=554)$.

\begin{tabular}{|c|c|c|c|}
\hline Fator 1 - Extroversão - Fidedignidade $=0,79$ & CF & $\mathbf{h}^{2}$ & $\mathbf{r i r}_{\mathbf{i r}}$ \\
\hline Item 1. Extrovertido / Tímido & 0,69 & 0,48 & 0,60 \\
\hline Item 5. Comunicativo / Calado & 0,87 & 0,76 & 0,69 \\
\hline Item 6. Sociável / Reservado & 0,69 & 0,48 & 0,60 \\
\hline Média & 0,75 & 0,57 & 0,69 \\
\hline \multicolumn{4}{|l|}{ Correlação média entre os itens $=0,56$} \\
\hline Fator 2 - Conscienciosidade - Fidedignidade $=0,67$ & $\mathbf{C F}$ & $\mathbf{h}^{2}$ & $\mathbf{r i r}_{\mathbf{i r}}$ \\
\hline Item 2. Persistente / Desistente & 0,64 & 0,41 & 0,49 \\
\hline Item 10. Motivado / Desmotivado & 0,77 & 0,59 & 0,54 \\
\hline Item 12. Obstinado / Inconstante & 0,51 & 0,26 & 0,41 \\
\hline Média & 0,64 & 0,42 & 0,48 \\
\hline \multicolumn{4}{|l|}{ Correlação média entre os itens $=0,40$} \\
\hline Fator 3 - Amabilidade - Fidedignidade $=0,69$ & $\mathbf{C F}$ & $\mathbf{h}^{2}$ & $\mathbf{r}_{\mathrm{ir}}$ \\
\hline Item 4. Simpático / Antipático & 0,65 & 0,42 & 0,52 \\
\hline Item 7. Amoroso / Indiferente & 0,62 & 0,38 & 0,47 \\
\hline Item 14. Gentil / Rude & 0,70 & 0,49 & 0,53 \\
\hline Média & 0,66 & 0,43 & 0,51 \\
\hline \multicolumn{4}{|l|}{ Correlação média entre os itens $=0,43$} \\
\hline Fator 4 - Neuroticismo - Fidedignidade $=0,74$ & $\mathbf{C F}$ & $\mathbf{h}^{2}$ & rir \\
\hline Item 3. Calmo / Nervoso & 0,69 & 0,48 & 0,58 \\
\hline Item 13. Paciente / Impaciente & 0,77 & 0,59 & 0,58 \\
\hline Item 18. Tranquilo / Ansioso & 0,63 & 0,40 & 0,54 \\
\hline Média & 0,70 & 0,49 & 0,57 \\
\hline \multicolumn{4}{|l|}{ Correlação média entre os itens $=0,49$} \\
\hline Fator 5 - Abertura para experiências - Fidedignidade $=0,58$ & $\mathbf{C F}$ & $\mathbf{h}^{2}$ & $\mathbf{r}_{\mathrm{ir}}$ \\
\hline Item 8. Criativo / Prosaico & 0,57 & 0,32 & 0,42 \\
\hline Item 9. Entusiasta / Apático & 0,59 & 0,35 & 0,40 \\
\hline Item 15. Autêntico / Simulado & 0,50 & 0,25 & 0,32 \\
\hline Média & 0,55 & 0,31 & 0,38 \\
\hline Correlação média entre os itens $=0,30$ & & & \\
\hline
\end{tabular}

Correlação entre os fatores: F1-F2 = 0,40; F1-F3 = 0,25; F1-F4 = -0,02; F1-F5 = 0,47; F2-F3 = 0,63; F2$\mathrm{F} 4=-0,27 ; \mathrm{F} 2-\mathrm{F} 5=0,86 ; \mathrm{F} 3-\mathrm{F} 4=-0,26 ; \mathrm{F} 3-\mathrm{F} 5=0,66 ; \mathrm{F} 4-\mathrm{F} 5=-0,10$. 
No que se refere à correlação entre os fatores, observa-se que Abertura para Novas Experiências apresentou correlações positivas e altas com o fator Conscienciosidade $(\mathrm{r}=$ 0,86) e com o fator Amabilidade $(\mathrm{r}=0,66)$. Já o fator Neuroticismo apresentou correlação negativa com Conscienciosidade $(r=-0,27)$ e com Amabilidade $(r=-0,26)$. Os valores encontrados são corroborados pelo estudo realizado por Herzberg e Brahler (2006) sobre avaliação de instrumentos reduzidos. Os autores, ao aplicarem a 16-Adjective Measure, também encontraram correlações negativas entre Neuroticismo e Conscienciosidade $(\mathrm{r}=$ -0,09) e correlações positivas entre Abertura para Novas Experiências e Amabilidade ( $\mathrm{r}$ $=0,23)$.

$\mathrm{Na}$ Tabela 4, são apresentados os dados de média, desvio-padrão e variância da escala. Como se trata de uma escala que está em fase de avaliação da sua qualidade psicométrica foi realizada uma comparação entre as médias encontradas no estudo de construção e as encontradas no estudo de validade.

Tabela 4. Média, desvio-padrão e variância dos cinco escores fatoriais da Escala Reduzida de Cinco Grandes Fatores de Personalidade (ER5FP) no estudo de construção (N=365) e no estudo de validade convergente $(\mathrm{N}=554)$.

\begin{tabular}{llcllll}
\hline & \multicolumn{3}{c}{ Estudo de construção $(\mathrm{N}=365)$} & \multicolumn{2}{c}{ Estudo de validade $(\mathrm{N}=554)$} \\
\hline Fator & Média & DP & Variância & Média & DP & Variância \\
\hline Extroversão & 4,48 & 1,71 & 2,91 & 4,55 & 1,54 & 2,38 \\
Conscienciosidade & 5,61 & 1,12 & 1,26 & 5,34 & 1,08 & 1,17 \\
Amabilidade & 5,84 & 1,07 & 1,14 & 5,71 & 1,05 & 1,11 \\
Neuroticismo & 3,95 & 1,64 & 2,68 & 3,81 & 1,60 & 2,57 \\
Abertura & 5,33 & 1,13 & 1,27 & 5,40 & 0,96 & 0,92 \\
\hline
\end{tabular}

Nota: os escores fatoriais foram calculados com base nos mesmos três itens.

Os dados apresentados na Tabela 4 mostram que em ambos os estudos a Amabilidade foi o fator que tinha a média mais elevada, enquanto o fator Neuroticismo tinha a média mais baixa. Ainda na inspeção da Tabela 4, observa-se que, em comparação 
com o estudo de construção da ER5FP, a variância dos escores fatoriais no estudo de validade foi menor, principalmente nos fatores Abertura e Extroversão (respectivamente $28 \%$ e $18 \%$, menos variância). Este fato pode explicar o motivo pelo qual no estudo de validade os valores encontrados de fidedignidade dos fatores foram inferiores em comparação com o estudo de construção. $\mathrm{O}$ fato que no estudo de validade tinha menos variância também oferece uma explicação que apenas três itens ficaram para cada fator no modelo de mensuração em vez de quatro itens, como foi o caso no estudo de construção.

Foi feito uma análise de diferenças nos cinco escores fatoriais da ER5FP entre grupos baseados nas seguintes covariáveis: sexo (homem vs. mulher), idade, o fato de ter filhos ou não, estado civil e escolaridade. No que se refere ao sexo, observou-se que as mulheres tendem a apresentar níveis mais elevados de Neuroticismo do que os homens $\left(\mathrm{M}_{\mathrm{fem}}=3,96, \mathrm{M}_{\mathrm{masc}}=3,59, \mathrm{p}<0,01\right)$. Ao avaliar a covariável idade, foram obtidas médias mais altas pelas pessoas mais velhas nos fatores Abertura $\left(M_{1}=5,52, M_{0}=5,27, p<0,05\right) \mathrm{e}$ Amabilidade $\left(\mathrm{M}_{1}=5,79 \mathrm{M}_{0}=5,60, \mathrm{p}<0,05\right)$. Quanto ao fato de ter filhos ou não, os resultados indicam que os participantes que indicaram ter filhos tendem a serem mais extrovertidos $\left(M_{1}=4,70, M_{0}=4,42, p<0,05\right)$, mais amáveis $\left(M_{1}=5,85, M_{0}=5,59, p<0,01\right)$ e mais abertos a novas experiências $\left(\mathrm{M}_{1}=5,52, \mathrm{M}_{0}=5,30, \mathrm{p}<0,01\right)$. Por fim, apesar da diferença não ter sido elevada, os casados apresentaram maiores índices no fator Amabilidade que os solteiros $\left(\mathrm{M}_{1}=5,82, \mathrm{M}_{0}=5,60, \mathrm{p}<0,01\right)$. Na análise da ER5FP, não foram encontradas diferenças significativas para o fator escolaridade, considerando os vários níveis.

\section{Resultados da IGFP-5R}

O modelo original de mensuração do IGFP-5R também não foi satisfatório com valores de RMSEA e SRMR acima do valor critério e com valores de CFI e GFI abaixo 
do valor critério. Foram realizadas modificações baseadas nos índices de modificação (Modification indexes) para obter um bom ajuste. Foram excluídos 16 dos 32 itens do modelo de mensuração original. O ajuste do modelo de mensuração final ficou bom com um valor de RMSEA de 0,038 e um valor de SRMR de 0,043 e valores de CFI e GFI de 0,95 e 0,96 respectivamente.

Tabela 5. Índices de ajuste dos modelos de mensuração iniciais e finais do Inventário Reduzido dos Cinco Grandes Fatores de Personalidade (IGFP-5R).

\begin{tabular}{lccccccc}
\hline Modelo & $\mathrm{n}$ itens & $\chi^{2}$ & $\chi^{2 / \mathrm{gl}}$ & CFI & GFI & RMSEA & SRMR \\
IGFP-5R inicial & 32 & 1389,43 & 4,09 & 0,65 & 0,82 & 0,075 & 0,084 \\
IGFP-5R final & 16 & 169,61 & 1,80 & 0,95 & 0,96 & 0,038 & 0,043 \\
\hline
\end{tabular}

Notas. $\chi^{2}=$ qui-quadrado; $\mathrm{gl}=$ graus de liberdade; $\mathrm{CFI}=$ Comparative Fix Index $; \mathrm{GFI}=$ Goodness of Fit Index; RMSEA = Root Mean Square Error of Approximation; SRMR = Standardized Root mean Square Residual.

Na Tabela 6, são demonstradas as cargas fatoriais, as comunalidades, as correlações item-resto $\left(\mathrm{r}_{\text {ir }}\right.$ ) dos itens, os índices de consistência interna dos fatores e as correlações entre os fatores da IGFP-5R. Como pode ser observado, os dados da consistência interna dos fatores foram considerados razoáveis, uma vez que se apresentaram entre 0,65 e 0,72.

Já as correlações entre os itens de cada fator apresentaram valores compreendidos entre 0,34 e 0,46, com destaque para o fator Neuroticismo, que apresentou o maior valor. Ainda na inspeção da Tabela 6, ressalta-se a correlação positiva existente entre os fatores Amabilidade e Abertura para Novas Experiências $(r=0,33)$ e a correlação negativa entre os fatores Neuroticismo e o Conscienciosidade $(\mathrm{r}=-0,44)$. Os coeficientes de fidedignidade dos escores nos fatores corroboram com dados encontrados na literatura sobre evidências de validade de instrumentos reduzidos (Herzberg \& Bahler, 2006). 
Tabela 6. Cargas fatoriais (CF), comunalidades $\left(h^{2}\right)$, correlações entre os fatores e índices de ajuste do modelo aos dados do IGFP-5R utilizando Análise Fatorial Confirmatória; correlações item-resto (rir), coeficientes de fidedignidade (lambda 2 de Guttman) e correlação média entre os itens por fator $(\mathrm{N}=554)$.

\begin{tabular}{|c|c|c|c|}
\hline Fator 1 - Extroversão - Fidedignidade $=0,65$ & $\mathbf{C F}$ & $\mathbf{h}^{2}$ & $\mathbf{r i r}_{\mathrm{ir}}$ \\
\hline Item 12. É reservado & 0,50 & 0,25 & 0,41 \\
\hline Item 16. É, às vezes, tímido, inibido & 0,64 & 0,41 & 0,46 \\
\hline Item 42. Tende a ser quieto, calado & 0,70 & 0,49 & 0,50 \\
\hline Média & 0,61 & 0,38 & 0,46 \\
\hline \multicolumn{4}{|l|}{ Correlação média entre os itens $=0,37$} \\
\hline Fator 2 - Conscienciosidade - Fidedignidade $=0,68$ & $\mathbf{C F}$ & $\mathbf{h}^{2}$ & $\mathbf{r}_{\mathrm{ir}}$ \\
\hline Item 17. Pode ser um tanto descuidado & 0,61 & 0,37 & 0,50 \\
\hline Item 19. Tende a ser preguiçoso & 0,57 & 0,32 & 0,43 \\
\hline Item 22. É facilmente distraído & 0,57 & 0,32 & 0,44 \\
\hline Item 38. Tende a ser desorganizado & 0,61 & 0,37 & 0,47 \\
\hline Média & 0,59 & 0,35 & 0,46 \\
\hline \multicolumn{4}{|l|}{ Correlação média entre os itens $=0,34$} \\
\hline Fator 3 - Amabilidade - Fidedignidade $=0,66$ & $\mathbf{C F}$ & $\mathbf{h}^{2}$ & rir \\
\hline Item 8. Gosta de cooperar com os outros & 0,61 & 0,37 & 0,48 \\
\hline Item 15. É prestativo e ajuda os outros & 0,76 & 0,58 & 0,55 \\
\hline Item 18. É amável, tem consideração pelos outros & 0,60 & 0,36 & 0,48 \\
\hline Média & 0,66 & 0,44 & 0,50 \\
\hline \multicolumn{4}{|l|}{ Correlação média entre os itens $=0,43$} \\
\hline Fator 4 - Neuroticismo - Fidedignidade $=0,72$ & $\mathbf{C F}$ & $\mathbf{h}^{2}$ & rir \\
\hline Item 10. É temperamental, muda de humor facilmente & 0,54 & 0,29 & 0,46 \\
\hline Item 34. Fica tenso com frequência & 0,70 & $\cap 10$ & 0,55 \\
\hline Item 36. Fica nervoso facilmente & 0,80 & 0,64 & 0,61 \\
\hline Média & 0,68 & 0,47 & 0,54 \\
\hline \multicolumn{4}{|l|}{ Correlação média entre os itens $=0,46$} \\
\hline Fator 5 - Abertura para experiências - Fidedignidade $=0,67$ & CF & $\mathbf{h}^{2}$ & $\mathbf{r}_{\mathrm{ir}}$ \\
\hline Item 9. É original, tem sempre novas ideias & 0,69 & 0,48 & 0,51 \\
\hline Item 11. É inventivo, criativo & 0,81 & 0,66 & 0,57 \\
\hline Item 39. Gosta de refletir, brincar com as ideias & 0,43 & 0,18 & 0,37 \\
\hline Média & 0,64 & 0,44 & 0,48 \\
\hline
\end{tabular}

Correlação média entre os itens $=0,43$

Correlação entre os fatores: F1-F2 = 0,25; F1-F3 = 0,03*; F1-F4 = 0,18; F1-F5 = 0,11*; F2-F3 = 0,26; F2F4 = -0,44; F2-F5 = 0,19; F3-F4 = -0,23; F3-F5 = 0,33; F4-F5 = -0,12* (correlações com asterisco não são estatisticamente significativas).

Índices de ajuste: $\chi^{2}=169,61 ; \mathrm{gl}=94 ; \chi^{2} / \mathrm{gl}=1,80 ; \mathrm{TLI}=0,94 ; \mathrm{CFI}=0,95 ; \mathrm{GFI}=0,96 ; \mathrm{RMSEA}=0,038$; SRMR $=0,043$. 
A Tabela 7 demonstra os dados referentes às médias para cada fator, com seus respectivos desvios-padrão e variância. A maior média encontrada foi para Amabilidade $(M=4,48, D P=0,61)$, seguida do fator Abertura para Experiências $(M=3,90, D P=0,75)$.

Tabela 7. Média, desvio-padrão e variância dos cinco escores fatoriais do Inventário Reduzido dos Cinco Grandes Fatores de Personalidade (IGFP-5R) no estudo de validade convergente ( $\mathrm{N}=554)$.

\begin{tabular}{llll}
\hline & \multicolumn{2}{l}{ Estudo de validade $(\mathrm{N}=554)$} & \\
\hline Fator & Média & DP & Variância \\
\hline Extroversão & 2,61 & 1,01 & 1,02 \\
Conscienciosidade & 3,37 & 0,95 & 0,90 \\
Amabilidade & 4,48 & 0,61 & 0,38 \\
Neuroticismo & 2,74 & 1,13 & 1,27 \\
Abertura & 3,90 & 0,75 & 0,57 \\
\hline
\end{tabular}

Por fim, foram comparados os dados obtidos nos grupos, conforme as covariáveis sexo, idade, o fato de ter filhos ou não, estado civil e escolaridade. Os resultados revelaram maiores índices de Neuroticismo entre as mulheres do que entre os homens $\left(\mathrm{M}_{\mathrm{fem}}=2,90, \mathrm{M}_{\mathrm{masc}}=2,51, \mathrm{p}<0,01\right)$. Apesar das diferenças não terem sido grandes, as mulheres também apresentaram maiores escores no fator Amabilidade $\left(\mathrm{M}_{\mathrm{fem}}=4,53\right.$, $\left.\mathbf{M}_{\text {masc }}=4,41, \mathrm{p}<0,05\right)$. Os resultados da Tabela 7 ainda revelaram que os homens tendem a serem mais abertos a novas experiências $\left(M_{\text {fem }}=3,82, M_{\text {masc }}=4,00, p<0,05\right)$. Na avaliação das diferenças de idade, pessoas mais velhas tendem a evidenciar maiores índices nos fatores Conscienciosidade $\left(\mathrm{M}_{1}=3,48, \mathrm{M}_{0}=3,25, \mathrm{p}<0,01\right)$ e Amabilidade $\left(\mathrm{M}_{1}=4,54\right.$, $\left.\mathrm{M}_{0}=4,42, \mathrm{p}<0,05\right)$. Ainda no que se refere à idade, os dados encontrados por meio do IGFP-5R indicam que as pessoas mais jovens apresentam maiores índices no fator Neuroticismo $\left(\mathrm{M}_{1}=2,63, \mathrm{M}_{0}=2,85, \mathrm{p}<0,05\right)$. Ao avaliar diferenças nos grupos baseados na variável "ter filhos ou não", observou-se que os participantes que revelaram ter filhos apresentaram maiores médias para o fator Amabilidade $\left(\mathrm{M}_{1}=4,56, \mathrm{M}_{0}=4,42, \mathrm{p}<0,05\right)$. 
Com relação às demais categorias, estado civil e escolaridade, as médias encontradas não revelaram diferenças significativas.

\section{Evidências de validade convergente}

Na diagonal da Tabela 8, estão demonstrados os coeficientes de validade brutos e corrigidos por atenuação. Os coeficientes corrigidos podem ser interpretados como evidências de validade convergente entre a ER5FP e o IGFP5-R. Os valores no triângulo inferior e superior representam evidências da validade discriminante. Como pode ser observado, os valores dos coeficientes de validade corrigidos, apresentados na diagonal, permaneceram entre 0,43 e 0,80 . Urbina (2007) assinala que os coeficientes de validade entre 0,20 e 0,30 são os comuns e que valores maiores ou iguais a 0,40 podem ser interpretados como coeficientes satisfatórios.

Tabela 8. Coeficientes de correlação brutos e corrigidos por atenuação entre os fatores da Escala Reduzida de Cinco Grandes Fatores de Personalidade (ER5FP) e os fatores do Inventário de Cinco Grandes Fatores de Personalidade (IGFP-5R) [N=554].

Correlações corrigidas por atenuação e correlações brutas

\begin{tabular}{|c|c|c|c|c|c|}
\hline & Ex1 & $\mathrm{Ne} 1$ & $\mathrm{Ab} 1$ & Co1 & Am1 \\
\hline Ex2 & $0,80(0,57)$ & $-0,10(-0,07)$ & $-0,23(-0,14)$ & $-0,20(-0,13)$ & $-0,02(-0,01)$ \\
\hline $\mathrm{Ne} 2$ & $-0,07(-0,05)$ & $0,60(0,44)$ & $-0,17(-0,11)$ & $-0,39(-0,27)$ & $-0,28(-0,20)$ \\
\hline $\mathrm{Ab} 2$ & $0,27(0,20)$ & $-0,09(-0,06)$ & $0,74(0,46)$ & $0,42(0,28)$ & $0,29(0,20)$ \\
\hline $\mathrm{Co} 2$ & $0,11(0,08)$ & $-0,13(-0,09)$ & $0,35(0,21)$ & $0,43(0,29)$ & $0,24(0,15)$ \\
\hline Am2 & $0,22(0,16)$ & $-0,10(-0,07)$ & $0,39(0,25)$ & $0,31(0,21)$ & $0,48(0,33)$ \\
\hline
\end{tabular}

Notas: Ex1 = Fator Extroversão da ER5FP; Ne1 = Fator Neuroticismo da ER5FP; Ab1 = Fator Abertura da ER5FP; Co1 = Fator Conscienciosidade da ER5FP; Am1 = Fator Amabilidade da ER5FP; Ex2 = Fator Extroversão do IGFP5-R; Ne2 = Fator Neuroticismo do IGFP5-R; Ab2 = Fator Abertura do IGFP5-R; $\mathrm{Co} 2$ = Fator Conscienciosidade do IGFP5-R; Am2 = Fator Amabilidade do IGFP5-R. Os primeiros valores são os coeficientes corrigidos por atenuação e os valores entre parênteses são os coeficientes brutos. Os valores negritos no diagonal são os coeficientes de validade da ER5FP e do IGFP-5R

O maior coeficiente de validade convergente foi encontrado para o fator Extroversão e o menor coeficiente de validade convergente foi apresentado pelo fator Conscienciosidade. Ainda na inspeção da Tabela 8, são observadas as correlações entre 
diferentes fatores que merecem atenção, como, por exemplo, entre Abertura para Novas Experiências (IGFP-5R) e Conscienciosidade (ER5FP), que apresentou $r=0,42$, e entre Abertura para Novas Experiências (ER5FP) e Amabilidade (IGFP5-R), cuja correlação foi de $r=0,39$.

$\mathrm{O}$ achado que o fator Extroversão mostrou maior coeficiente de validade convergente está relacionado que este fator tende a ser identificado em diversas culturas conforme indicado por Yamagata et al (2006). Os fatores Abertura para Novas Experiências e Neuroticismo apresentaram um coeficiente de validade convergente de respectivamente 0,74 e 0,60 . Estes dois últimos fatores também geralmente são identificados em outras culturas.

\section{Discussão}

O objetivo do presente estudo foi verificar as evidências de validade convergente do ER5FP, utilizando o IGFP-5. Este estudo também se propôs a analisar os efeitos das variáveis sociodemográficas - sexo, idade, estado civil, ter ou não filhos, escolaridade na avaliação da personalidade. O modelo dos CGF, abordagem que fundamenta o presente estudo, foi colocado como base para a estruturação do modelo de mensuração. Foi considerada a existência dos cinco fatores inter-relacionados entre si: Extroversão, Conscienciosidade, Amabilidade, Neuroticismo e Abertura para Novas Experiências. A versão inicial do modelo de mensuração não apresentou um bom ajuste, conforme critérios sugeridos por Weston, Gore, Chan e Catalano (2008). Assim, foi realizada a análise dos Modification Indexes a fim de tomar decisões quanto à modificação do modelo proposto em um primeiro momento. O modelo final do ER5FP ficou com 15 itens e o do IGFP-5R ficou com 16 itens. 
As duas escalas apresentaram boa qualidade psicométrica e os dados de consistência interna demonstraram adequação para cada um dos fatores, tendo variado entre 0,58 (Abertura para Experiências) e 0,79 (Extroversão) na ER5FP. Já na análise dos dados do IGFP-5R, os índices de consistência interna variaram entre 0,65 (Extroversão) e 0,72 (Neuroticismo). Os dados encontrados foram semelhantes aos identificados na literatura, ao estudarem instrumentos reduzidos (Donnellan et al, 2006; Laverdiere et al, 2010).

A Extroversão e o Neuroticismo apresentaram os maiores índices de consistência interna e de correlação entre os seus itens, para o ER5FP e IGFP-5R respectivamente. Este fato pode ser decorrente da qualidade e da clareza da definição dos fatores em questão, o que pode ter permitido maior cobertura do conteúdo de cada fator por meio dos pares de adjetivos opostos (Frazier, Naugle \& Harggety, 2006). Já as altas correlações entre os fatores, tanto para a ER5FP como para o IGFP-5R, podem representar, como sinaliza Hauck Filho et al (2012), a estruturação de um modelo hierárquico para o instrumento, apresentando uma perspectiva oblíqua.

As médias da ER5FP, identificadas no estudo de construção e no estudo atual, se assemelham aos dados encontrados por Donnellan et al (2006). Os dados para dois fatores, Conscienciosidade e Abertura para Novas Experiências, se aproximam dos resultados apresentados pelos autores na análise dos dados do TIPI (Ten Item Personality Inventory), uma escala, assim como a ER5FP, de 7 pontos. Apresentou, para Conscienciosidade $\mathrm{M}=5,55(\mathrm{DP}=1,17)$ e para Abertura a $\mathrm{M}=5,51(\mathrm{DP}=1,07)$.

Na comparação entre grupos, semelhanças foram encontradas para os dados obtidos pelas duas escalas. Ao comparar os homens com as mulheres, nas duas escalas as mulheres apresentaram maiores índices para o fator Neuroticismo. Apesar de terem apresentado médias compatíveis para o fator Amabilidade, por meio dos quais as 
mulheres demonstraram ser mais amáveis que os homens, os dados só foram significativos para a IGFP-5R. No que se refere ao fato de ter ou não filhos, os dados apresentam congruência entre as duas escalas para três fatores: Amabilidade, Abertura para Experiências e Extroversão. No entanto, apenas o fator Amabilidade apresentou dados significativos para as duas escalas, denotando que pessoas que têm filhos tendem a ser mais amáveis. Já a covariável idade revela diferenças significativas para o fator Amabilidade para as duas escalas, indicando que os mais velhos tendem a ser mais amáveis. O estudo ainda indicou que as pessoas mais velhas apresentaram valores mais elevados para o fator Abertura para Experiências por meio do IGFP-5R. Não foram identificadas diferenças significativas por meio da ER5FP.

A Conscienciosidade também merece destaque na análise por meio da idade. Os dados indicam que as pessoas mais velhas tendem a ser mais realizadoras. No entanto, os dados encontrados por meio da escala ER5FP apresentaram $\mathrm{p}<0,07$, o que demandaria investigações futuras para aferição dos referidos dados. Esses achados foram semelhantes aos identificados por Donnellan e Lucas (2008) em estudo realizado com Alemães e Ingleses. Os autores, assim como Terraciano, McCrae, Brant e Costa (2005), identificaram em seus estudos um padrão curvilíneo, denotando que há uma semelhança entre as médias apresentadas pelos adolescentes e pelos mais velhos, acima de 60 anos. Segundo os autores, as médias desses grupos de idade tendem a ser mais baixas do que as evidenciadas por participantes entre 20 e 50 anos. No presente estudo, apesar de não ter sido possível identificar o padrão curvilíneo, como se trata de um fator que avalia a capacidade de realização, a população economicamente ativa tende a apresentar médias mais elevadas para o mesmo. Sobre esse aspecto, ainda podem ser feitas duas considerações. A primeira é que o estudo não apresentou uma variabilidade significativa para a construção de um padrão curvilíneo. A segunda é que esta diferença mínima entre 
as faixas etárias reflete a extensão da população economicamente ativa no Brasil, que demanda a inserção de pessoas cada vez mais jovens no mercado de trabalho.

No que se refere aos dados de evidências de validade convergente entre as duas escalas, denotando o cumprimento dos objetivos na mensuração dos fatores de personalidade. Este dado, atrelado aos índices de consistência interna identificados, sugere que o diferencial semântico também pode ser uma alternativa para avaliação de personalidade.

O estudo em questão apresentou limitações na execução. A primeira delas referese à amostra. Por ter sido realizado basicamente no Distrito Federal e na Região Metropolitana de Salvador-Bahia, o estudo não apresentou uma amostra representativa de toda a população. Além disso, como a coleta de dados foi realizada em instituições de ensino pública e privada, houve pouca variabilidade no padrão de resposta, o que não é o mais recomendável em estudos que buscam avaliar qualidade psicométrica dos instrumentos.

Uma outra limitação refere-se à discriminação dos itens. A correlação alta e positiva entre Conscienciosidade e Abertura para Experiências, nos dados apresentados pela ER5FP, pode indicar pouca discriminação destes dois fatores. Nesse sentido, mesmo trabalhando com a hipótese de estrutura oblíqua, em que os fatores encontram-se interrelacionados entre si, espera-se que as correlações sejam menores.

Depois de realizar modificações no modelo original, segundo Byrne (2010), o pesquisador deixa de trabalhar no modo confirmatório e começa a trabalhar no modo exploratório. Assim, os resultados obtidos neste estudo, com a análise dos modelos de mensuração usando MEE, precisam ser confirmados em outros estudos futuros. Como agenda de pesquisa, sugere-se que o estudo possa ser realizado com amostras representativas, de modo a abranger todo o território nacional. 
Por fim, conclui-se que investigar a validade convergente para análise de instrumento em construção se mostrou eficaz e necessária, principalmente no que se refere à mensuração de um mesmo construto. Assim, os avanços nos estudos sobre o modelo dos CGF, assim como sobre os seus modelos de mensuração, podem contribuir para a ampliação da intensificação das pesquisas sobre a relação entre personalidade e questões relacionadas ao contexto social. 


\section{Referências}

Andrade, J. M. (2008). Evidências de validade do inventário dos cinco grandes fatores de personalidade para o Brasil. Tese de Doutorado, Universidade de Brasília, Brasília.

Arbuckle, J. L. (2009). Amos ${ }^{\mathrm{TM}} 18$ User's Guide. Chicago, IL: SPSS Inc.

Byrne, B. M. (2010). Structural Equation Modeling with AMOS: Basic concepts, applications and programming. New York: Routledge, Taylor \& Francis.

Carvalho, L. de F., Nunes, M. F. O., Primi, R., \& Nunes, C. H. S. da S. (2012). Evidências desfavoráveis para avaliação da personalidade com um instrumento de 10 itens. Paidéia, 22, 63-71.

De Raad, B., \& Perugini, M. (2002). Big five assessment: Introduction. In B. De Raad \& M. Perugini (Eds.), Big five assessment (pp.1-26). Germany: Hogrefe \& Huber Publishers.

Donnellan, M. B., \& Lucas, R. E. (2008). Age differences in the Big Five across the life span: Evidence from two national samples. Psychology and Aging, 23, 558-562.

Donnellan, M. B., Oswald, F. L., Baird, B. M., \& Lucas, R. E. (2006). The Mini-IPIP scales: Tiny-yet-effective measures of the big five factors of personality. Psychological Assessment, 18, 192-203.

Frazier, T., Naugle, R., \& Haggerty, K. A. (2006). Psychometric adequacy and comparability of the short and full forms of the Personality Assessment Inventory. Psychological Assessment, 18(3), 324-333.

Hauck Filho, N., Machado, W. de L., Teixeira, M. A. P., \& Bandeira, D. R. (2012). Evidências de validade de marcadores reduzidos para a avaliação da personalidade no modelo dos cinco grandes fatores. Psicologia: Teoria e Pesquisa, 28, 417-423.

Herzberg, P., \& Brähler, E. (2006). Assessing the big-five personality domains via short forms: A cautionary note and a proposal. European Journal of Psychological Assessment, 22(3), 139-148.

Hofstee, W., Kiers, H., De Raad, B., Goldberg, L., \& Ostendorf, F. (1997). A comparison of big-five structures of personality traits in Dutch, English, and German. European Journal of Personality, 11(1), 15-31. 
Hogan, T. P. (2006). Introdução à Prática de Testes Psicológicos. Rio de Janeiro: LTC.

Hutz, C.S., Nunes, C., Silveira, A. D., Serra, J., Anton, M., \& Wieczorek, L. (1998). O desenvolvimento de marcadores para a avaliação da personalidade no modelo dos cinco grandes fatores. Psicologia: Reflexão e Crítica, 11, 395-411.

Laverdiere, O., Diguer, L., Gamache, D., \& Evans, D. (2010). The French adaptation of the short form of the Adult Temperament Questionnaire. European Journal of Psychological Assessment, 26, 212-219.

Lee, J. E. C., Sudom, K. A., \& McCreary, D. R. (2011). Higher-order model of resilience in the Canadian Forces. Canadian Journal of Behavioral Science, 43, 222-234.

McCrae, R. (2009). The five-factor model of personality traits: Consensus and controversy. In P. Corr \& G. Matthews (Eds.), The Cambridge handbook of personality psychology (pp. 148-161). New York: Cambridge University Press.

McCrae, R. R., \& Costa, P. (1997). Personality trait structure as a human universal. American Psychologist, 52, 509-516.

McDonald, R. P., \& Ho, M. R. (2002). Principles and practice in reporting structural equation analyses. Psychological Methods, 7, 64-82.

Miles, J., \& Shevlin, M. (2001). Applying regression \& correlation. A guide for students and researchers. London: Sage Publications.

Nunes, C. H. S., \& Hutz, C. S. (2007). Escala Fatorial de Socialização. São Paulo: Casa do Psicólogo.

Nunes, C. H. S., Hutz, C. S., \& Nunes, M. (2010). Bateria Fatorial de Personalidade (BFP): Manual Técnico. São Paulo: Casa do Psicólogo.

Nunnally, J. C., \& Bernstein, I. H. (1994). Psychometric Theory (3rd ed.). New York: McGraw-Hill.

O'Connor, B. P. (2000). SPSS and SAS programs for determining the number of components using parallel analysis and Velicer's MAP test. Behavior Research Methods, Instrumentation, and Computers, 32, 396-402.

Rammstedt, B. (2007). The 10-item Big Five Inventory: Norm values and investigation of sociodemographic effects based on a German population representative sample. European Journal of Psychological Assessment 23(3), 193-201. 
Schmitt, D., Realo, A., Voracek, M., \& Allik, J. (2008). Why can't man be more like a woman? Sex differences in big five personality traits across 55 cultures. Journal of Personality and Social Psychology, 94, 168-172.

Sijtsma, K. (2012). Future of psychometrics: Ask what psychometrics can do for psychology. Psychometrika, 77, 4-20.

Srivastava, S., John, O. Gosling, S., \& Potter, J. (2003). Development of personality in early and middle adulthood: Set like plaster or persistent change? Journal of Personality and Social Psychology, 84(5), 1041-1053.

Tabachnick, B. G., \& Fidell, L. S. (2007). Using multivariate statistics. Boston: Allyn \& Bacon (5 $\left.5^{\mathrm{a}} \mathrm{Ed}.\right)$.

Tellegen, P. J., \& Laros J. A. (2014). SON-R 6-40. Snijders-Oomen Non-verbal intelligence test. Volume I: Research report. Hogrefe: Göttingen, Germany.

Ten Berge, J. M. F., \& Zegers, F. E. (1978). A series of lower bounds to the reliability of a test. Psychometrika, 43, 575-579.

Terraciano, A., McCrae, R. R., Brant, L. J., \& Costa, P. T., Jr. (2005). Hierarchical linear modeling analyses of the NEO-PI-R scales in the Baltimore longitudinal study of aging. Psychology and Aging, 20, 493-506.

Thalmayer, A. G., Saucier, G., \& Eigenhuis, A. (2011). Comparative validity of brief to medium-length big five and big six personality questionnaires. Psychological Assessment, 23, 995-1009.

Thompson, B. (2004). Exploratory and confirmatory factor analysis: Understanding concepts and applications. Washington, DC: American Psychological Association.

Urbina, S. (2007). Fundamentos da testagem psicológica. Porto Alegre: Artmed.

Weston, R., \& Gore, P. A., Chan, F., \& Catalano, D. (2008). An introduction to using structural equation models in rehabilitation psychology. Rehabilitation Psychology, $53,340-356$.

Yamagata, S., Suzuki, A., Ando, J., Ono, Y., Kijima, N., Yoshimura, K., Ostendorf, F., Angleitner, A., Riemann, R., Spinath, F. M., Livesley, W. J., \& Jang, K. L. (2006). Is the genetic structure of human personality universal? A cross-cultural twin study from 
North America, Europe and Asia. Journal of Personality and Social Psychology, 90, 987-998. 


\section{Considerações finais}

A presente tese se propôs a investigar o modelo dos CGF, a partir da construção de uma escala reduzida de diferencial semântico. No manuscrito 1, ao realizar a análise das publicações nacionais e internacionais, apresentou um panorama geral da discussão sobre a sustentação do modelo. A grande concentração de pesquisas foi observada no campo da avaliação psicológica, focada na construção de instrumentos, o que evidencia, uma preocupação, por parte dos pesquisadores, de verificar a consistência do modelo e a existência dos cinco fatores em culturas com características diferentes.

Apesar de identificarem, em sua maioria a presença dos cinco grandes fatores, ainda não há consenso entre os autores sobre a quantidade de fatores que se sustentam e que são considerados universais. Essa discussão é endossada por Lee e Ashton (2007), que indica a existência de seis fatores e De Raad (2009), que sinaliza a presença de três fatores que são amplamente localizados nas diversas culturas, que são a Extroversão, o Neuroticismo e a Abertura para Experiências. No entanto, Hendriks et al (2003) refutam esta perspectiva, ao afirmarem, a partir dos dados obtidos por meio de um estudo transcultural realizado em 13 países, que a Extroversão, junto com a Amabilidade, tende a ser mais sensível aos efeitos culturais.

Um dado identificado por meio da análise dos estudos diz respeito à aplicabilidade do modelo. A personalidade, construto considerado base para a compreensão da Psicologia, vem sendo cada vez mais estudada a partir da interlocução com outros construtos. Tal questão pode ser ilustrada com os estudos que se dedicaram a investigar o bem-estar (Dessen \& Paz, 2010) e preferência musical (Chamorro-Premuzic et al, 2009). Este dado revela que, em que pese as discordâncias no que se refere à quantidade de fatores, o modelo fatorial acaba por facilitar os processos de investigação e permitir a ampliação dos estudos de personalidade. 
Tomando como base a principal área de investigação do modelo dos CGF, a avaliação psicológica, o segundo manuscrito, de cunho mais técnico, apresentou as etapas de elaboração de uma escala que apresentou duas características: ser reduzida e ser construída com base na técnica de diferencial semântico. As etapas foram constituídas de modo a demarcar a importância de cada uma dela para aferir a qualidade da escala.

O terceiro manuscrito abordou o processo de construção da ER5FP, tendo testado três modelos e realizado a análise da sua estrutura fatorial interna. $\mathrm{O}$ instrumento final que apresentou melhor ajuste e os melhores dados de fidedignidade dos escores foi o estruturado com 20 itens. Além disso, o diferencial semântico também demonstrou ser uma técnica eficaz para avaliação de personalidade, por ser prática e de fácil entendimento. Faz-se, no entanto a ressalva de que ainda é necessário realizar outros estudos para aferir a sustentação do modelo.

Os resultados apresentados no manuscrito 3 foram semelhantes aos relatos de Hauck Filho et al (2012) e se apresentaram de modo diferente dos dados encontrados por Carvalho et al (2012). Estes dois estudos foram tomados como parâmetro por serem as duas investigações mais recentes, realizadas no contexto brasileiro. As semelhanças e diferenças encontradas, a partir da comparação com os dois estudos em questão, são justificadas em função do número de itens de cada um dos instrumentos elaborados. Hauck Filho et al (2012) elaboraram um instrumento com 25 itens, também formados por adjetivos, enquanto Carvalho et al (2012) analisaram a estrutura fatorial de um instrumento com 10 itens (TIPI), por meio do qual identificaram três fatores, ao invés de cinco. Os autores sugeriram a ampliação do número de itens para 20, com a hipótese de melhoria da qualidade psicométrica e o estudo de evidências de validade convergente com instrumentos que se propõem a avaliar o modelo dos CGF. 
Nessa perspectiva, foi elaborado o quarto manuscrito, que buscou investigar as evidências de validade convergente entre a ER5FP e o IGFP-5R. Após a avaliação inicial, os modelos que apresentaram melhor índices de ajustes apresentaram 15 itens para a ER5FP e 16 itens para o IGFP-5R. Os dados evidenciaram correlações positivas entre os dois instrumentos, com destaque para Extroversão e Abertura para Experiências. No entanto, a amostra em questão apresentou pouca variabilidade para avaliação de uma escala, mesmo tendo sido com participantes com três níveis de escolaridade diferenciados (médio/técnico, graduação e pós-graduação)

Além das evidências de validade convergente identificadas entre as duas escalas, outro aspecto importante refere-se à congruência entre as comparações de grupos. As duas escalas demonstraram que as mulheres tendem a apresentar maiores valores médios para o fator Neuroticismo, e que as pessoas mais velhas e que têm filhos tendem a serem mais amáveis.

\section{Limitações}

São identificadas como limitações o tamanho e a abrangência da amostra. Apesar da qualidade dos dados encontrados para a validade e fidedignidade dos escores, para garantir que a referida escala possa ser utilizada de modo a ampliar os estudos sobre personalidade, é necessário que os dados tenham abrangência nacional. No caso em questão, as amostras foram advindas apenas de duas regiões, e mesmo assim com estudantes universitários, o que interfere na variabilidade de resposta.

Como se trata de um instrumento construído com pares de adjetivos opostos, sugere-se a verificação do fator "Abertura para Experiências", uma vez que o valor de fidedignidade dos escores foi considerado dentro do limite do aceitável. Sugere-se rever, de modo mais específico, um dos seus pares, o Criativo / Prosaico, a fim de verificar se é de fácil entendimento para os respondentes. Os juízes já haviam sinalizado uma possível 
dificuldade por parte dos respondentes e as cargas fatoriais $(\mathrm{CF}=0,69$ no primeiro estudo e $\mathrm{CF}=0,57$ no segundo estudo) evidenciam que trata-se de um par que precisa continuar a ser averiguado. Uma indicação seria localizar um adjetivo oposto para o termo Criativo, em substituição ao adjetivo Prosaico.

\section{Agenda de pesquisa}

Mesmo considerando a qualidade dos dados obtidos, relata-se a necessidade de ampliar estudos de modo a aprofundar a investigação sobre a qualidade do modelo obtido nesta tese. Ao considerar que o instrumento reduzido pode ser uma alternativa a ser adotada na realização de pesquisas que tenham como construto a personalidade e em contextos profissionais que demandem a tomada de decisão, o estudo com outras amostras com diferentes idades e perfis serão uteis para aferição do modelo.

Ao reconhecer a funcionalidade dos instrumentos reduzidos para a realização de pesquisas cujo modelo insere a personalidade como variável mediadora, sugere-se que, após a aferição do modelo, a ER5FP seja utilizada em pesquisas desta natureza. Nesse sentido, sugere-se também que a técnica do diferencial semântico possa ser amplamente testada, a fim de aferir se o fácil entendimento que a referida técnica tende a proporcionar se legitima em estudos que envolvem testes de hipóteses.

Ainda como agenda de pesquisa, sugere-se a realização, no Brasil, de estudos multimétodos para avançar na adoção de outras estratégias metodológicas na investigação não só do modelo dos Cinco Grandes Fatores de Personalidade como também da qualidade dos instrumentos construídos. A utilização de entrevistas e grupos focais se constituem como caminhos possíveis que podem vir a contribuir para a sofisticação do modelo. Assim, adotar estudos multimétodos pode contribuir para a construção de outras alternativas para avaliação do modelo fatorial de personalidade, uma vez que a tradição se sustenta por meio de estudos que se baseiam na utilização de escalas, tanto para 
mensuração do modelo dos CGF como para a realização de interlocução com outras variáveis.

Ainda para a realidade brasileira, sugere-se a realização de estudos longitudinais para avaliação da personalidade com base no modelo dos CGF. Os estudos longitudinais podem contribuir para a investigação do modelo oblíquo, que, como indicado anteriormente, prevê a existência de fatores inter-relacionados entre si. Além disso serão fundamentais para a investigação da estabilidade e plasticidade dos traços de personalidade e para o seu entendimento, como uma esfera ampla de estudo da Psicologia e como construto que se dedica a compreender as características das pessoas e sua inserção nos diversos contextos sociais. 


\section{Referências gerais}

Barenaum, N., \& Winter, D. G. (2009). History of modern personality theory and research. In O. P. John, R. W. Robins, \& L. A. Pervin (Eds.), Handbook of personality: Theory and research (pp.3-28). 3th edition. New York: The Guilford Press.

Buss, D. M. (2008). Human nature and individual differences: Evolution of human personality. In O. P. John, R. W. Robins, \& L. A. Pervin (Eds.), Handbook of personality: Theory and research (pp. 29-60). New York: The Guilford Press.

Chamorro-Premuzic, T., Goma-i-Freixanet, M., Furnham, A., \& Muro, A. (2009). Personality, self-estimated intelligence and uses of music: A Spanish replication and extension using structural equation modeling. Psychology of Aesthetics, Creativity and the Arts, 3, 149-155.

Cloninger, S. (2009). Conceptual issues in personality theory. In P. Corr \& G. Matthews (Eds.), The Cambridge handbook of personality psychology (pp. 3-26). New York: Cambridge University Press.

De Raad, B. (2009). Structural models of personality. In P. Corr \& G. Matthews (Eds.), The Cambridge handbook of personality psychology (pp. 127-147). New York: Cambridge University Press.

Dessen, M. C., \& Paz, M. G. T. (2010). Bem-estar pessoal nas organizações: o impacto de configurações de poder e características de personalidade. Psicologia: Teoria e Pesquisa. 26(3), 549-556.

Gomes, C., Gouveia, V., Silva Junior, N. A., Coutinho, M. \& Santos, L. C. (2013). Escolha do(a) parceiro(a) ideal por heterossexuais: são seus valores e traços de personalidade uma explicação? Psicologia: Reflexão e Crítica, 26(1), 29-37.

Hendriks, J., Perugini, M., Angleitner, A., Ostendorf, F., Johnson, J., Fruyt, F., Hrebickova, M., Kreitler, S., Murakami, T., Bratko, D., Conner, M., Nagy, J. Rodriguez-Fornells, A., \& Ruisel, I. (2003). The five-factor personality inventory: cross-cultural generalizability across 13 countries. European Journal of Personality, $17,347-373$. 
Jenkins-Guarnieri, M. Wright, S., \& Johnson, B. (2013). The interrelationships among attachment style, personality traits, interpersonal competency, and facebook use. Psychology of Popular Media Culture, 2, 117-131.

John, O. P., Naumann, L. P., \& Soto, C. J. (2008). Paradigm shift to the integrative big five trait taxonomy: History, measurement, and conceptual issues. In O. P. John, R. W. Robins \& L. A. Pervin (Eds.), Handbook of personality: Theory and research (pp.114-158). New York: The Guilford Press.

Lee, K., \& Ashton, M. (2007). Factor analysis in personality research. In R.W. Robins, R.C. Fraley, \& R.F. Kruger (Eds.), Handbook of research methods in personality psychology (pp. 429-443). New York: Guilford Press.

McCrae, R. (2009). The five-factor model of personality traits: Consensus and controversy. In P. Corr \& G. Matthews (Eds.), The Cambridge handbook of personality psychology (pp. 148-161). New York: Cambridge University Press..

Nunes, C. H. S. S., Nunes, M. F. O., Cunha, T. F. C., \& Hutz, C. S. (2009). Chemical dependence and personality. Revista Interamericana de Psicología. 43(1), 68-76. 


\section{ANEXO 1}

\section{Anexos}

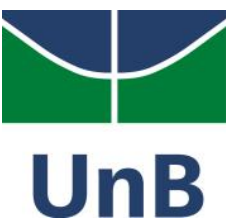

Car@ Participante

Convido você a responder esta pesquisa, que busca identificar o grau de compreensão que você tem a respeito de cada palavra abaixo e o quanto cada uma te descreve. O referido estudo está vinculado ao Laboratório de Métodos e Técnicas de Avaliação Psicológica - META, coordenado pelo prof. Dr. Jacob Laros, que é professor do Instituto de Psicologia do Programa de Pós-Graduação em Psicologia Social, do Trabalho e das Organizações - PSTO, da Universidade de Brasília-UnB.

Informo, desde já, que os dados aqui coletados serão utilizados somente para fins de pesquisa e que, em momento algum, sua identidade será revelada.

Caso se disponibilize a participar, favor marcar um X:

( ) Concordo em participar da pesquisa

( )Não concordo em participar da pesquisa.

Agradeço a sua participação.

Fabiana Damásio

Como você pode observar, logo abaixo há uma lista de adjetivos. A sua tarefa será analisar cada um deles e responder as seguintes perguntas:

Você sabe o significado da palavra?

Essa palavra descreve o seu modo de ser? Para esta pergunta, utilize a seguinte escala:

$1=$ Não descreve

$2=$ Descreve muito pouco

$3=$ Descreve em parte

$4=$ Descreve muito

$5=$ Descreve plenamente

Tente responder da forma mais rápida possível e, caso você não saiba o significado da palavra, você deverá deixar em branco a segunda pergunta.

\begin{tabular}{|l|l|lllll|}
\hline Adjetivos & Você sabe o significado da palavra? & \multicolumn{5}{|l|}{ Essa palavra te descreve? } \\
\hline Aberto & ( ) Sim ( ) Não & 1 & 2 & 3 & 4 & 5 \\
\hline Acessível & ( ) Sim ( ) Não & 1 & 2 & 3 & 4 & 5 \\
\hline Acomodado & ( ) Sim ( ) Não & 1 & 2 & 3 & 4 & 5 \\
\hline Acrítico & ( ) Sim ( ) Não & 1 & 2 & 3 & 4 & 5 \\
\hline Afetivo & ( ) Sim ( ) Não & 1 & 2 & 3 & 4 & 5 \\
\hline Ágil & ( ) Sim ( ) Não & 1 & 2 & 3 & 4 & 5 \\
\hline Agitador & ( ) Sim ( ) Não & 1 & 2 & 3 & 4 & 5 \\
\hline Agressivo & ( ) Sim ( ) Não & 1 & 2 & 3 & 4 & 5 \\
\hline Alegre & ( ) Sim ( ) Não & 1 & 2 & 3 & 4 & 5 \\
\hline Alienado & ( ) Sim ( ) Não & 1 & 2 & 3 & 4 & 5 \\
\hline Altivo & ( ) Sim ( ) Não & 1 & 2 & 3 & 4 & 5 \\
\hline Altruísta & ( ) Sim ( ) Não & 1 & 2 & 3 & 4 & 5 \\
\hline Ambicioso & ( ) Sim ( ) Não & & 1 & 5 \\
\hline
\end{tabular}




\begin{tabular}{|c|c|c|c|c|c|c|c|}
\hline Amigável & ( ) Sim ( & ) Não & 1 & 2 & 3 & 4 & 5 \\
\hline Amistoso & ( ) Sim ( & ) Não & 1 & 2 & 3 & 4 & 5 \\
\hline Amoroso & ( ) Sim ( & ) Não & 1 & 2 & 3 & 4 & 5 \\
\hline Ansioso & ( ) Sim ( & ) Não & 1 & 2 & 3 & 4 & 5 \\
\hline Antipático & ( ) Sim ( & ) Não & 1 & 2 & 3 & 4 & 5 \\
\hline Assertivo & ( ) Sim ( & ) Não & 1 & 2 & 3 & 4 & 5 \\
\hline Atencioso & ( ) Sim ( & ) Não & 1 & 2 & 3 & 4 & 5 \\
\hline Ativo & ( ) Sim ( & ) Não & 1 & 2 & 3 & 4 & 5 \\
\hline Autêntico & ( ) $\operatorname{Sim}($ & ) Não & 1 & 2 & 3 & 4 & 5 \\
\hline Auto-suficiente & ( ) Sim ( & ) Não & 1 & 2 & 3 & 4 & 5 \\
\hline Aventureiro & ( ) Sim ( & ) Não & 1 & 2 & 3 & 4 & 5 \\
\hline Benevolente & ( ) $\operatorname{Sim}($ & ) Não & 1 & 2 & 3 & 4 & 5 \\
\hline Calmo & ( ) Sim ( & ) Não & 1 & 2 & 3 & 4 & 5 \\
\hline Caprichoso & ( ) Sim ( & ) Não & 1 & 2 & 3 & 4 & 5 \\
\hline Carinhoso & ( ) $\operatorname{Sim}($ & ) Não & 1 & 2 & 3 & 4 & 5 \\
\hline Categórico & ( ) Sim ( & ) Não & 1 & 2 & 3 & 4 & 5 \\
\hline Cauteloso & ( ) Sim ( & ) Não & 1 & 2 & 3 & 4 & 5 \\
\hline Competitivo & ( ) $\operatorname{Sim}($ & ) Não & 1 & 2 & 3 & 4 & 5 \\
\hline Comportado & ( ) $\operatorname{Sim}($ & ) Não & 1 & 2 & 3 & 4 & 5 \\
\hline Comunicativo & ( ) $\operatorname{Sim}($ & ) Não & 1 & 2 & 3 & 4 & 5 \\
\hline Confiável & ( ) Sim ( & ) Não & 1 & 2 & 3 & 4 & 5 \\
\hline Conformado & ( ) $\operatorname{Sim}($ & ) Não & 1 & 2 & 3 & 4 & 5 \\
\hline Conformista & ( ) Sim ( & ) Não & 1 & 2 & 3 & 4 & 5 \\
\hline Conselheiro & ( ) $\operatorname{Sim}($ & ) Não & 1 & 2 & 3 & 4 & 5 \\
\hline Construtivo & ( ) Sim ( & ) Não & 1 & 2 & 3 & 4 & 5 \\
\hline Contagiante & ( ) Sim & ) Não & 1 & 2 & 3 & 4 & 5 \\
\hline Contido & ( ) $\operatorname{Sim}($ & ) Não & 1 & 2 & 3 & 4 & 5 \\
\hline Contraditório & ( ) Sim ( & ) Não & 1 & 2 & 3 & 4 & 5 \\
\hline Controlado & ( ) $\operatorname{Sim}($ & ) Não & 1 & 2 & 3 & 4 & 5 \\
\hline Controlador & ( ) $\operatorname{Sim}($ & ) Não & 1 & 2 & 3 & 4 & 5 \\
\hline Cooperativo & \begin{tabular}{|l|} 
\\
\end{tabular} & ) Não & 1 & 2 & 3 & 4 & 5 \\
\hline Corajoso & ( ) Sim ( & ) Não & 1 & 2 & 3 & 4 & 5 \\
\hline Cordial & ( ) Sim ( & ) Não & 1 & 2 & 3 & 4 & 5 \\
\hline Criativo & ( ) Sim ( & ) Não & 1 & 2 & 3 & 4 & 5 \\
\hline Crítico & ( ) $\operatorname{Sim}$ & ) Não & 1 & 2 & 3 & 4 & 5 \\
\hline Curioso & ( ) Sim ( & ) Não & 1 & 2 & 3 & 4 & 5 \\
\hline Decidido & ( ) $\operatorname{Sim}($ & ) Não & 1 & 2 & 3 & 4 & 5 \\
\hline Dedicado & ( ) $\operatorname{Sim}($ & ) Não & 1 & 2 & 3 & 4 & 5 \\
\hline Depressivo & ( ) Sim ( & ) Não & 1 & 2 & 3 & 4 & 5 \\
\hline Desanimado & ( ) $\operatorname{Sim}($ & ) Não & 1 & 2 & 3 & 4 & 5 \\
\hline Desconfiado & ( ) Sim ( & ) Não & 1 & 2 & 3 & 4 & 5 \\
\hline Descontraído & ( ) $\operatorname{Sim}($ & ) Não & 1 & 2 & 3 & 4 & 5 \\
\hline Descontrolado & ( ) Sim ( & ) Não & 1 & 2 & 3 & 4 & 5 \\
\hline Descuidado & ( ) Sim ( & ) Não & 1 & 2 & 3 & 4 & 5 \\
\hline Desiludido & ( ) Sim ( & ) Não & 1 & 2 & 3 & 4 & 5 \\
\hline Desmotivado & ( ) Sim ( & ) Não & 1 & 2 & 3 & 4 & 5 \\
\hline Desobediente & ( ) Sim ( & ) Não & 1 & 2 & 3 & 4 & 5 \\
\hline
\end{tabular}




\begin{tabular}{|c|c|c|c|c|c|c|c|}
\hline Determinado & ( ) Sim ( & ) Não & 1 & 2 & 3 & 4 & 5 \\
\hline Dinâmico & ( ) Sim ( & ) Não & 1 & 2 & 3 & 4 & 5 \\
\hline Disperso & ( ) Sim ( & ) Não & 1 & 2 & 3 & 4 & 5 \\
\hline Disposto & ( ) Sim ( & ) Não & 1 & 2 & 3 & 4 & 5 \\
\hline Eficaz & ( ) Sim ( & ) Não & 1 & 2 & 3 & 4 & 5 \\
\hline Eficiente & ( ) Sim ( & ) Não & 1 & 2 & 3 & 4 & 5 \\
\hline Emotivo & ( ) Sim ( & ) Não & 1 & 2 & 3 & 4 & 5 \\
\hline Entusiasmado & ( ) Sim ( & ) Não & 1 & 2 & 3 & 4 & 5 \\
\hline Entusiasta & ( ) Sim ( & ) Não & 1 & 2 & 3 & 4 & 5 \\
\hline Equilibrado & ( ) Sim ( & ) Não & 1 & 2 & 3 & 4 & 5 \\
\hline Espontâneo & ( ) Sim ( & ) Não & 1 & 2 & 3 & 4 & 5 \\
\hline Expansivo & ( ) $\operatorname{Sim}($ & ) Não & 1 & 2 & 3 & 4 & 5 \\
\hline Extrovertido & ( ) Sim ( & ) Não & 1 & 2 & 3 & 4 & 5 \\
\hline Feliz & ( ) Sim ( & ) Não & 1 & 2 & 3 & 4 & 5 \\
\hline Firme & ( ) Sim ( & ) Não & 1 & 2 & 3 & 4 & 5 \\
\hline Flexível & ( ) Sim ( & ) Não & 1 & 2 & 3 & 4 & 5 \\
\hline Franco & ( ) $\operatorname{Sim}($ & ) Não & 1 & 2 & 3 & 4 & 5 \\
\hline Generoso & ( ) Sim & ) Não & 1 & 2 & 3 & 4 & 5 \\
\hline Gentil & ( ) $\operatorname{Sim}($ & ) Não & 1 & 2 & 3 & 4 & 5 \\
\hline Humilde & ( ) $\operatorname{Sim}($ & ) Não & 1 & 2 & 3 & 4 & 5 \\
\hline Impaciente & ( ) Sim ( & ) Não & 1 & 2 & 3 & 4 & 5 \\
\hline Imprudente & ( ) $\operatorname{Sim}($ & ) Não & 1 & 2 & 3 & 4 & 5 \\
\hline Impulsivo & ( ) Sim ( & ) Não & 1 & 2 & 3 & 4 & 5 \\
\hline Incapaz & ( ) $\operatorname{Sim}($ & ) Não & 1 & 2 & 3 & 4 & 5 \\
\hline Incisivo & ( ) $\operatorname{Sim}($ & ) Não & 1 & 2 & 3 & 4 & 5 \\
\hline Inconveniente & ( ) $\operatorname{Sim}($ & ) Não & 1 & 2 & 3 & 4 & 5 \\
\hline Independente & ( ) $\operatorname{Sim}($ & ) Não & 1 & 2 & 3 & 4 & 5 \\
\hline Indisciplinado & ( ) $\operatorname{Sim}($ & ) Não & 1 & 2 & 3 & 4 & 5 \\
\hline Indiscreto & ( ) $\operatorname{Sim}($ & ) Não & 1 & 2 & 3 & 4 & 5 \\
\hline Individualista & ( ) $\operatorname{Sim}($ & ) Não & 1 & 2 & 3 & 4 & 5 \\
\hline Ineficaz & ( ) $\operatorname{Sim}($ & ) Não & 1 & 2 & 3 & 4 & 5 \\
\hline Infeliz & ( ) Sim ( & ) Não & 1 & 2 & 3 & 4 & 5 \\
\hline Inovador & ( ) Sim ( & ) Não & 1 & 2 & 3 & 4 & 5 \\
\hline Inquieto & ( ) $\operatorname{Sim}($ & ) Não & 1 & 2 & 3 & 4 & 5 \\
\hline Inseguro & ( ) $\operatorname{Sim}($ & ) Não & 1 & 2 & 3 & 4 & 5 \\
\hline Insensato & ( ) Sim ( & ) Não & 1 & 2 & 3 & 4 & 5 \\
\hline Instável & ( ) Sim ( & ) Não & 1 & 2 & 3 & 4 & 5 \\
\hline Interessado & ( ) $\operatorname{Sim}($ & ) Não & 1 & 2 & 3 & 4 & 5 \\
\hline Irônico & ( ) Sim ( & ) Não & 1 & 2 & 3 & 4 & 5 \\
\hline Justo & ( ) Sim ( & ) Não & 1 & 2 & 3 & 4 & 5 \\
\hline Leal & ( ) Sim ( & ) Não & 1 & 2 & 3 & 4 & 5 \\
\hline Metódico & ( ) $\operatorname{Sim}($ & ) Não & 1 & 2 & 3 & 4 & 5 \\
\hline Motivado & ( ) Sim ( & ) Não & 1 & 2 & 3 & 4 & 5 \\
\hline Nervoso & ( ) Sim ( & ) Não & 1 & 2 & 3 & 4 & 5 \\
\hline Obsessivo & ( ) Sim ( & ) Não & 1 & 2 & 3 & 4 & 5 \\
\hline Obstinado & ( ) Sim ( & ) Não & 1 & 2 & 3 & 4 & 5 \\
\hline Oportunista & ( ) Sim ( & ) Não & 1 & 2 & 3 & 4 & 5 \\
\hline
\end{tabular}




\begin{tabular}{|c|c|c|c|c|c|c|c|}
\hline Organizado & ( ) Sim ( & ( ) Não & 1 & 2 & 3 & 4 & 5 \\
\hline Oscilante & ( ) Sim ( & ( ) Não & 1 & 2 & 3 & 4 & 5 \\
\hline Otimista & ( ) Sim & ( ) Não & 1 & 2 & 3 & 4 & 5 \\
\hline Ousado & ( ) Sim & ( ) Não & 1 & 2 & 3 & 4 & 5 \\
\hline Pacificador & ( ) Sim & ( ) Não & 1 & 2 & 3 & 4 & 5 \\
\hline Perfeccionista & ( ) Sim ( & ( ) Não & 1 & 2 & 3 & 4 & 5 \\
\hline Perseverante & ( ) Sim ( & ( ) Não & 1 & 2 & 3 & 4 & 5 \\
\hline Persistente & ( ) Sim & ( ) Não & 1 & 2 & 3 & 4 & 5 \\
\hline Perspicaz & ( ) Sim ( & ( ) Não & 1 & 2 & 3 & 4 & 5 \\
\hline Persuasivo & ( ) $\operatorname{Sim}($ & ( ) Não & 1 & 2 & 3 & 4 & 5 \\
\hline Pessimista & ( ) Sim ( & ( ) Não & 1 & 2 & 3 & 4 & 5 \\
\hline Ponderado & ( ) Sim ( & ( ) Não & 1 & 2 & 3 & 4 & 5 \\
\hline Possessivo & ( ) Sim ( & ( ) Não & 1 & 2 & 3 & 4 & 5 \\
\hline Pragmático & ( ) $\operatorname{Sim}($ & ( ) Não & 1 & 2 & 3 & 4 & 5 \\
\hline Prático & ( ) Sim ( & ( ) Não & 1 & 2 & 3 & 4 & 5 \\
\hline Produtivo & ( ) $\operatorname{Sim}($ & ( ) Não & 1 & 2 & 3 & 4 & 5 \\
\hline Protetor & ( ) $\operatorname{Sim}($ & ( ) Não & 1 & 2 & 3 & 4 & 5 \\
\hline Realista & ( ) $\operatorname{Sim}$ & ( ) Não & 1 & 2 & 3 & 4 & 5 \\
\hline Rebelde & ( ) Sim ( & ( ) Não & 1 & 2 & 3 & 4 & 5 \\
\hline Receptivo & ( ) $\operatorname{Sim}($ & ( ) Não & 1 & 2 & 3 & 4 & 5 \\
\hline Reservado & \begin{tabular}{|l|} 
\\
\end{tabular} & ( ) Não & 1 & 2 & 3 & 4 & 5 \\
\hline Responsável & ( ) $\operatorname{Sim}($ & ( ) Não & 1 & 2 & 3 & 4 & 5 \\
\hline Rígido & ( ) Sim ( & ( ) Não & 1 & 2 & 3 & 4 & 5 \\
\hline Rigoroso & ( ) $\operatorname{Sim}($ & ( ) Não & 1 & 2 & 3 & 4 & 5 \\
\hline Rude & ( ) $\operatorname{Sim}($ & ( ) Não & 1 & 2 & 3 & 4 & 5 \\
\hline Sagaz & ( ) $\operatorname{Sim}($ & ( ) Não & 1 & 2 & 3 & 4 & 5 \\
\hline Seguro & ( ) Sim ( & ( ) Não & 1 & 2 & 3 & 4 & 5 \\
\hline Sensato & ( ) $\operatorname{Sim}($ & ( ) Não & 1 & 2 & 3 & 4 & 5 \\
\hline Sereno & ( ) Sim ( & ( ) Não & 1 & 2 & 3 & 4 & 5 \\
\hline Severo & ( ) Sim ( & ( ) Não & 1 & 2 & 3 & 4 & 5 \\
\hline Simpático & ( ) Sim ( & ( ) Não & 1 & 2 & 3 & 4 & 5 \\
\hline Sistemático & ( ) $\operatorname{Sim}($ & ( ) Não & 1 & 2 & 3 & 4 & 5 \\
\hline Solidário & ( ) Sim ( & ( ) Não & 1 & 2 & 3 & 4 & 5 \\
\hline Teimoso & ( ) $\operatorname{Sim}($ & ( ) Não & 1 & 2 & 3 & 4 & 5 \\
\hline Temperamental & ( ) $\operatorname{Sim}($ & ( ) Não & 1 & 2 & 3 & 4 & 5 \\
\hline Tímido & ( ) $\operatorname{Sim}($ & ( ) Não & 1 & 2 & 3 & 4 & 5 \\
\hline Tolerante & ( ) Sim ( & ( ) Não & 1 & 2 & 3 & 4 & 5 \\
\hline Tranqüilo & ( ) Sim ( & ( ) Não & 1 & 2 & 3 & 4 & 5 \\
\hline Triste & ( ) Sim ( & ( ) Não & 1 & 2 & 3 & 4 & 5 \\
\hline Versátil & ( ) Sim ( & ( ) Não & 1 & 2 & 3 & 4 & 5 \\
\hline Vigilante & ( ) $\operatorname{Sim}($ & ( ) Não & 1 & 2 & 3 & 4 & 5 \\
\hline Vívido & ( ) Sim ( & ( ) Não & 1 & 2 & 3 & 4 & 5 \\
\hline
\end{tabular}




\section{Anexo 2}

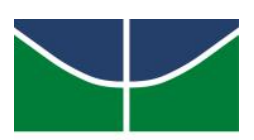

\section{Un Termo de consentimento livre e esclarecido}

Você está sendo convidado(a) a participar de uma pesquisa que tem como objetivo elaborar uma escala que possibilite o mapeamento das características de personalidade. $\mathrm{A}$ sua participação no referido estudo será no sentido de responder um questionário.

Esclarecemos que a sua privacidade será respeitada, ou seja, seu nome ou qualquer outro dado ou elemento que possa, de qualquer forma, identificar você, será mantido em sigilo. Você também pode se recusar a participar do estudo, ou retirar o seu consentimento a qualquer momento, sem precisar justificar.

A pesquisadora responsável pelo referido projeto é Maria Fabiana Damásio Passos, aluna de doutorado do Instituto de Psicologia da Universidade de Brasília - UnB, que se encontra disponível para esclarecer quaisquer dúvidas e outras informações adicionais por meio do email: fabiana.damasio@hotmail.com e do telefone 6184587002.

Tendo sido orientado(a) quanto ao teor da pesquisa e compreendido a natureza e o objetivo do referido estudo, você manifesta seu livre consentimento em participar, estando totalmente ciente de que não há nenhum valor econômico, a receber ou a pagar, por sua participação.

Brasília, abril de 2014.

Assinatura do(a) participante da pesquisa

Maria Fabiana Damásio Passos

Responsável pela pesquisa

fabiana.damasio@hotmail.com

6184587002 